\title{
Evidencias en la variabilidad pluvio y fluviométrica en contexto de sequias. El caso de la cuenca del río Maule, Chile entre los años 2000-2019
}

Evidence in rainfall and fluviometric variability in the context of droughts. The case of the Maule river basin, Chile between the years 2000-2019

Francisco Maturana

(iD) https://orcid.org/0000-0003-3963-5807 Instituto de Ciencias de la Tierra, Universidad Austral de Chile Chile francisco.maturana@uach.cl

José Araos E

(iD) https://orcid.org/0000-0002-5443-9911 Universidad Alberto Hurtado (UAH) Chile jaraos@uahurtado.cl

Macarena Fernández Carvajal

Universidad Alberto Hurtado (UAH) Chile macarena.fer23@gmail.com

\section{RESUMEN}

El Cambio Climático y la gestión del recurso hídrico son elementos que impactan en la disponibilidad de agua en una amplia gama de territorios. En este trabajo se analiza el comportamiento de la variabilidad pluviométrica y fluviométrica en la cuenca del río Maule, Chile una de las principales y de mayor envergadura a nivel nacional con un área correspondiente a $20.300 \mathrm{~km} 2$, y en donde predomina la actividad silvoagropecuaria. Se realizó un análisis clúster basado en los datos disponibles para las precipitaciones (periodo 2000-2019) y caudales (periodo 2003-2019) cuyo vínculo 
entre este último y el primero se asocia a la magnitud de la escorrentía. El comportamiento de estos muestra una tendencia a la disminución, presumiblemente producto de la mega sequía y variaciones en el comportamiento climático de meso escala. El análisis de datos permite suponer una relación entre el comportamiento pluviométrico y la disminución del caudal medio de canales y ríos, acarreando consecuencias negativas a las actividades socioeconómicas vinculadas al uso del agua y demandando nuevas formas de gestión hídrica en los territorios.

PALABRAS CLAVE: Cuenca del Maule, análisis clúster, precipitaciones, caudales.

\begin{abstract}
Climate change and the management of water resources are elements that impact the availability of water in the territories. This work analyzes the behavior of the pluviometric and fluviometric variabilities in the Maule river basin, Chile, one of the main and largest at the national level with an area corresponding to 20,300 km2, and where silvo-agricultural activity predominates. A cluster analysis was performed based on the data available for rainfall (period 2000-2019) and flows (period 2003-2019) whose link between the latter and the former is associated with the magnitude of runoff. The behavior of these shows that an attention to the decrease, presumably due to the mega drought and variations in the mesoscale climatic behavior. The data analysis allows us to suppose a relationship between the rainfall behavior and the decrease in the average flow of channels and rivers, causing negative consequences to the socio-economic activities related to the use of water and demanding new forms of water management in the territories.
\end{abstract}

KEYWORD: Maule basin, cluster analysis, rainfall, flow.

\title{
INTRODUCCIÓN
}

En los últimos años se ha presentado un aumento sostenido en el crecimiento de la población y con ello la sobreexplotación de todo tipo de recursos, modificando los territorios con diversos impactos en diversos sectores del planeta (Becerra, Mance et.al, 2009). Uno de estos impactos corresponde a las emisiones de gases de efecto invernadero (GEI), que, debido a su prolongada subsistencia en la atmósfera, presentan un efecto acumulativo (Barros, 2005). En efecto, el Quinto Informe de Evaluación del Grupo Intergubernamental de Expertos sobre el Cambio Climático (IPCC) señala que las emisiones de tales gases invernadero y su acumulación, causarán un mayor calentamiento atmosférico y nuevos cambios en todos los componentes del sistema climático (IPCC, 2014) 
Según el IPCC (2014) el Cambio Climático hace referencia a un cambio en el estado del clima, identificado a través de pruebas estadísticas por alteraciones en el promedio y/o variabilidad de sus propiedades, y que subsiste en un tiempo prolongado. Tal cambio, trae consigo importantes alteraciones de todo tipo de variables climáticas importantes para la vida y actividades productivas; tales como: temperatura, precipitación, humedad y vientos (Barros, 2005).

Bajo tal contexto, es que se han podido asociar la recurrencia de ciertos fenómenos extremos, los cuales están relacionados entre sí (Moreda, Madruga, \& Espino, 2020), Los modelos climáticos elaborados a cabo por la comunidad científica, predicen un calentamiento mundial de $1,4^{\circ} \mathrm{C}$ a $5,8^{\circ} \mathrm{C}$ entre 1990 al 2100 .

Estos fenómenos extremos se han observado en inundaciones, sequías, modificación en el régimen de precipitaciones, frio y calor intenso, incendios, derretimiento de glaciares, escasez de agua, extinciones, etc. (TERRAM, 2019), constituyéndose la variación de precipitaciones como un elemento distintivo del proceso, particularmente cuando se producen procesos de sequía.

La seguía, se define como un "período de condiciones anormalmente secas durante suficiente tiempo para causar un desequilibrio hidrológico" (CentroUC, 2017), dependiendo en gran medida de la región geográfica en que se esté analizando. En tal sentido Wilhite \& Glantz (1985) categorizan las sequías en eventos de 4 clases las cuales siguen un orden lógico y conducente. i) sequía meteorológica, asociada a datos climáticos, disminución/falta de precipitación sobre una región durante un período de tiempo; ii) sequía agrícola, alude a la disminución de la humedad del suelo, el cual no permite el desarrollo de un determinado cultivo; iii) sequía hidrológica; se relaciona con el déficit de recursos hídrico (superficial y subterránea) expresándose en la disminución de caudales o volumen de reservas; y por último, iv) sequía socio económica, la cual apunta a los daños a la población (personales o económicos), es decir, está relacionado con la actividad económica que se vea afectada.

Chile ha sido catalogado como uno de los países vulnerables al impacto del Cambio Climático, por la Convención Marco de Naciones Unidas por el Cambio Climático realizada el año 1992, que en su artículo 4, número 8, expresa que el país presenta características que lo condicionan a ser susceptible ante este fenómeno, tal como: 
áreas de borde costero de baja altura; zonas áridas, semiáridas; zonas con cobertura forestal y zonas expuestas al deterioro forestal; propenso a desastres naturales; zonas expuestas a la sequía y la desertificación; zonas urbanas con problemas de contaminación atmosférica y zonas de ecosistemas frágiles, incluidos los sistemas montañosos (Font, 2019).

Particularmente, se debe considerar la fuerte dependencia de las actividades económicas del país de las variables físicas y climáticas, especialmente frente al recurso hídrico, sujeto además a debate por el contexto de privatización y escasez (Hernández, 2017). Según el informe de simulaciones climáticas regionales del Centro chileno de Ciencia del Clima y la Resiliencia (CR2), bajo los escenarios RCP 2.6 y 8.5 debiera esperarse una disminución de la precipitación, principalmente en las zonas costeras del norte y centro del país para el periodo 2021-2050 (Rojas \& Gallardo, 2018). En este sentido, el aumento de temperatura y la disminución de precipitaciones, sumado a la creciente demanda de agua por diversas actividades socio económicas, presuponen una mayor exposición al riesgo de sequía en un futuro cercano.

En Chile la sequía ha mostrado una tendencia al incremento en las últimas décadas, denominándose como “Mega sequía”. En efecto, desde el año 2010, el territorio que abarca las regiones de Coquimbo a La Araucanía, Figura 2, ha experimentado un déficit de precipitaciones cercano al 30\%, esta disminución en la pluviometría viene acompañada de las temperaturas más cálidas de los últimos 100 años, agravando la carencia hídrica en lagos y embalses (Garreaud, 2015).

Una causa de esta sequía estaría asociada a los eventos Niña que, en la zona central, de Chile, determina una disminución persistente de las precipitaciones (Santibáñez, 2016). Específicamente, en las últimas décadas han ocurrido varios episodios de sequía en Chile central. Desde el año 2008 la Dirección General de Aguas de Chile (DGA), bajo la Resolución DGA N¹674 - en la que se estipulan los criterios para la calificación de épocas de sequias extraordinarias - ha decretado un total de 145 eventos de sequias extraordinarias a nivel país. Particularmente en la Región del Maule, ha sido expuesta desde el 2008 a continuos decretos de escasez hídrica, en primeras instancias a escala comunal, luego provincial, hasta llegar dos años consecutivos (2019 y 2020) a escala regional. 
En la Actualidad esta región se destaca por el cambio de uso de suelo de agrícola a forestal en las zonas periurbanas y rurales, modificando también el comportamiento hidrológico de sus cuencas, particularmente las zonas de secano, generando además una degradación del suelo (Pizarro-Tapia et. al, 2013). Por otro lado, son las condiciones de humedad del suelo y las intensidades de precipitaciones las que establecen los aumentos/disminuciones de las escorrentías sobre la cuenca, más allá de la cobertura vegetal que posea el territorio (Pizarro-Tapia et.al, 2006)

Según el estudio del Centro de Ciencia del Clima y la Resiliencia (CR2) (2015) diversos impactos por la mega sequía se están experimentando en la Región del Maule: 1) en los recursos costeros, asociado a la disminución de los caudales, se produce una menor cantidad de nutrientes (nitrato y fosfato) dañando la productividad biológica en la zona costera; 2 ) incendios forestales, durante la mega sequía la región es más propensa a quemas que pueden dañar plantaciones forestales; 3) vulnerabilidad ante la sequía. En tal sentido, se determinó que la Región del Maule es la más vulnerable frente a cambios climáticos dado que posee características climáticas de tipo mediterráneo altamente expuesta, con un intenso cambio de suelo y alta proporción de agricultura familiar campesina (AFC) (Garreaud, 2015); y 4) 'sequíacódigo de aguas', esta región se ha visto impactada por innumerables decretos de escasez hídrica que comenzó a emplearse desde el año 2008 al año 2020.

En esta región, existen diversos estudios (Boisier et al., 2018; Garreaud et al, 2017; Gonzalez-Reyes, 2016; Quintana \& Aceituno, 2012) que han evidenciado una baja de precipitaciones y otros, aluden más a una disminución, a una nueva distribución del nivel pluviométrico (Figueroa, 2014). Sin embargo, dado el nivel de la cuenca y su fuerte influencia en la comunidad agraria, resulta interesante comprender patrones del comportamiento fluviométrico, considerando que los ríos y canales son los afluentes importantes para el regadío y ecosistemas ligados a este ambiente.

De lo expuesto se desprende la importancia de analizar el comportamiento tanto pluviométrico como fluviométrico en cuanto a sus patrones y variaciones en la Cuenca del Maule que impactan o podrían impactar en la población y actividades económicas, las cuales se vinculan a la actividad agropecuaria- silvícola con una participación de $13,5 \%$ a nivel regional, por su parte el sector agrícola emplea en torno al $20 \%$ de la fuerza de trabajo (Oficina de Estudios y Políticas Agrarias, 2019). 
El objetivo de este estudio es analizar la evolución y patrones espaciales recientes de las precipitaciones y volumen de caudal en los territorios de la Cuenca del Maule entre los años 2000-2019 esperando con esto aportar al conocimiento del comportamiento de las precipitaciones y caudal, en un territorio cuya actividad agrícola es primordial.

\section{METODOLOGÍA Y MATERIALES}

\section{Materiales}

Para la realización de este artículo se utilizaron los datos pluviométricos y fluviométricos a escala anual de la base de datos dispuesta por la Dirección General de Aguas (DGA) de manera abierta en su sitio web ${ }^{1}$. Los datos fueron analizados en los programas gratuitos y libres Calc y $R$. Se procesaron utilizando el paquete FactoMineR de $\mathrm{R}$ mediante el procedimiento de clúster, la espacialización de ellos se realizó en QGis 3.12 e Inkscape (ambos gratuitos y libres). Dichos mapas están proyectados en datos geodésicos datum WGS 1984, proyección UTM Huso 18S.

\section{Metodología}

Las fases metodológicas de este estudio fueron seis, Figura 1. La primera correspondió a la elaboración de la base de datos para la pluviometría y fluviometría de la Cuenca del río Maule. En un segundo momento se completaron los datos faltantes (NA), que se presentaban en tal base. Posteriormente se lleva a cabo el clúster, permitiendo establecer los patrones de las variabilidades que persisten a nivel pluviométrico y fluviométrico al interior de la cuenca. Finalmente se realiza un análisis de los resultados mediante cartografías que permitieron visualizar espacialmente el comportamiento de las variables.

1 https://dga.mop.gob.cl/servicioshidrometeorologicos/Paginas/default.aspx, Consultada el 26 de noviembre del 2020. 


\section{Elaboración de base de datos pluviométricos para el periodo 2000-2019 y fluviométricos el periodo 2003-2019}

Los datos pluviométricos fueron extraídos de la plataforma de la DGA ‘Estadísticas

Estaciones DGA" de las 40 estaciones distribuidas en la cuenca del Río Maule ${ }^{2}$, solo 36 cuentan con datos relevantes para el periodo 2000-2019, excluyendo el año 2018, puesto que no cuentan con registros ${ }^{3}$. Por su parte, los datos correspondientes a caudal se encontraban disponibles en 53 estaciones, de ellas solo 38 presentan registros que se pueden analizar para el periodo 2003-2019. Estos datos recopilados poseen una resolución mensual, pero se agregaron a nivel anual. Cabe mencionar que las estaciones que presentaban una alta tasa de ausencia de datos no fueron consideradas, el criterio de selección de datos en este sentido se remitió a eliminar toda estación que no tuviese registros en más de 2 años, tanto para el caso de pluviometría como de fluviometría. Las bases de datos tanto para caudales como precipitaciones se presentan en anexo.

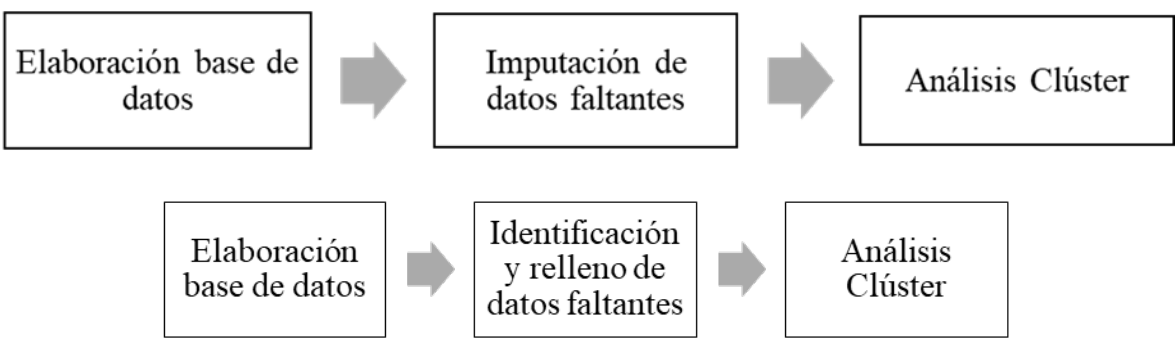

Figura 1. Fases metodológicas de estudio Fuente: Elaboración propia

Las bases de datos de los parámetros pluviométricos y fluviométricos presentaban dos categorías: magnitudes brutas y medidas porcentuales, por lo que se elaboraron

2 https://snia.mop.gob.cl/BNAConsultas/reportes, consultada el 6 de abril del 2020.

3 Los datos pluviométricos del año 2018, no se encuentran proporcionados en la base de datos de la DGA e incluso, bajo solicitud de Sistema de Información y Atención Ciudadana (SIAC) del Ministerio de Obras Públicas, no fue entregada dicha información 
un total de 4 bases. Las magnitudes brutas permitieron considerar patrones similares en relación a los valores que presentan en cada uno de los años. Los valores porcentuales, tienden a eliminar el efecto "cantidad o volumen" y les entrega mayor importancia a los años, puesto que se analizan porcentualmente respecto al periodo. Estos elementos son importantes cuando se lleva a cabo el proceso estadístico y además permiten explorar y focalizar el análisis de manera diferente.

\section{Estimación de datos faltantes o perdidos (NA) de la base de datos}

Se utilizó el paquete MissMDA en R, para generar los valores ausentes en las bases de datos empleadas. Como se indicó, en la base de datos se eliminaron estaciones que presentaban un alta volumen de datos faltantes. Sin embargo, en la nueva base presentaba un total de 8 valores faltantes en el caso de precipitaciones y 16 para los caudales, dando así un $1,2 \%$ y $2,4 \%$ respectivamente. Para subsanar tal problema y contar con datos continuos se empleó tal paquete en $\mathrm{R}$, que incorpora la metodología propuesta por Josse y Husson (2016), basada en el método de componentes principales sobre datos incompletos. La estimación de datos considera tanto similitudes entre individuos como relaciones entre variables (por eso está construida a partir de un análisis de componentes principales) otorgándole una robustez estadística a tal proceso (Josse \& Husson, 2016).

\section{Análisis clúster de las variables}

Para desarrollar la propuesta se realizó un análisis multivariado mediante clúster cuya finalidad es permitir el agrupamiento de individuos de una serie estadística en función de sus variables, buscando maximizar la variabilidad al interior de la clase (Fernández, 2011). Tal procedimiento ha sido utilizado para modelación de recursos hídricos y otros en diferentes trabajos (Poblete, Arevalo, Nicolis \& Figueroa, 2020; Jiang, Cooley, \& Wehner, 2020).

Para tal efecto, se procedió de la siguiente manera. A las bases brutas tanto de caudales como precipitaciones se les aplicó directamente un análisis clúster mediante el método de clasificación ascendente jerárquica, el cual permite construir un árbol jerarquizado para apreciar cómo se organizan los objetos o individuos en 
función de sus distancias. En este sentido se utilizó la distancia euclidiana y el método ward para generar el agrupamiento lo cual entregaba un dendograma como resultado.

Una vez obtenido tal clúster jerárquico se procedió a establecer las clases, es decir cortar tal árbol. Para determinar estas clases, se procedió seleccionar una cantidad cuya pérdida de inercia entre una clase y otra no fuera significativa. Lo anterior posibilita una mayor discriminación inter clase e intra clase y por tanto agrupar de manera más correcta los diferentes individuos - en este caso las estaciones - y así entregar una mayor robustez estadística al proceso posibilitando explicar la mayor varianza del conjunto de datos según las posibilidades del proceso (Josse y Husson, 2016). En el caso particular de FactoMineR, este software entrega como resultado un gráfico que permite orientar al usuario el número de clases a establecer según tal pérdida de varianza explicada de pasar de una clase a otra.

Tal resultado es posible de expresar en un plano factorial gracias a las coordenadas de los individuados (estaciones) sobre este. En este caso, más que utilizar tal plano, se exporta la tabla resultante con el valor de clúster obtenido para cada estación meteorológica y se espacializa mediante QGIS, para posteriormente elaborar las cartografías en cuestión mediante Inkscape, ambos programas como se indicó de carácter libres y gratuitos.

Para el caso de las bases de datos expresadas en porcentaje, se realiza exactamente el mismo procedimiento, sin embargo, antes de la aplicación del clúster se procede a realizar el análisis multivariado de Análisis de Componentes Principales (ACP) tal como lo sugieren Josse \& Husson (2016). Los autores indican que tal proceso mejora sustancialmente el particionamiento empleado, es decir, cuando el clúster se aplica sobre un ACP en el cual se guardaron las dimensiones o componentes que explican sobre el $95 \%$ de la varianza del conjunto de datos (Husson, Josse \& Pages, 2010). En este caso una vez realizado el ACP para los caudales fue en la 11va dimensión o componente donde se explicaba el $97,1 \%$ del conjunto de datos y para las precipitaciones en la 14 va con un $96,3 \%$. 


\section{Área de estudio}

La cuenca del Río Maule tiene una superficie de 20.300 km2, presentando un clima asociado a un régimen típicamente mediterráneo, es decir, ostenta al menos dos meses consecutivos secos principalmente en temporada de verano. Nace en la Cordillera de los Andes en la Laguna del Maule y tiene como tributarios en su parte superior los ríos Puelche, Cipreses y el Melado, los principales afluentes están en el valle longitudinal que son el río Loncomilla por el sur y el río Claro que drena en el sector norte, para finalmente desembocar en el mar a la altura de Constitución, Figura 2.

Desde el punto de vista político-administrativo, la cuenca del Río Maule abarca prácticamente toda la superficie de la Región del mismo nombre así también una pequeña parte de la Región de Ñuble. A nivel provincial, contempla las provincias de Talca, Linares y Cauquenes.

La Región posee un alto porcentaje de población rural en torno al 26,8\% según el Censo 2017, y cuyo sector productivo se compone de una parte importante con el silvoagropecuario (13,5\%), la actividad agrícola emplea casi un $22,6 \%$ de la fuerza de trabajo, siendo uno de los principales motores productivos de la región (GORE, 2018).

Desde el punto de vista de uso de agua, la cuenca presenta un alto consumo del recurso hídrico destinado al riego, siendo la capital regional la principal demandante de este recurso. Según los datos de la DGA, al año 2019, se han otorgado un total de 2.080 derechos de agua, en la que Talca y Linares poseen 1.826 y 138 respectivamente; sin embargo, a nivel de consumo (acciones de agua) estas dos comunas tienen similitud de caudal con aproximadamente 31.000 acciones.

Además, si observamos el número de glaciares, según el inventario de glaciares entregado por el documento de la Biblioteca del Congreso Nacional (2016) en el marco de la tramitación de una ley para tal efecto, al menos 98 glaciares serían posibles de apreciar en el marco del río Maule.

La variación pluvial y la oscilación térmica en la cordillera de Los Andes implican dos tipos bioclimáticos en la cuenca del Maule. El primero corresponde al Mediterráneo pluviestacional-oceánico en los sectores costeros, Cordillera de la Costa, Valle 
Central y pisos inferiores de la Cordillera de los Andes. El segundo referente a Mediterráneo pluviestacional-continental en las zonas andinas altas (Dirección General de Aguas, 2004: 12).

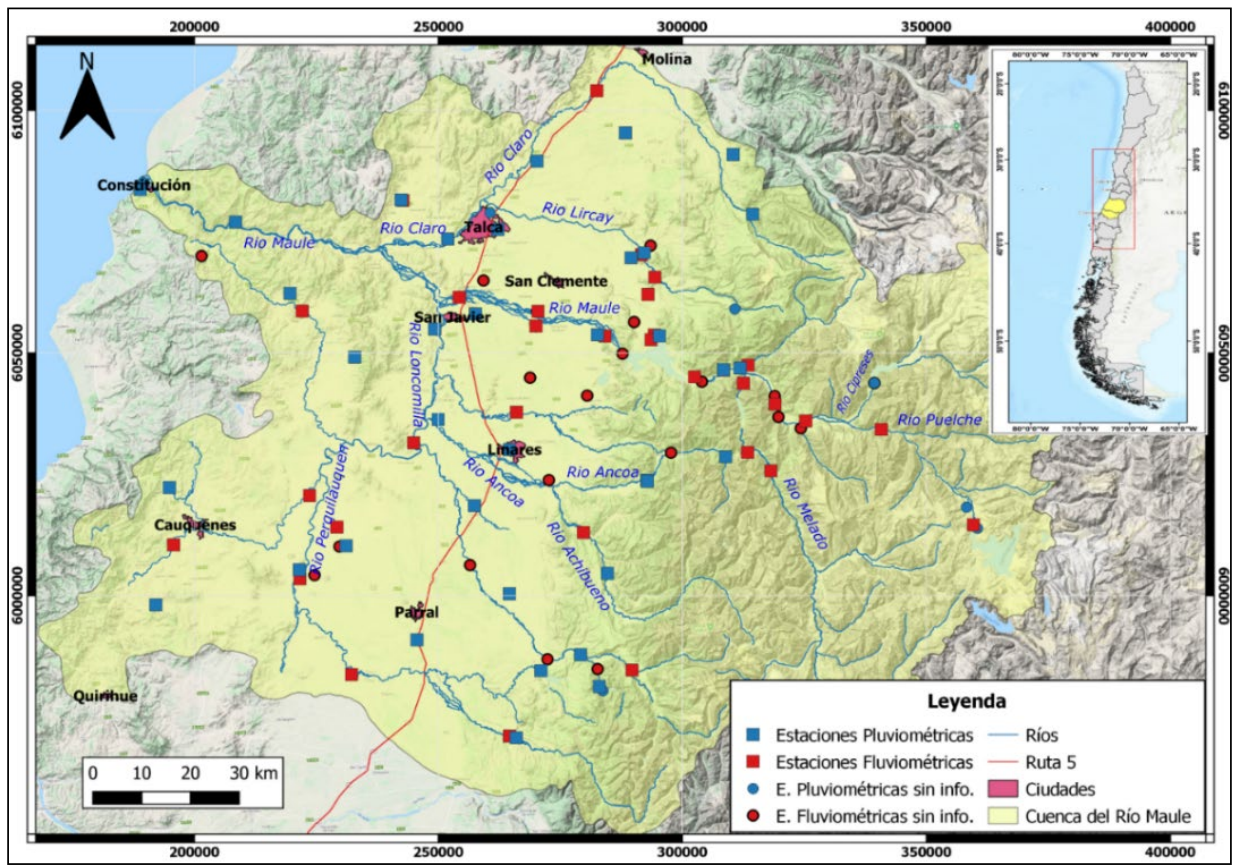

Figura 2. Área de Estudio

Fuente: Elaboración propia. Datos obtenidos de DGA.

\section{RESULTADOS Y DISCUSIÓN}

\section{Comportamiento general en los últimos 20 años}

Los resultados permitieron caracterizar de manera general tanto la evolución de las precipitaciones como caudales para el periodo analizado ${ }^{4}$. Con relación a las primeras, desde el año 2000 al 2019 expresan un mínimo de 5\% y un máximo de

4 Cuando se habla de incrementos o disminuciones en este texto se debe contextualizar en el periodo analizado y no como tendencias absolutas que puedan estar ocurriendo en la cuenca. 
$11 \%$, Figura 3. En términos generales las precipitaciones experimentaron una tendencia a la baja, de un $7 \%$ a un $4 \%$. No obstante, se destaca un alza importante en el año 2002 llegando a 9\%, lo anterior se debería según el Centro de Investigación y Transferencia en Riego y Agroclimatología de la Universidad de Talca de a un superávit que tuvo la Región del Maule en los meses de mayo (94\%) y agosto (151\%) (Colville, 2002). Los años que le siguen en mayor índice es el 2005 y 2001 teniendo un promedio similar con 7,5\% y 7,3\% correspondientemente Los años con menores índices de precipitaciones están dispuestos en los años 2007 y 2016 , con 3,3\% y 3,5\% correspondientemente.

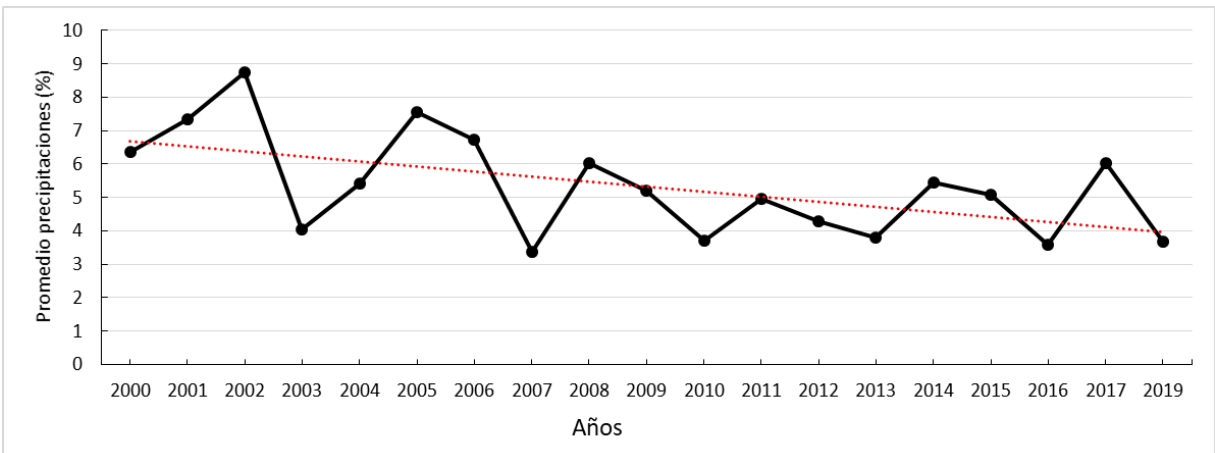

Figura 3. Promedio de precipitaciones (\%) anuales en la Cuenca del Río Maule, periodo 2000-2019 Fuente: Elaboración propia. Datos obtenidos de DGA

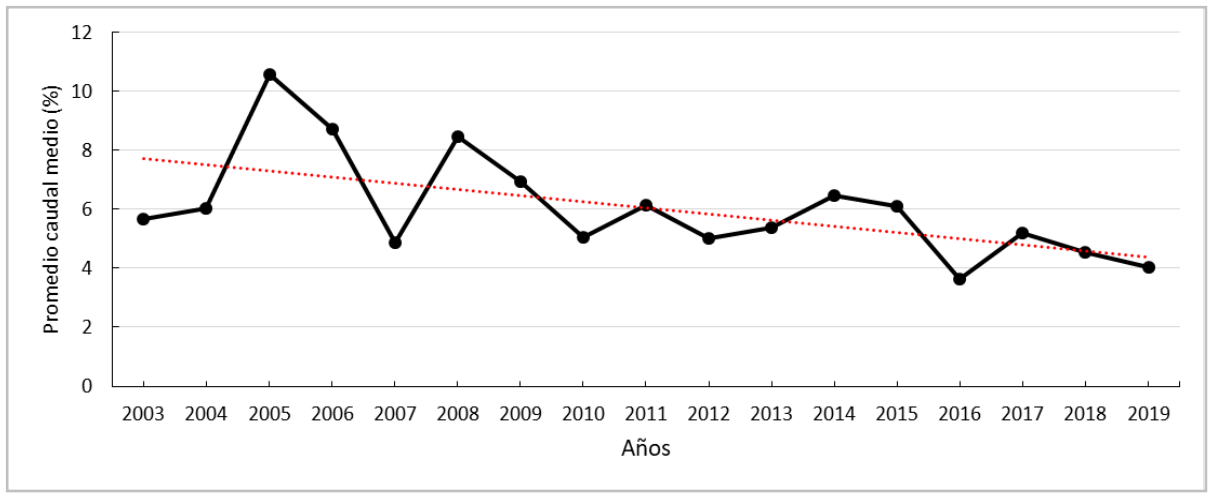

Figura 4. Promedio de caudal medio (\%) anuales en la Cuenca del Río Maule, periodo 2003-2019 Fuente: Elaboración propia. Datos obtenidos de DGA 
El caudal medio de la cuenca ha experimentado un comportamiento similar a las precipitaciones. El año 2016 presenta el índice más bajo con un 3\%, asimismo se muestra una baja sostenida desde el año 2017 al 2019 de un 5\% a un 4\%, Figura 4. Por otro lado, el año más alto es el 2005 sobrepasando el 10\%, seguidamente por el año 2006 y 2008 con $8,7 \%$ y $8,4 \%$ correspondientemente.

\section{Análisis pluviométrico en magnitudes brutas y porcentuales}

En términos de magnitudes brutas, se logró identificar cuatro clústeres a partir de las bases de datos elaboradas. Tales conglomerados se caracterizan por la estación más representativa, es decir la que se localiza más próxima al baricentro de la partición generada.

El Clúster 1 agrupa 14 estaciones pluviométricas, abarcando un rango de magnitud de precipitaciones de 30 a $100(\mathrm{~mm})$ aproximadamente, cuenta con la estación más representativa a "Huerta del Maule", Figura 5, (Clúster 1), teniendo los años con mayor índice de milímetros caídos los años 2002 y 2005 con un 92,6 mm y 74,5 mm correspondientemente.

En este clúster, las distribuciones de las distintas estaciones se encuentran localizadas en el sector poniente, entre la Cordillera de la costa y la depresión intermedia, Figura 6. Por otro lado, la estación "Constitución” posee la particularidad de estar ubicada en la desembocadura del Río Maule, distanciándose del patrón de localización con respecto al resto de las estaciones.

El Clúster 2 está compuesto por 11 estaciones pluviométricas, que muestran un rango de precipitaciones que va desde 43 a $132(\mathrm{~mm})$ aproximadamente. La estación más representativa es "Colbun (Maule Sur)", Figura 5, (Clúster 2), en ella se puede distinguir que el año 2002 y 2005 son las que presentaron mayor nivel de agua caída con $132 \mathrm{~mm}$ y $107 \mathrm{~mm}$ correspondientemente, mientras que el año 2007 es el más bajo con $50 \mathrm{~mm}$.

Desde una perspectiva espacial, este clúster está localizado en la zona de la depresión intermedia hacia el sector oriente, sin embargo, las estaciones "El Álamo", "Tutuven Embalse" y "Río Maule en Forel" están ubicado en sector poniente, siendo esta última localizada cercano a la desembocadura del Río Maule, Figura 5. 
El Clúster 3 contiene 8 estaciones, que muestran magnitudes de precipitaciones van desde 43 como la mínima (correspondiente a la estación "Río Longaví en la Quiriquina", año 2007) y la máxima de $217(\mathrm{~mm})$ como la máxima. La estación más representativa de este clúster es "Ancoa en Embalse", Figura 5, (Clúster 3) al igual que en el clúster 1 y 2 los años con mayor precipitación son los años 2002 y 2005 con $217 \mathrm{~mm}$ y $174 \mathrm{~mm}$ correspondientemente, mientras que el 2013 es el año con menor índice de precipitación con $77 \mathrm{~mm}$. Desde el punto de vista espacia leste este clúster se concentra en el sector precordillerano a lo largo de la Cordillera de los Andes, Figura 5.

Por último, el Clúster 4 presenta 4 estaciones, las que muestran mayores magnitudes de precipitaciones, los rangos varían desde $99 \mathrm{~mm}$ a $283 \mathrm{~mm}$ aproximadamente. La estación más representativa es "Río Maule en Armerrillo", Figura 5, (Clúster 4), al igual que los clústeres anteriores los años con mayor índice de precipitaciones son los años 2002 y 2005 con $283 \mathrm{~mm}$ y $266 \mathrm{~mm}$ correspondientemente, mientras que el año con menor índice es 2016 con 99 mm de agua caída. Este clúster agrupa las estaciones localizadas hacia áreas de mayor elevación de la cuenca.

Respecto al análisis pluviométrico en magnitudes porcentuales, es decir, tomando protagonismo los datos anuales, se disponen 4 clúster, a continuación, se describen.

El Clúster 1 agrupa sólo una estación, la cual corresponde a "Río Maule en Forel". Esta posee una particularidad con respecto a las demás, puesto que expresa un comportamiento inusual de índice, mostrando para el año 2001 un porcentaje de 12,55\%, por otro lado, el 2003 es un año con menores valores llegando a solo un 1,83\%, Figura 6, (Clúster 1). La variabilidad de esta estación es bastante alta comparada con las demás, no obstante, está expresando que a nivel de años en relación con las otras no presenta ninguna similitud, es decir, se excluye totalmente del patrón entre e intra grupos. Asimismo, desde un análisis espacial, tal como muestra la Figura 6, la estación está localizada en la Cordillera de la Costa, a unos kilómetros de la desembocadura del Río Maule. 


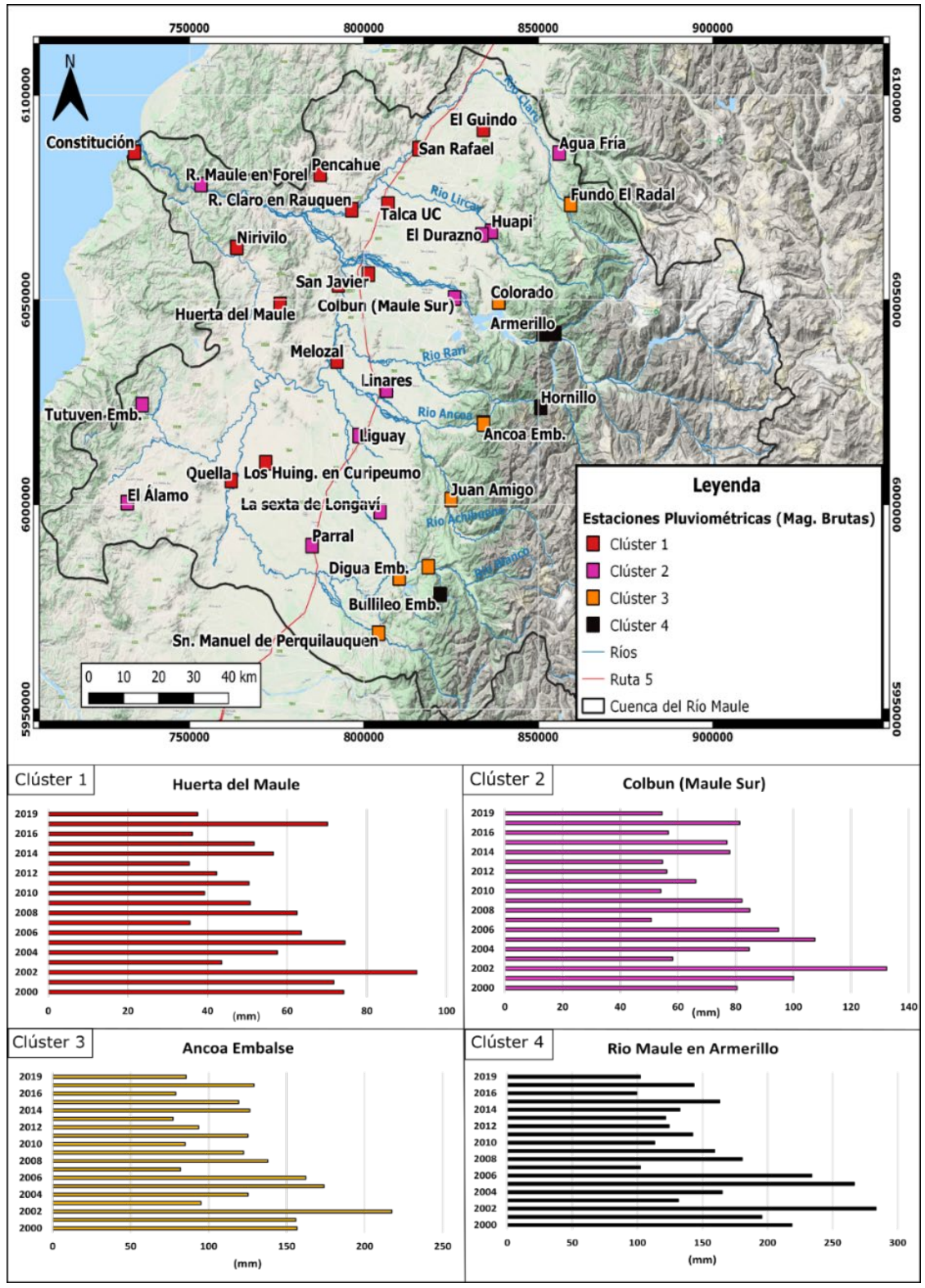

Figura 5. Mapa Clúster de estaciones pluviométricas en magnitudes brutas. Fuente: Elaboración propia. Base de datos DGA procesados en R. Qgis 3.12 
El Clúster 2 es el más grande agrupando15 estaciones, de ellas la más representativa es "Bullileo Embalse". Para el año 2002 tiene un alto índice con un 7,79\%, mientras que en el 2016 tiende a la baja con un 3,12\%, Figura 6, (Clúster 2). Las estaciones que componen este clúster no presentan una alta variabilidad, la cual se desarrolla en torno a 4,67\%. Desde una perspectiva del territorio, en la Figura 6 se aprecia una disposición en el sector sur de la cuenca, ubicándose predominantemente en el sector de la Depresión intermedia y precordillerano, sin embargo, hay una estación que se distancia la cual es la estación "Constitución", localizada en la ciudad del mismo nombre en la desembocadura del Río Maule.

El Clúster 3 posee 12 estaciones, de ellas la más representativa es "Talca U.C". El año con menor índice corresponde al 2019 con tan solo 3,35\%, mientras que el mayor porcentaje ocurre durante el 2002 con un 8,63\%, Figura 6, (Clúster 3). No obstante, a partir de la carta de la Figura 6 se evidencia una disposición un tanto homogénea, el grupo de estaciones están ubicadas hacia el sector Norte de la Cuenca desde una transversal de la C. de la Costa, hacia la C. de los Andes.

El Clúster 4 contiene 8 estaciones, de ellas la más representativa es la estación "Ancoa Embalse". El año con mayor índice es el 2002 con un 9,95\% disminuyendo tangencialmente en el año 2013 con un 3,53\%, Figura 6, (Clúster 4). Desde un ámbito espacial, en la carta de la Figura 6 se logra apreciar una disposición un tanto más aleatorio que el caso anterior, sin embargo 5 estaciones están ubicadas en el sector cordillerano, mientras que la estación "Río Loncomilla en las Brisas" y "Quella" están dispuestas en el sector de la Depresión Intermedia.

\section{Análisis fluviométrico en magnitudes brutas y porcentuales}

El Clúster 1 agrupa 32 estaciones, de ellas la más representativa corresponde a "Río Claro en San Carlos". Los años con mayor caudal medio son el 2005 y 2008 con $27,38 \mathrm{~m} 3 / \mathrm{s}$ y $25,47 \mathrm{~m} 3 / \mathrm{s}$ correspondientemente; mientras que el menor caudal fue el 2016 con 12,51 m3/s, Figura 8, (Clúster 1). Desde el ámbito espacial, en la Figura 7 se aprecia que este clúster no sigue un patrón geográfico, ya que está localizado tanto en la depresión intermedia como en los sectores cordilleranos (de la Costa y de los Andes). 


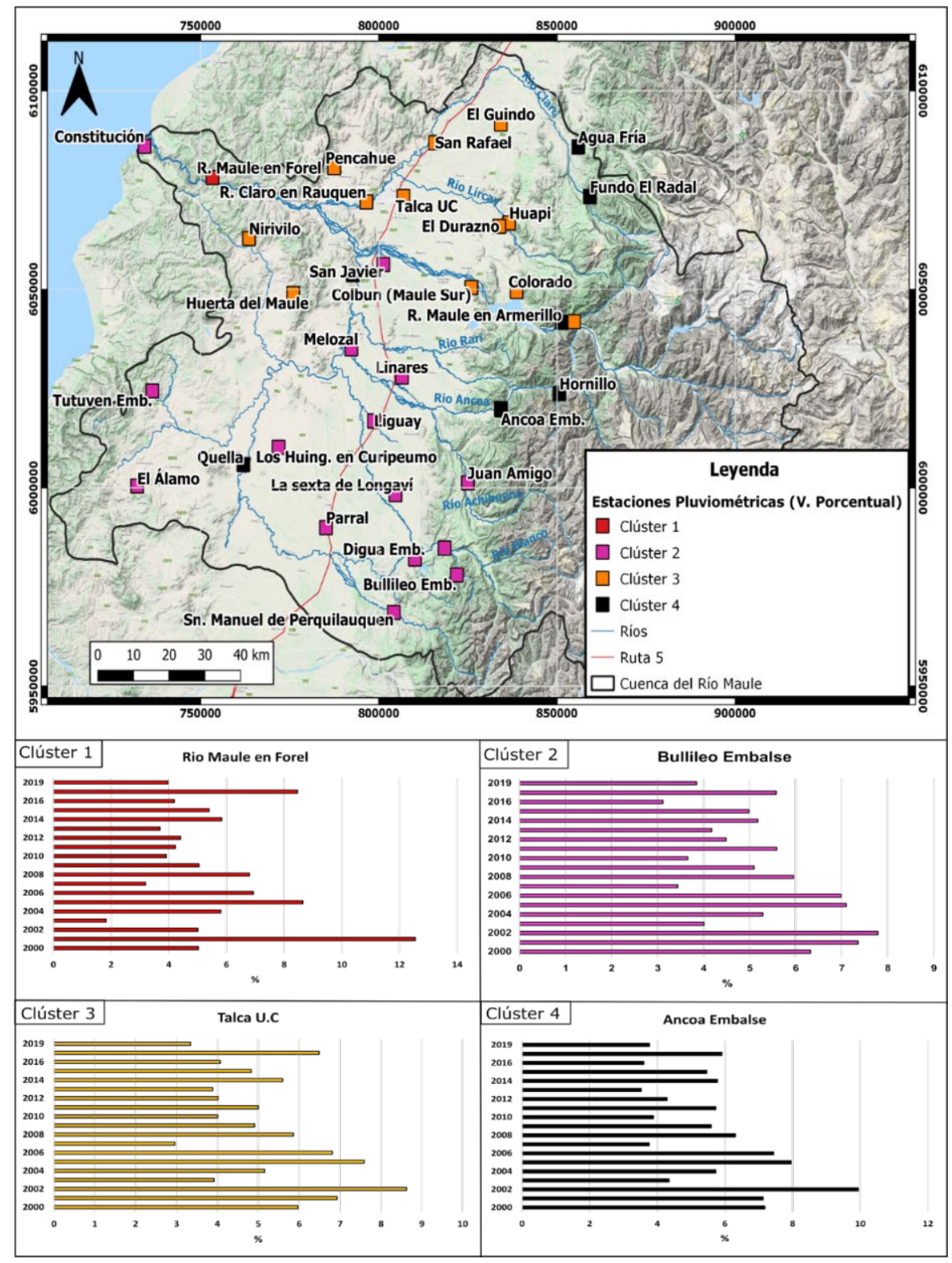

Figura 6. Mapa Clúster de estaciones pluviométricas en magnitudes porcentuales.

Fuente: Elaboración propia. Base de datos DGA procesados en R. Qgis 3.12 
El Clúster 2 contiene 5 estaciones, de ellas la más representativa es "Río Loncomilla en Bodega". Su mayor caudal medio anual fue el 2005 , casi duplicando la media de los otros años, así llega a tener $221,3 \mathrm{~m} 3 / \mathrm{s}$ para tal momento. De manera contraria, para el año 2016 presenta una importante baja alcanzando los $34,52 \mathrm{m3} / \mathrm{s}$, Figura 7, (Clúster 2). En ámbito territorial, como muestra la Figura 8, este clúster está localizado en el sector poniente de Talca y San Javier (hacia la cordillera de la Costa), donde también existe una estación que se escapa de tale patrón correspondiente a "Río Melado en el Salto" localizada en altas latitudes de la Cordillera de los Andes.

El Clúster 3 posee una sola estación la cual es "Río Maule en Forel". Esta se caracteriza por ser la única con altos índices de caudal. Para el año 2019 de 233,48 m3/s y para el 2006 de 767,9 m3/s, Figura 7, (Clúster 3). Estos elevados números se pueden explicar dada la ubicación de tal estación en la desembocadura del Río Maule, donde también se unen dos afluentes (Río Claro y Río Loncomilla), lo que involucra mayor caudal medio a diferencias de las otras estaciones, Figura 7.

Desde la perspectiva del análisis fluviométrico en magnitudes porcentuales, existen estaciones que poseen mayor similitud entre sí respecto a los años. Es posible agrupar en 4 clúster clúster que se desarrollaran a continuación.

El Clúster 1 posee solo 3 estaciones, de ellas la más representativa es la "Río Maule en Armerillo", posee un volumen de caudal medio, en promedio bajo el $5 \%$. Sin embargo, en el año 2005 muestra un pico de volumen de caudal de 23,41\% para posteriormente presentar una importante baja al 2019 de 0,67\%, Figura 8, (Clúster 1). Desde una perspectiva espacial y como muestra la Figura 8 , las estaciones de este clúster están localizadas en el sector precordillerano.

El Clúster 2 agrupa 4 estaciones. Su representativa es "Río Cauquenes en el Arrayan". Esta para el año 2005 muestra un aumento importante de volumen de caudal de 15,55\%, mientras que tiene una baja pronunciada en el año 2016 con un 1,37\%, Figura 8, (Clúster 2). Por otro lado, como muestra la Figura 8 la disposición de las estaciones es en el sector SW de la cuenca, emplazados en la depresión intermedia en el sector de Cauquenes. 


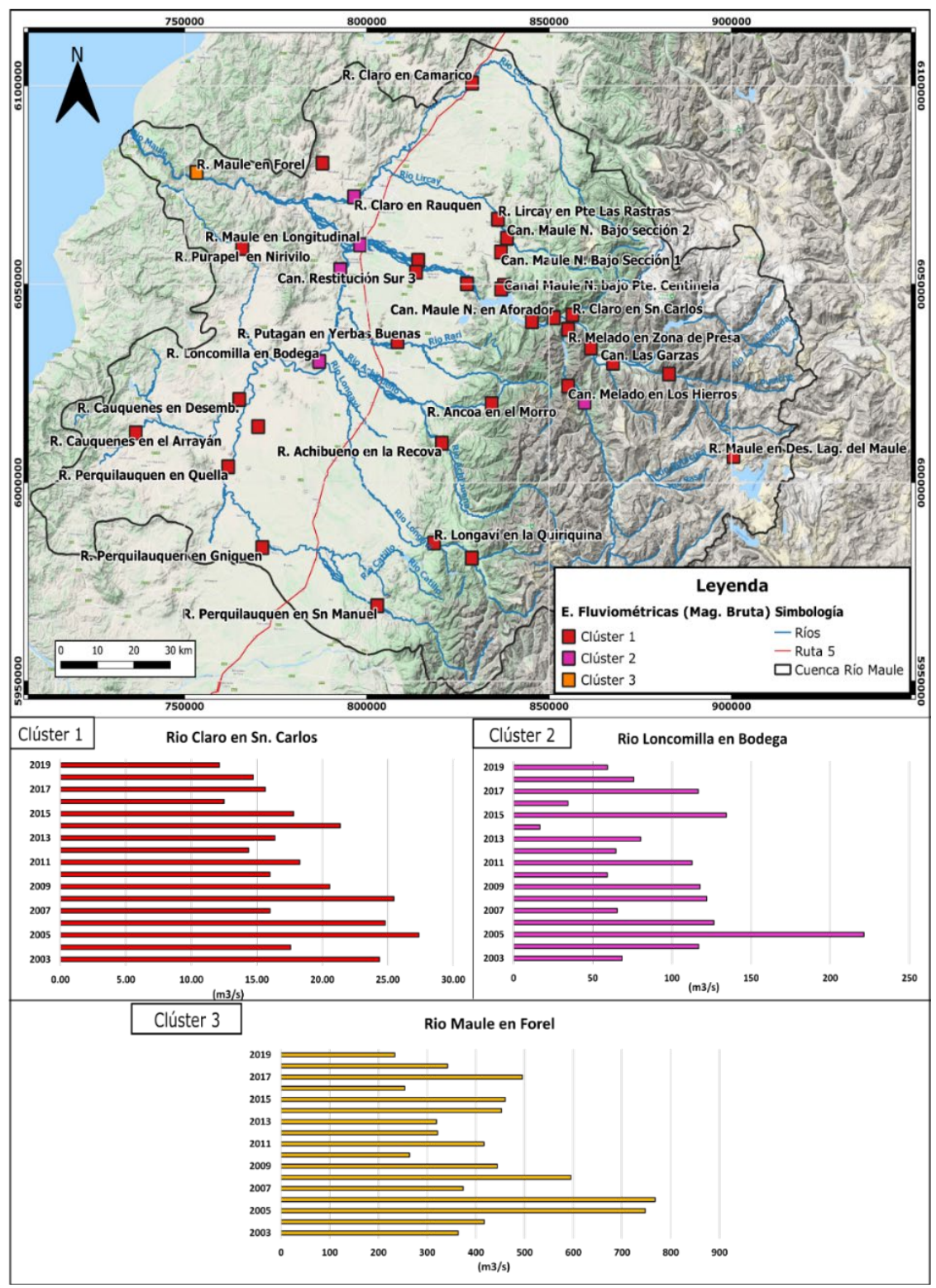

Figura 7. Mapa Clúster de estaciones fluviométricas en magnitudes brutas Fuente: Elaboración Propia. Base de datos DGA procesados en R. Qgis 3.12 
El Clúster 3 posee 18 estaciones, de ellas la más próxima al baricentro de la clase es "Río Perquilauquen en San Manuel" su pico es en el año 2006 con un 10,56\% de volumen de caudal, mientras que para el año 2016 sufre una baja destacable llegando a un 2,72\%, Figura 8, (Clúster 3). Como muestra la Figura 8, este clúster está dispuesto en toda la cuenca de forma heterogénea, es decir no sigue un patrón geográfico como las demás descritas.

Por último, el Clúster 4 está compuesto por 13 estaciones, de ellas la más representativa es "Canal San Clemente", la cual posee un comportamiento bastante estable, Figura 8, (Clúster 4), es decir, tiene poca variabilidad, no obstante, para el año 2013 se ve un aumento sustantivo de $8,48 \%$ de caudal medio, mientras que el 2019 muestra una baja de la mitad con un 4,68\%. Desde una perspectiva espacial, la carta de la Figura 8 muestra que la ubicación de este clúster está dispuesta en el cauce del Río Maule desde su nacimiento hasta el sector de San Clemente, más allá de la estación "Río Putagan en Yerbas Buenas", la cual está localizada en otro río en las cercanías de Linares, teniendo el mismo comportamiento de caudal, que el resto de las estaciones pertenecientes a este clúster.

Así, la disposición aleatoria de los diferentes clústeres a lo largo y ancho de la cuenca demuestra que el volumen de caudal medio - en medida porcentual - a través de los años no existe una relación estrecha con las características geográficas. En el caso del Clúster 4 las estaciones pertenecientes a este grupo están situadas en su mayoría en el Río Maule, es decir, existe una similitud en el comportamiento del volumen de caudal en los años establecidos; a diferencia del Clúster 3 y 2 que poseen una heterogeneidad en la disposición de los clústeres.

Tras observar los resultados de las 4 bases trabajadas, emergen algunos elementos relevantes a discutir y soslayar. El primero corresponde a lo relevante de poder contar con un método que permita completar datos faltantes, entregando así la posibilidad de generar análisis con mayores series de tiempos, lo cual pese a los resguardos que se deben considerar en la materia, entregan la posibilidad de mayor amplitud al análisis efectuado. 


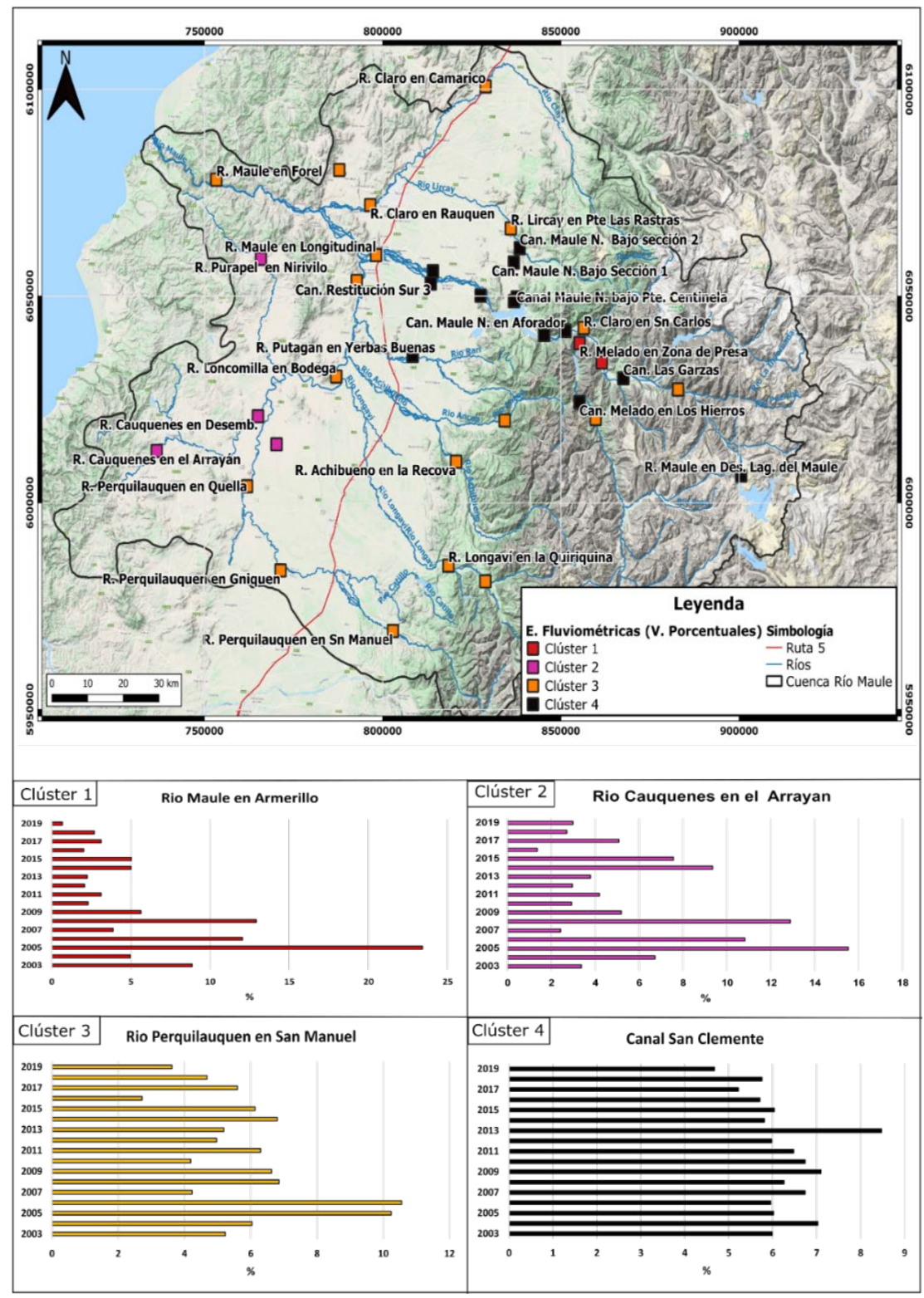

Figura 8. Mapa Clúster de estaciones fluviométricas en magnitudes porcentuales Fuente: Elaboración propia. Base de datos DGA procesados en R. Qgis 3.12 
Otro elemento importante, corresponde a los patrones de los espaciales de los clústeres generados, los cuales van en relación con las componentes físicas y comportamiento climáticos (sombra orográfica, gradiente de precipitaciones). Elemento importante, considerando que en este trabajo la aproximación del proceso estadístico no involucra una variable como tal, como podría ser -por ejemplo- la aplicación del índice de auto correlación espacial Moran, lo cual entrega un punto de discusión relevante respecto a las posibilidades de emplear métodos estadísticos en cuya formulación matemática no incluya necesariamente el componente espacial.

Además, restan espacios abiertos respecto a las causas de las variabilidades hídricas que podrían ser imputables tanto a problemas de gestión y manejo de agua como a efectos del Cambio Climático, donde otros estudios podrían profundizar en la materia.

Sumado a lo anterior, las debilidades de este trabajo están enmarcadas en haber contado con series de datos de tiempo acotadas (20 años), pero que sin dudas futuros trabajos podrían ampliar. Además, el ingreso de otras variables climáticas que entran en juego en la heterogeneidad de los datos analizados podría también ser abordadas en futuros textos para así robustecer los resultados.

Finalmente, otro complemento al trabajo sería efectuar visitas a terreno y realizar entrevistas con la comunidad de la región, para poder tener una percepción de las comunidades que se ven afectadas por el déficit hídrico o mal uso de las aguas, fenómeno que se presenta a lo largo del país.

\section{CONCLUSIONES}

Tras los análisis planteados se logran cumplir los objetivos en cuanto a describir y a comprender para el periodo 2000 al 2019 los patrones y comportamiento de las precipitaciones y caudales en la cuenca del Maule. En tal sentido, los parámetros pluviométricos y fluviométricos de la cuenca del Maule muestran una disminución entre los años 2009 y 2019 de manera constante, sin embargo, a la luz de los clústeres y distribución de las estaciones que los contienen se observan diferenciaciones que podrían estar expresadas por las características topográficas, el efecto orográfico de la cordillera y el gradiente de precipitaciones este - oeste o 
posiblemente la gestión del recurso hídrico en sí. Elementos que deberían ser profundizados en futuros estudios.

En lo que refiere a los clústeres que emergen de los caudales, su comportamiento resulta aleatorio. Lo que puede vincularse a parámetros morfométricos de la cuenca, pendiente, litología, estructura geológica, tipos de suelos, entre otras variables. En general los índices son mayores aguas arriba de la cuenca, presumiblemente por la presencia de los afluentes que aportan aguas al río principal.

Se recomienda adquirir mayor número de estaciones - en buenas condiciones - de pluviometría y fluviometría, que estén dispuestas a lo largo y ancho de la cuenca y ampliar la escala temporal del análisis, los cuales podrían contribuir a robustecer el análisis de la distribución espacial.

Además, este trabajo se debe comprender en los alcances y márgenes presentados y por lo tanto las dinámicas climáticas en las cuales, por ejemplo, años Niña o Niño, no han sido incorporadas, así como otros fenómenos que podrían entregar una mayor profundidad al análisis pero que a su vez implican un mayor desarrollo no efectuado en este texto.

Finalmente, sería necesario que en trabajos futuros se puedan ahondar en las consecuencias de la variabilidad y déficit de precipitaciones y caudales en las actividades económicas de la zona y destacar la importancia de planes de mitigación y adaptación frente al Cambio Climático con una perspectiva del uso sustentable del recurso agua que deban ser elaborados en tal dirección. En tal sentido, la puesta en marcha de los Planes Regionales de Ordenamiento Territorial PROT a escala regional y donde una de sus componentes de análisis es la cuenca, es una oportunidad para avanzar en la gestión del recurso hídrico.

\section{BIBLIOGRAFÍA}

Barros, V. (2005). El Cambio Climático Global. 2da Ed. Buenos Aires: Libros del Zorzal.

Biblioteca del Congreso Nacional BCN (2016). Glaciares de Chile. Recuperado de: https://www.camara.cl/verDoc.aspx?prmTIPO=DOCUMENTOCOMUNICACIONCUENTA\&prmID=14323

Biblioteca del Congreso Nacional BCN. (s.f.). Clima y vegetación Región del Maule Chile. Nuestro País. Recuperado de https://www.bcn.cl/siit/nuestropais/region7/clima.htm 
Becerra, Mance, et al. (2009). Cambio climático: lo que está en juego. Bogotá, Colombia: Foro Nacional Ambiental.

Boisier, J. P., Alvarez-Garreton, C., Cordero, R. R., Damiani, A., Gallardo, L., Garreaud, R. D., Lambert, F., Ramallo, C., Rojas, M., \& Rondanelli, R. (2018). Anthropogenic drying in central-southern Chile evidenced by long-term observations and climate model simulations. Elementa: Science of the Anthropocene, (6). doi) https://doi.org/10.1525/elementa.328

CentroUC. (2017). Centro UC Cambio Global. Recuperado de https://cambioglobal.uc.cl/comunicacion-yrecursos/recursos/glosario/sequia

Cordero, G. D. (2012). El Cambio Climático. Revista Ciencia y Sociedad Vol. XXXVII, (2), 227-240.

Colville, P. G. (2002). Centro de Investigación y Transferencia en Riego y Agroclimatología. Universidad de Talca. Recuperado de http://met.dgf.uchile.cl/clima/HTML/BOL_ANT/AGOSTO02/agosto02.htm

CR2. (s.f.). La megasequía 2010-2019: Una lección para el futuro. Recuperado de http://www.cr2.cl/megasequia/

Dirección General de Agua DGA (2004). Diagnóstico y clasificación de los cursos y cuerpos de agua según objetivos de calidad. Cuenca del río Maule. Gobierno de Chile, Ministerio de Obras públicas. Recuperado de: https://mma.gob.cl/wp-content/uploads/2017/12/Maule.pdf

Fernández, S. d. (2011). Análisis Conglomerados. Madrid: Universidad Autónoma de Madrid.

Figueroa, P. (2014). Variabilidad de las precipitaciones (1965-2012) en Chile centro-sur $\left(33,9^{\circ} \mathrm{S}-41,6^{\circ} \mathrm{S}\right)$ mediante índices estadísticos y temporales de la irregularidad. Santiago, Chile: Tesis Universidad de Chile.

Font, E. V. (2019). Institucionalidad del cambio climático en Chile. Biblioteca del Congreso Nacional (BCN).

Garreaud, R. D., Alvarez-Garreton, C., Barichivich, J., Boisier, J. P., Christie, D., Galleguillos, M., LeQuesne, C., McPhee, J., \& Zambrano-Bigiarini, M. (2017). The 2010--2015 megadrought in central Chile: impacts on regional hydroclimate and vegetation. Hydrology and Earth System Sciences, 21(12), 6307-6327. do) https://doi.org/10.5194/hess-21-6307-2017.

Garreaud, R. (2015). La megasequía 2010-2015: Una lección para el futuro. Centro de Investigación del Clima y la Resiliencia (CR2).

González-Reyes, Álvaro. (2016). Ocurrencia de eventos de sequías en la ciudad de Santiago de Chile desde mediados del siglo XIX. Norte Grande, (64), 21-32. doi https://dx.doi.org/10.4067/S071834022016000200003

GORE. (2018). Plan Regional de Gobierno 2018-2022 Región del Maule, SUBDERE.

Hernández, J. I. (2017). Impacto económico y social del cambio climático en Chile. IPSUSS. Recuperado de http://www.ipsuss.cl/ipsuss/columnas-de-opinion/jose-ignacio-hernandez/impacto-economico-y-socialdel-cambio-climatico-en-chile/2017-12-01/133721.html 
Husson, F., Josse J. \& Pages, J. (2010). Principal component methods-hierarchical clustering-partitional clustering: why would we need to choose for visualizing data. Applied Mathematics Department, 1-17.

IPCC. (2014). Cambio climático 2014: Informe de síntesis. Contribución de los Grupos de trabajo I, II y III al Quinto Informe de Evaluación del Grupo Intergubernamental de Expertos sobre el Cambio Climático. Ginebra.

Josse, J., \& Husson, F. (2016). MissMDA: A Package for Handling Missing Values in Multivariate Data Analysis, Journal of Statistical Software, 70(1), 1-31.

Llorente, A. (2020). Megasequía en Chile: las imágenes satelitales que muestran las consecuencias de la escasez de lluvia en el país, la peor desde 1915. BBC News Mundo. Recuperado de https://www.bbc.com/mundo/noticias-52288489

Moreda, B. G., Madruga, R. P., \& Espino, Z. G. El Cambio Climático, sus consecuencias e impactos principales. UNESCO. Recuperado de http://www.unesco.org/new/fileadmin/MULTIMEDIA/FIELD/ Havana/pdf/cap1.pdf, consultado el 20 de agosto de 2020.

Oficina de Estudios y Políticas Agrarias ODEPA (2019). Panorama de la agricultura chilena. Oficina de Estudios y Políticas Agrarias (ODEPA) del Ministerio de Agricultura del Gobierno de Chile. Recuperado de: https://www.odepa.gob.cl/wp-content/uploads/2019/09/panorama2019Final.pdf

Pizarro-Tapia, R., Cornejo, M. T., \& Arellano, L. R. (2006). Coeficientes de escorrentía instantáneos para la cuenca del río Tutuvén, VII Región del Maule, Chile. Bosque (Valdivia),27 (2), 83-91.

Pizarro-Tapia, R., Balocchi-Contreras, F., \& Andrade-Vilaró, F. (2013). Análisis comparativo de tres hidrogramas unitarios sintéticos en dos cuencas mediterráneas de Chile, Región del Maule, Chapingo, Serie Ciencias Forestales y del Ambiente, 5-18.

Poblete, D., Arevalo, J., Nicolis, O., \& Figueroa, F. (2020). Optimization of Hydrologic Response Units (HRUs) Using Gridded Meteorological Data and Spatially Varying Parameters. Water, 12(12). doi) https://doi.org/10.3390/w12123558

Quintana, J. M. \& Aceituno, P. (2012). Changes in the rainfall regime along the extratropical west coast of South America (Chile): 30-43오. Atmósfera, 25(1), 1-22.

Rojas, M., \& Gallardo, L. (2018). Proyecto Simulaciones climáticas regionales y marco de evaluación de la vulnerabilidad. Santiago, Chile: Centro de Ciencia del Clima y la Resiliencia (CR)2.

Santibáñez, F. (2016). El cambio climático y los recursos hídricos de Chile; La transición hacia la gestión del agua en los nuevos escenarios climáticos de Chile. Santiago: Ministerio de Agricultura - Oficina de Estudios y Políticas Agrarias.

TERRAM. (2019). Cartilla Ciudadana de Cambio Climático; lo que debemos saber. Santiago de Chile: TERRAM - Fundación Heinrich Böll. 
Jiang, Y., Cooley, D., \& Wehner, M. F. (2020). Principal Component Analysis for Extremes and Application to U.S. Precipitation. Journal of Climate, 33(15), 6441-6451.doi) https://doi.org/10.1175/JCLI-D-190413.1.

Wilhite, D., \& Glantz, M. (1985). Understanding the Drougth Phenomenon: The Role of Definitions, Water International, (10), 111-120.

\section{LOS AUTORES}

Francisco Maturana. Es Geógrafo de la Pontificia Universidad Católica de Chile, Máster en ciudades de la Universidad de Toulouse 2 y Doctor en Planificación Territorial, Urbanismo y Dinámicas del Espacio, de la Universidad de Paris-Sorbonne. Área de investigación: planificación territorial y métodos cuantitativos aplicados en Geografía, particularmente en el sur de Chile. Sus proyectos de investigación son Fondecyt Iniciación № 11150087 como investigador responsable; Co-investigador Fondecyt Regular N 1190874 y $\mathrm{N}^{\circ} 1161280$ y director alterno e investigador FONDEF IDeA I+D ID18I10284.

\section{francisco.maturana@uach.cl}

José Araos E. Es Geógrafo y Doctor en Geología de la Universidad de Chile. Actualmente es Académico del Departamento de Geografía de la Universidad Alberto Hurtado (UAH) en Santiago, Chile. Sus intereses de investigación se concentran en la Geología y Geomorfología glacial, geocronológicas cuaternarias, riesgos naturales, cambios climáticos pasados y efectos del actual cambio climático sobre glaciares de la región sur y austral de los Andes. Su publicación más reciente en relación a estas temáticas corresponde al capítulo "Nuevas regiones climáticas. El espacio bajo escenarios de cambio climático" del libro Praxis de la geografía contemporánea: apuntes para el siglo XXI. Actualmente es miembro de la Asociación de Jóvenes Investigadores Polares (APECS- CHILE) y de la Asociación Chilena de Geomorfología, además es director del Diplomado en Cambio Climático que ofrece la UAH.

\section{jaraos@uahurtado.cl}

Macarena Fernández Carvajal es Geógrafa de la Universidad Alberto Hurtado. Ha desarrollado sus estudios de pregrado en temáticas sobre el cambio climático, específicamente en las implicancias de crisis hídrica en la Cuenca del río Maule. Cuenta con experiencia ligada al área académica, principalmente en la docencia (ayudantía) en ramas de la geografía física tales como: Climatología y Geomorfología Estructural. Actualmente se desempeña como profesional en CSW Consultores Ambientales contribuyendo a la generación de proyectos que son ingresados al Servicio de Evaluación Ambiental (SEA) de Chile.

macarena.fer23@gmail.com 


\section{Anexo:}

Caudales brutos para las estaciones trabajadas según DGA

\begin{tabular}{|c|c|c|c|c|c|c|c|c|c|c|c|c|c|c|c|c|c|}
\hline 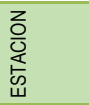 & 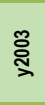 & 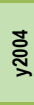 & & 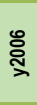 & 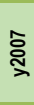 & ڤ్ & ఫ్త్రి & 옳 & 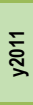 & స్్ํ & స్ָે & 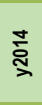 & 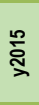 & 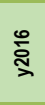 & 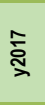 & 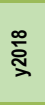 & $\stackrel{\infty}{\stackrel{\circ}{x}}$ \\
\hline 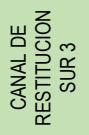 & $\underline{z}$ & $\stackrel{\hat{m}}{\stackrel{f}{n}}$ & $\underset{N}{\mathbb{J}}$ & $\stackrel{\stackrel{\leftrightarrow}{\circ}}{\mathrm{d}}$ & $\underset{m}{\stackrel{N}{m}}$ & $\stackrel{\sim}{\stackrel{m}{m}}$ & $\underset{\mathrm{d}}{\stackrel{\mathrm{d}}{ }}$ & 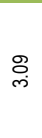 & $\underline{z}$ & $\stackrel{\bar{n}}{\sim}$ & $\underset{\substack{\infty \\
\text { de }}}{ }$ & $\underset{\sim}{\stackrel{N}{N}}$ & 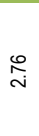 & $\stackrel{m}{m}$ & $\stackrel{\tilde{n}}{\stackrel{n}{n}}$ & $\stackrel{\mathbb{J}}{\mathrm{J}}$ & 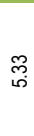 \\
\hline 志怘恋 & $\begin{array}{l}\stackrel{0}{0} \\
\stackrel{0}{0}\end{array}$ & $\stackrel{\infty}{0}$ & 曽 & $\stackrel{\substack{\infty \\
0}}{0}$ & in & $\begin{array}{l}\stackrel{0}{0} \\
\stackrel{0}{0}\end{array}$ & ஜֶ: & 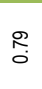 & గ్రి & ్ֻలి & 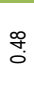 & $\stackrel{\text { }}{0}$ & $\stackrel{\text { I }}{0}$ & $\ddot{0}$ & $\stackrel{R}{\circ}$ & న్రి & $\underline{z}$ \\
\hline 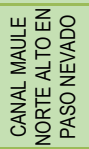 & 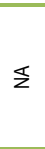 & $\Sigma$ & 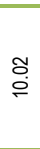 & 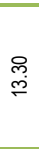 & 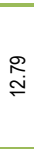 & $\begin{array}{l}\infty \\
\infty \\
\infty\end{array}$ & 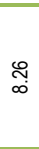 & $\underset{ָ}{\mathbb{N}}$ & 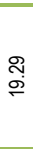 & 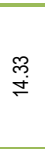 & $\stackrel{m}{\stackrel{m}{L}}$ & 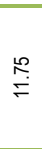 & 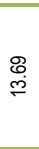 & 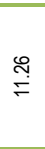 & 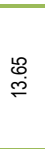 & 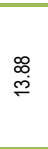 & $\underset{\mathrm{N}}{\mathrm{N}}$ \\
\hline 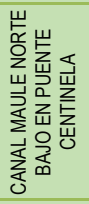 & $\begin{array}{l}\stackrel{\leftrightarrow}{\leftrightarrow} \\
\stackrel{+}{+}\end{array}$ & 桶 & $\stackrel{\stackrel{N}{\sim}}{\stackrel{N}{n}}$ & 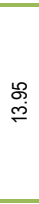 & $\stackrel{\text { đ্ }}{\mathrm{N}}$ & $\stackrel{\text { స్ }}{\sim}$ & $\stackrel{\substack{\infty \\
\infty}}{\stackrel{\infty}{\infty}}$ & $\begin{array}{l}\text { న్ } \\
\stackrel{\sim}{\rho}\end{array}$ & 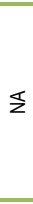 & $\stackrel{\stackrel{g}{\rightleftarrows}}{\stackrel{2}{F}}$ & $\stackrel{\stackrel{?}{\rightleftarrows}}{=}$ & $\underset{\stackrel{p}{\rho}}{\bar{p}}$ & 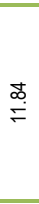 & 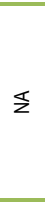 & 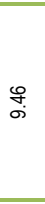 & \begin{tabular}{l}
$\stackrel{\circ}{\circ}$ \\
\hdashline
\end{tabular} & $\stackrel{\bar{m}}{\rightleftarrows}$ \\
\hline 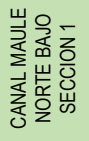 & 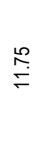 & $\stackrel{\stackrel{\leftrightarrow}{\stackrel{P}{F}}}{ }$ & $\stackrel{?}{\stackrel{P}{\rightleftarrows}}$ & $\underset{\stackrel{ }{\sim}}{ }$ & $\stackrel{\stackrel{8}{\sim}}{\underset{\sim}{*}}$ & $\begin{array}{l}\infty \\
\infty \\
\infty \\
\infty\end{array}$ & 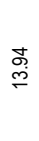 & $\underset{+}{\stackrel{夭}{\leftarrow}}$ & 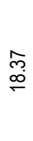 & $\begin{array}{l}\stackrel{\infty}{\infty} \\
\infty \\
\sim\end{array}$ & 吕 & 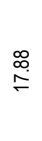 & 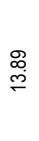 & $\underline{z}$ & $\begin{array}{l}\infty \\
\infty \\
\stackrel{\infty}{c}\end{array}$ & 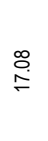 & $\stackrel{\infty}{\stackrel{\infty}{b}}$ \\
\hline 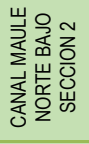 & 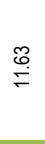 & ?̊. & 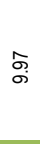 & 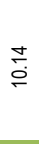 & 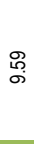 & 艿 & 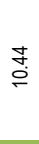 & 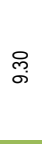 & $\underline{z}$ & $\underset{N}{\mathbb{N}}$ & 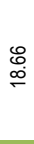 & $\stackrel{\widetilde{T}}{\underset{+}{+}}$ & $\underset{\infty}{=}$ & 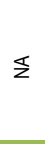 & 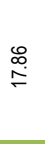 & $\underset{\infty}{\stackrel{\sim}{\infty}}$ & $\begin{array}{l}\text { of } \\
\text { of }\end{array}$ \\
\hline 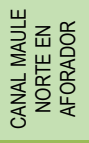 & $\begin{array}{l}\hat{N} \\
\widetilde{\rho}\end{array}$ & $\stackrel{\text { oo }}{\stackrel{+}{\leftarrow}}$ & 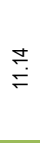 & $\begin{array}{l}\infty \\
\stackrel{+}{+}\end{array}$ & 点 & 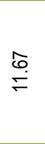 & $\begin{array}{l}\mathbb{N} \\
\stackrel{N}{n}\end{array}$ & $\stackrel{\stackrel{f}{\rho}}{\underline{p}}$ & $\frac{\pi}{z}$ & $\begin{array}{l}\text { 艿 } \\
\stackrel{\text { ph }}{\sim}\end{array}$ & 㿣 & $\stackrel{\infty}{\underset{\sim}{\sim}}$ & 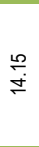 & $\stackrel{\stackrel{g}{\sim}}{\sim}$ & $\begin{array}{l}\hat{\hat{o}} \\
\stackrel{\rho}{\rho}\end{array}$ & $\begin{array}{l}\text { ర్ } \\
\stackrel{\leftrightarrow}{\circ}\end{array}$ & 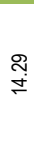 \\
\hline 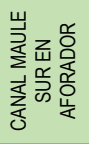 & 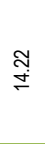 & 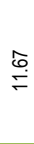 & $\stackrel{\stackrel{R}{\rightleftharpoons}}{=}$ & 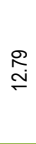 & $\stackrel{\widetilde{N}}{\text { N }}$ & $\begin{array}{l}\infty \\
\stackrel{\infty}{\leftarrow}\end{array}$ & $\begin{array}{l}\mathscr{B} \\
\stackrel{\circ}{\circ}\end{array}$ & $\stackrel{\infty}{\circ}$ & $\underset{\infty}{\mathbb{\infty}}$ & 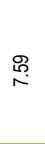 & 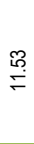 & 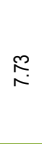 & 㐫 & 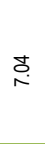 & 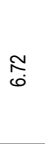 & $\stackrel{8}{8}$ & $\underset{N}{\stackrel{d}{N}}$ \\
\hline 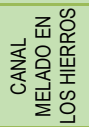 & $\begin{array}{l}\text { ָొ } \\
\stackrel{0}{\circ}\end{array}$ & $\begin{array}{l}\hat{f} \\
\stackrel{0}{0}\end{array}$ & $\underset{\infty}{\mathbb{\infty}}$ & న్ని & ô. & $\stackrel{\sim}{\sigma}$ & 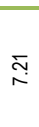 & 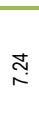 & $\Sigma$ & 胥 & $\stackrel{\stackrel{8}{\rightleftarrows}}{\stackrel{8}{F}}$ & $\underset{0}{\mathbb{0}}$ & 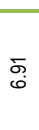 & 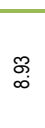 & $\underset{\mathbb{O}}{\mathbb{S}}$ & 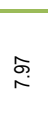 & $\underset{\infty}{\tilde{\infty}}$ \\
\hline 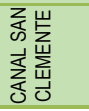 & $\mathbb{z}$ & 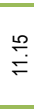 & 㟔 & 昌 & $\begin{array}{l}\infty \\
\stackrel{\circ}{\circ}\end{array}$ & హ్ & $\stackrel{\stackrel{\leftrightarrow}{\leftrightarrow}}{=}$ & : & $\begin{array}{l}\text { ָ̃ } \\
\stackrel{0}{\circ}\end{array}$ & $\stackrel{\infty}{\stackrel{\infty}{\sigma}}$ & & ๙ే & مై & 并 & $\underset{\infty}{\infty}$ & $\stackrel{+}{\sigma}$ & 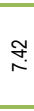 \\
\hline
\end{tabular}




\begin{tabular}{|c|c|c|c|c|c|c|c|c|c|c|c|c|c|c|c|c|c|}
\hline 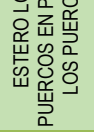 & $\underset{+}{\stackrel{\sigma}{+}}$ & $\stackrel{\widetilde{f}}{\sigma}$ & $\begin{array}{l}\widetilde{O} \\
\infty\end{array}$ & ָ̊ & 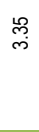 & đ̊ & $\begin{array}{l}8 \\
\text { in }\end{array}$ & 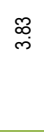 & $\underset{\widetilde{r}}{\widetilde{r}}$ & $\underset{\sim}{\stackrel{\sim}{\sim}}$ & $\stackrel{n}{m}$ & $\stackrel{\infty}{\circ}$ & $\stackrel{\infty}{\stackrel{\infty}{N}}$ & $\hat{\sim}$ & $\stackrel{\sigma}{\dot{m}}$ & 先 & $\stackrel{\infty}{\stackrel{\sim}{~}}$ \\
\hline 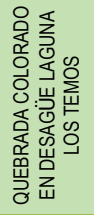 & $\Sigma$ & స్తి & $\stackrel{\text { ? }}{\circ}$ & 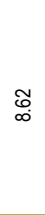 & $\underset{\infty}{\stackrel{\infty}{\infty}}$ & 志 & $\stackrel{0}{i}$ & 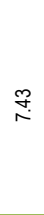 & $\stackrel{\circ}{i}$ & $\stackrel{\infty}{\stackrel{\infty}{\sim}}$ & $\stackrel{+}{i}$ & $\stackrel{\text { P }}{\sim}$ & $\underset{N}{\stackrel{N}{N}}$ & $\underset{\sim}{\stackrel{+}{N}}$ & 兽 & 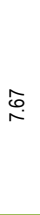 & $\stackrel{\circ}{ }$ \\
\hline 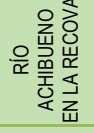 & $\begin{array}{l}\bar{\infty} \\
\bar{j}\end{array}$ & 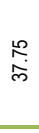 & $\begin{array}{l}\stackrel{0}{2} \\
\stackrel{2}{\sim}\end{array}$ & 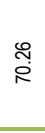 & 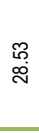 & 管 & $\begin{array}{l}\text { ల్లై } \\
\text { }\end{array}$ & $\stackrel{0}{\stackrel{N}{N}}$ & $\begin{array}{l}\bar{\delta} \\
\dot{q}\end{array}$ & $\begin{array}{l}\infty \\
\underset{N}{\infty}\end{array}$ & $\begin{array}{l}\text { बे. } \\
\text { ळ. }\end{array}$ & $\begin{array}{l}\stackrel{\Xi}{0} \\
\stackrel{m}{m}\end{array}$ & $\begin{array}{l}\text { స్ } \\
\text { ల్ }\end{array}$ & $\begin{array}{l}\bar{f} \\
\stackrel{\sigma}{\circ}\end{array}$ & 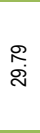 & 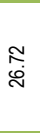 & $\stackrel{尺}{\stackrel{尺}{\digamma}}$ \\
\hline 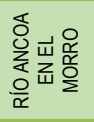 & 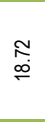 & $\stackrel{\infty}{\stackrel{\infty}{\sim}}$ & $\underset{\widetilde{ల}}{\stackrel{ల}{n}}$ & 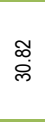 & 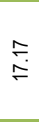 & 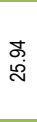 & $\stackrel{\leftrightarrow}{\circ}$ & $\begin{array}{l}\bar{m} \\
\stackrel{b}{\sim}\end{array}$ & 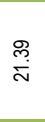 & $\begin{array}{l}\underset{\infty}{\infty} \\
\propto\end{array}$ & $\begin{array}{l}\stackrel{\leftrightarrow}{0} \\
\stackrel{\circ}{0}\end{array}$ & $\begin{array}{l}\stackrel{8}{\infty} \\
\propto\end{array}$ & $\begin{array}{l}\text { ثे } \\
\text { }\end{array}$ & $\begin{array}{l}\stackrel{9}{0} \\
\omega\end{array}$ & $\begin{array}{l}\text { 只 } \\
\stackrel{\sim}{\sim}\end{array}$ & $\begin{array}{l}\bar{f} \\
\stackrel{\sigma}{\circ}\end{array}$ & $\begin{array}{l}\hat{N} \\
\stackrel{\rho}{g}\end{array}$ \\
\hline 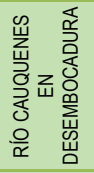 & $\underset{+}{\stackrel{+}{+}}$ & $\stackrel{ }{\circ}$ & 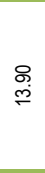 & 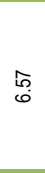 & $\stackrel{ }{\stackrel{ }{*}}$ & $\begin{array}{l}\text { \&. } \\
\stackrel{d}{~}\end{array}$ & 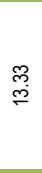 & 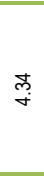 & $\underset{\sim}{\stackrel{S}{\sim}}$ & 胥 & 吕 & $\stackrel{m}{\rightleftarrows}$ & 究 & $\stackrel{\mathscr{R}}{\stackrel{R}{~}}$ & ભ્ટુ & z & $\stackrel{\stackrel{\llcorner}{\leftarrow}}{+}$ \\
\hline 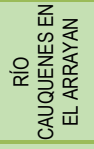 & 周 & $\stackrel{\circ}{i}$ & $\begin{array}{l}\mathcal{Y} \\
\stackrel{\sigma}{\sigma}\end{array}$ & $\stackrel{\stackrel{P}{F}}{=}$ & $\stackrel{\tilde{\omega}}{\mathrm{N}}$ & $\stackrel{\widetilde{ఠ}}{\stackrel{\varpi}{\sim}}$ & $\underset{\text { S }}{\text { f }}$ & 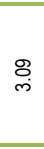 & $\underset{\forall}{J}$ & $\underset{j}{\stackrel{J}{j}}$ & $\underset{+}{\stackrel{\leftrightarrow}{+}}$ & $\begin{array}{l}\infty \\
\infty \\
\infty\end{array}$ & $\begin{array}{l}8 \\
\infty \\
\infty\end{array}$ & 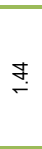 & 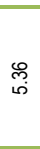 & $\stackrel{\infty}{\sim}$ & 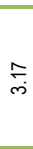 \\
\hline 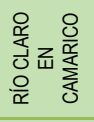 & $\stackrel{\text { p. }}{\rightleftharpoons}$ & 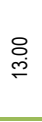 & $\frac{\mathbb{N}}{\dot{m}}$ & $\begin{array}{l}\stackrel{\infty}{\leftrightarrow} \\
\stackrel{\leftrightarrow}{N}\end{array}$ & $\stackrel{\overbrace{}}{\infty}$ & 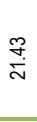 & $\stackrel{\varrho}{\stackrel{一}{\rightleftharpoons}}$ & 守 & $\begin{array}{l}\stackrel{0}{\circ} \\
\stackrel{0}{\circ}\end{array}$ & $\begin{array}{l}\stackrel{\Re}{0} \\
\stackrel{0}{0}\end{array}$ & $\begin{array}{l}\stackrel{8}{\otimes} \\
\stackrel{0}{\circ}\end{array}$ & $\begin{array}{l}\text { f } \\
\stackrel{6}{0}\end{array}$ & $\underset{\stackrel{8}{\stackrel{8}{\leftarrow}}}{ }$ & 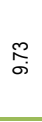 & $\underset{⿱ 丷}{\stackrel{E}{\sigma}}$ & §్ & $\underset{\sim}{\sim}$ \\
\hline 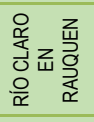 & $\underset{\text { 京 }}{ }$ & $\begin{array}{l}\stackrel{0}{0} \\
\text { هి }\end{array}$ & $\begin{array}{l}\bar{\infty} \\
\stackrel{\infty}{\sim}\end{array}$ & ম্ণু & $\begin{array}{l}\text { o } \\
\text { i. }\end{array}$ & 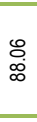 & 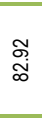 & $\underset{\infty}{\underset{\infty}{\infty}}$ & 芯 & $\begin{array}{l}\stackrel{\mathscr{L}}{0} \\
\stackrel{0}{0}\end{array}$ & 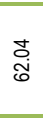 & $\begin{array}{l}\stackrel{\circ}{\circ} \\
\stackrel{1}{\circ}\end{array}$ & $\begin{array}{l}\stackrel{\infty}{\infty} \\
\stackrel{R}{\sim}\end{array}$ & 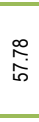 & $\stackrel{\sim}{\circ}$ & $\begin{array}{l}\text { fे } \\
\text { ष्ठ }\end{array}$ & $\stackrel{\stackrel{\circ}{\rightleftarrows}}{\dot{q}}$ \\
\hline 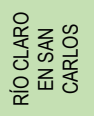 & 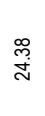 & 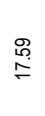 & $\stackrel{\infty}{\stackrel{\infty}{\sim}}$ & $\begin{array}{l}\bar{\infty} \\
\underset{\sim}{\sim}\end{array}$ & $\begin{array}{l}\text { Oे } \\
0 \\
0\end{array}$ & 点 & $\stackrel{\infty}{\stackrel{\infty}{\sim ి}}$ & $\begin{array}{l}\bar{\sigma} \\
0 \\
0\end{array}$ & $\begin{array}{l}\stackrel{\mathbb{2}}{\infty} \\
\stackrel{\infty}{\leftarrow}\end{array}$ & 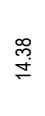 & $\begin{array}{l}\stackrel{9}{0} \\
\stackrel{6}{6}\end{array}$ & 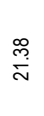 & $\begin{array}{l}\stackrel{\sim}{\infty} \\
\stackrel{-}{\rightleftharpoons}\end{array}$ & $\stackrel{i n}{\stackrel{i n}{ }}$ & $\begin{array}{l}\stackrel{\leftrightarrow}{\circ} \\
\stackrel{\rho}{\circ}\end{array}$ & 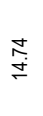 & $\stackrel{\circ}{\stackrel{0}{ }}$ \\
\hline 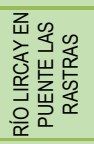 & 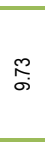 & $\underset{\stackrel{N}{r}}{\stackrel{N}{r}}$ & $\begin{array}{l}\stackrel{0}{2} \\
\stackrel{\sim}{N}\end{array}$ & 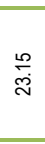 & 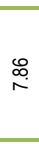 & 望 & $\stackrel{\infty}{\stackrel{\infty}{\digamma}}$ & $\begin{array}{l}\hat{\infty} \\
\stackrel{\infty}{\circ}\end{array}$ & $\begin{array}{l}\bar{N} \\
\text { ্ֶ }\end{array}$ & 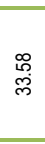 & $\overline{\tilde{c}}$ & $\stackrel{\infty}{\stackrel{\infty}{\sim}}$ & $\begin{array}{l}\text { : } \\
\stackrel{0}{0}\end{array}$ & $\stackrel{\substack{\infty \\
+}}{\infty}$ & $\stackrel{\hat{\infty}}{\infty}$ & ర్లై & $\stackrel{\circ}{i}$ \\
\hline 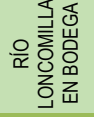 & $\begin{array}{l}\infty \\
0 \\
0 \\
0\end{array}$ & 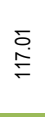 & 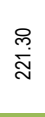 & 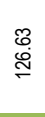 & $\begin{array}{l}\hat{i} \\
\text { ర్d }\end{array}$ & 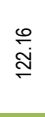 & 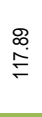 & 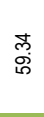 & $\stackrel{\stackrel{N}{N}}{\stackrel{N}{ }}$ & $\stackrel{\infty}{\stackrel{\infty}{f}}$ & $\stackrel{\infty}{\stackrel{\infty}{\infty}}$ & $\begin{array}{l}\stackrel{M}{0} \\
\stackrel{\sigma}{\sigma}\end{array}$ & 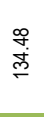 & $\begin{array}{l}\text { No } \\
\text { f్ }\end{array}$ & 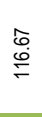 & $\begin{array}{l}0 \\
0 \\
0 \\
i\end{array}$ & $\begin{array}{c}\hat{m} \\
\text { i̊ }\end{array}$ \\
\hline
\end{tabular}




\begin{tabular}{|c|c|c|c|c|c|c|c|c|c|c|c|c|c|c|c|c|c|}
\hline 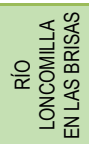 & 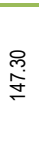 & \begin{tabular}{l}
$\hat{0}$ \\
\multirow{\sigma}{\sigma}{}
\end{tabular} & 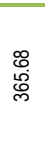 & $\underset{\mathbb{N}}{\bar{్}}$ & 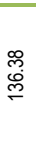 & $\begin{array}{l}\text { : } \\
\stackrel{8}{\circ}\end{array}$ & $\begin{array}{l}\hat{i} \\
\stackrel{N}{N} \\
\text { Non }\end{array}$ & $\begin{array}{l}\stackrel{8}{\circ} \\
\stackrel{\rho}{ }\end{array}$ & $\begin{array}{l}\stackrel{?}{\stackrel{N}{N}} \\
\text { }\end{array}$ & 㞧 & $\begin{array}{l}\text { ఠ̆ } \\
\stackrel{\leftrightarrow}{\circ}\end{array}$ & $\begin{array}{l}\text { \& } \\
\text { oj }\end{array}$ & 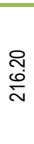 & $\underset{\infty}{\stackrel{f}{\sim}}$ & $\begin{array}{l}\infty \\
\stackrel{\infty}{0} \\
\infty \\
\leftarrow\end{array}$ & $\begin{array}{l}\stackrel{\Re}{\rho} \\
\stackrel{\rho}{\sigma}\end{array}$ & $\begin{array}{l}\mathscr{œ} \\
\infty \\
\infty\end{array}$ \\
\hline 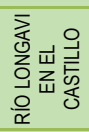 & $\begin{array}{l}\mathscr{8} \\
\stackrel{8}{ } \\
\stackrel{\sim}{2}\end{array}$ & $\begin{array}{l}\text { O } \\
\text { d. }\end{array}$ & $\begin{array}{l}\infty \\
\stackrel{\infty}{\alpha} \\
\stackrel{\infty}{\sigma}\end{array}$ & 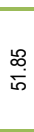 & ָิ & 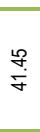 & 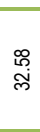 & i̊ & $\stackrel{\infty}{\infty}$ & 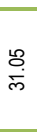 & 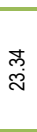 & $\begin{array}{l}\stackrel{\leftrightarrow}{0} \\
\text { }\end{array}$ & 怘 & $\begin{array}{l}\hat{N} \\
\stackrel{b}{\leftarrow}\end{array}$ & $\stackrel{\stackrel{N}{N}}{\text { N }}$ & 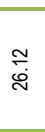 & 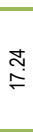 \\
\hline 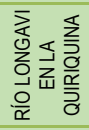 & $\begin{array}{l}\text { 号 } \\
\text { ì }\end{array}$ & $\begin{array}{l}\text { ஜ } \\
\stackrel{q}{q}\end{array}$ & $\begin{array}{l}\text { A } \\
\text { o }\end{array}$ & 항 & 总 & $\begin{array}{l}\stackrel{60}{\infty} \\
i \infty \\
i \infty\end{array}$ & $\begin{array}{l}\stackrel{\leftrightarrow}{q} \\
\stackrel{q}{2}\end{array}$ & $\begin{array}{l}\text { D. } \\
\stackrel{+}{+}\end{array}$ & $\begin{array}{l}\hat{\infty} \\
\stackrel{m}{\tilde{m}}\end{array}$ & 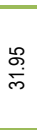 & $\begin{array}{l}\bar{\delta} \\
\text { p. }\end{array}$ & $\begin{array}{l}\text { Fै } \\
\text { o }\end{array}$ & $\begin{array}{l}\text { A } \\
\text { gi }\end{array}$ & $\begin{array}{l}\stackrel{\mathscr{R}}{\circ} \\
\stackrel{\circ}{\circ}\end{array}$ & 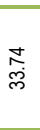 & $\begin{array}{l}\text { ळ. } \\
\text { ळ. }\end{array}$ & $\stackrel{\infty}{\stackrel{\infty}{N}}$ \\
\hline 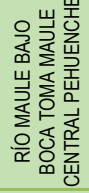 & 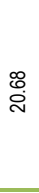 & f) & $\underset{\text { 임 }}{\stackrel{O}{7}}$ & $\stackrel{\overbrace{}}{\stackrel{ }{\mathrm{j}}}$ & $\underset{n}{\stackrel{R}{r}}$ & $\begin{array}{l}\stackrel{\infty}{\stackrel{m}{+}} \\
\stackrel{+}{*}\end{array}$ & $\begin{array}{l}\text { 条 } \\
\text { i }\end{array}$ & $\begin{array}{l}\stackrel{m}{+\infty} \\
+\end{array}$ & 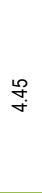 & $\underset{\leftarrow}{\stackrel{+}{\sim}}$ & 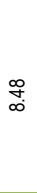 & $\underset{\infty}{N}$ & 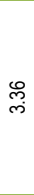 & $\stackrel{\frac{6}{0}}{\rho j}$ & 贲 & $\stackrel{m}{i s}$ & : \\
\hline 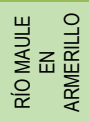 & 总 & 令 & $\begin{array}{l}\overline{5} \\
\infty \\
\infty\end{array}$ & $\begin{array}{l}9 \\
\text { ơ } \\
\text { in }\end{array}$ & 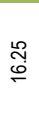 & 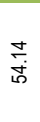 & 足 & 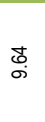 & 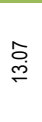 & $\begin{array}{l}\stackrel{\leftrightarrow}{0} \\
\infty\end{array}$ & 声 & 尺̊. & 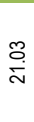 & $\begin{array}{l}\text { fa } \\
\infty\end{array}$ & $\begin{array}{l}\stackrel{\leftrightarrow}{\circ} \\
\stackrel{p}{\square}\end{array}$ & $\stackrel{\stackrel{\oplus}{\rightleftarrows}}{=}$ & $\stackrel{\sim}{\sim}$ \\
\hline 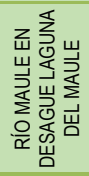 & $\mathbb{z}$ & 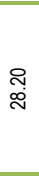 & 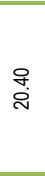 & $\underset{0}{\pi}$ & $\begin{array}{l}œ \\
\stackrel{\circ}{\circ}\end{array}$ & $\begin{array}{l}\infty \\
\infty \\
\infty \\
\infty\end{array}$ & 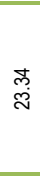 & 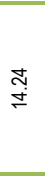 & 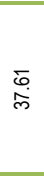 & 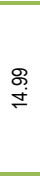 & $\begin{array}{l}\stackrel{2}{\sim} \\
\stackrel{\sim}{\sim}\end{array}$ & $\begin{array}{l}8 \\
0 \\
0\end{array}$ & $\stackrel{8}{8}$ & 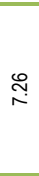 & $\stackrel{\bar{\sigma}}{\rightleftarrows}$ & 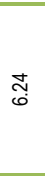 & 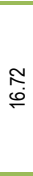 \\
\hline 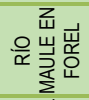 & 尺ి. & 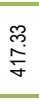 & $\begin{array}{l}\stackrel{N}{N} \\
\text { N }\end{array}$ & 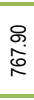 & $\begin{array}{l}\bar{\infty} \\
\stackrel{\infty}{\infty} \\
\bar{\infty}\end{array}$ & 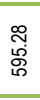 & $\begin{array}{l}\text { o } \\
\text { J } \\
\text { J }\end{array}$ & $\begin{array}{l}\text { ळ } \\
\stackrel{0}{0}\end{array}$ & 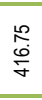 & 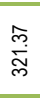 & 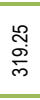 & 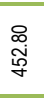 & 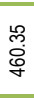 & 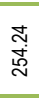 & 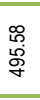 & 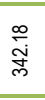 & 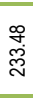 \\
\hline 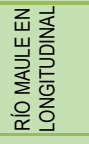 & 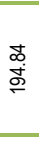 & $\begin{array}{l}\bar{\Phi} \\
\stackrel{\sigma}{\sigma}\end{array}$ & $\begin{array}{l}\frac{D}{c} \\
\stackrel{D}{N}\end{array}$ & $\begin{array}{l}\text { to } \\
\text { 总 } \\
\text { and }\end{array}$ & $\begin{array}{l}\stackrel{\leftrightarrow}{\infty} \\
\stackrel{+}{+}\end{array}$ & 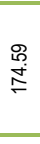 & 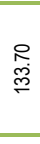 & 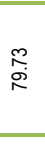 & 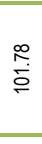 & $\underset{\substack{\infty \\
\infty}}{\stackrel{n}{0}}$ & $\underset{\substack{R \\
\text { R }}}{ }$ & 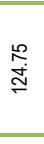 & 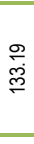 & ్ָ & $\begin{array}{l}\text { வ } \\
\text { চे }\end{array}$ & $\Sigma$ & 吕 \\
\hline 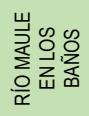 & $\begin{array}{l}\text { 官 } \\
\text { in }\end{array}$ & $\stackrel{\tilde{i}}{i}$ & 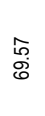 & $\stackrel{\circ}{\stackrel{8}{8}}$ & 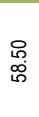 & 공 & 志 & $\begin{array}{l}\stackrel{8}{+} \\
\stackrel{+}{*}\end{array}$ & 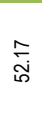 & $\begin{array}{l}\hat{0} \\
\stackrel{\infty}{N}\end{array}$ & 命 & $\stackrel{\substack{\infty \\
\infty}}{\infty}$ & $\begin{array}{l}\text {. } \\
\text { o. }\end{array}$ & $\stackrel{\circ}{\stackrel{\circ}{\circ}}$ & \begin{tabular}{l}
$\underset{J}{J}$ \\
\multirow{\forall}{*}{}
\end{tabular} & $\begin{array}{l}\text { Oे. } \\
\text { în }\end{array}$ & 心్లి \\
\hline 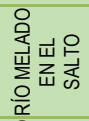 & $\begin{array}{l}\bar{\sigma} \\
\stackrel{\infty}{\sim}\end{array}$ & 夌 & $\begin{array}{l}\stackrel{\leftrightarrow}{ } \\
\stackrel{-}{2}\end{array}$ & 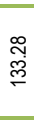 & $\begin{array}{l}8 \\
\& \\
0\end{array}$ & $\begin{array}{l}\text { f. } \\
\text { ळ̊ }\end{array}$ & $\stackrel{m}{\stackrel{\infty}{\infty}}$ & $\frac{8}{i}$ & $\begin{array}{l}8 \\
o 0 \\
0\end{array}$ & 응 & $\begin{array}{l}\text { 守 } \\
\text { 吕 }\end{array}$ & $\begin{array}{l}\frac{8}{8} \\
\frac{8}{\sigma}\end{array}$ & 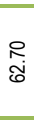 & $\stackrel{\infty}{\stackrel{i}{\sim}}$ & $\begin{array}{l}\dot{O} \\
\dot{J}\end{array}$ & $\begin{array}{l}\bar{\sigma} \\
\stackrel{\leftrightarrow}{\circ}\end{array}$ & 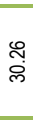 \\
\hline 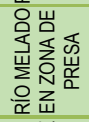 & $\begin{array}{l}0 \\
0 \\
0\end{array}$ & $\underset{\sim}{\stackrel{\leftrightarrow}{N}}$ & $\underset{\stackrel{A}{\sim}}{\stackrel{f}{N}}$ & $\begin{array}{l}\stackrel{\infty}{\infty} \\
\stackrel{\Phi}{\leftarrow}\end{array}$ & 守 & $\begin{array}{l}\widetilde{\widetilde{J}} \\
\underset{+}{+}\end{array}$ & 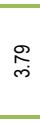 & ס্ & $\stackrel{\hat{N}}{\mathrm{i}}$ & $\stackrel{\sim}{N}$ & 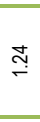 & 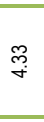 & $\stackrel{\text { S }}{\text { N }}$ & 管 & $\stackrel{\infty}{\stackrel{\circ}{\leftarrow}}$ & $\stackrel{\circ}{\rightleftarrows}$ & 寺 \\
\hline 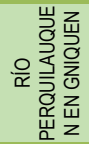 & $\begin{array}{l}\mathbb{N} \\
\stackrel{\sim}{L}\end{array}$ & 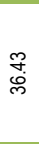 & 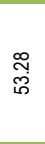 & $\begin{array}{l}\mathbb{N} \\
\tilde{0}\end{array}$ & $\stackrel{\overbrace{}}{\underset{\sim}{(}}$ & 옹 & ه্লি & $\begin{array}{l}\hat{\sigma} \\
\stackrel{\circ}{\circ}\end{array}$ & $\begin{array}{l}\stackrel{\mathscr{P}}{\sim} \\
\stackrel{+}{*}\end{array}$ & 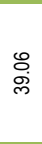 & 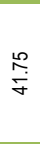 & $\stackrel{\frac{O}{7}}{\frac{\gamma}{d}}$ & 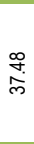 & $\begin{array}{l}\stackrel{ }{0} \\
\stackrel{0}{0}\end{array}$ & 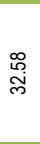 & $\begin{array}{l}0 \\
\stackrel{\leftrightarrow}{\circ} \\
\stackrel{\sim}{N}\end{array}$ & $\underset{\infty}{\stackrel{\sigma}{\infty}}$ \\
\hline
\end{tabular}




\begin{tabular}{|c|c|c|c|c|c|c|c|c|c|c|c|c|c|c|c|c|c|}
\hline 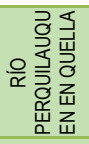 & 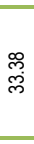 & $\begin{array}{l}\text { : } \\
:\end{array}$ & 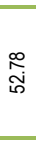 & \begin{tabular}{l}
$\infty$ \\
$\infty$ \\
$\infty$ \\
\hdashline
\end{tabular} & $\begin{array}{l}\bar{\delta} \\
\stackrel{\infty}{j}\end{array}$ & 怘 & 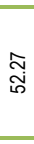 & $\begin{array}{l}\overline{i n} \\
\text { d. }\end{array}$ & $\begin{array}{l}\mathbb{T} \\
\mathscr{g}\end{array}$ & $\underset{\mathfrak{Z}}{\mathbb{Z}}$ & 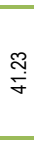 & $\begin{array}{l}\text { 总 } \\
\text { in }\end{array}$ & $\underset{\mathbb{H}}{\stackrel{7}{*}}$ & $\stackrel{\text { ọ }}{\text { N. }}$ & $\stackrel{\stackrel{\circ}{\digamma}}{=}$ & $\begin{array}{l}\text { o } \\
\text { d }\end{array}$ & 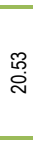 \\
\hline 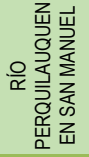 & $\underset{\mathbb{N}}{\mathbb{N}}$ & $\begin{array}{l}\bar{N} \\
\stackrel{\text { D }}{ }\end{array}$ & \begin{tabular}{l}
$\stackrel{\&}{+}$ \\
\multirow{j}{*}{}
\end{tabular} & $\begin{array}{l}8 \\
\& \\
\&\end{array}$ & $\begin{array}{l}\mathscr{\infty} \\
\infty \\
\stackrel{\infty}{\infty}\end{array}$ & $\begin{array}{l}\stackrel{R}{d} \\
\stackrel{N}{ }\end{array}$ & 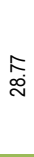 & 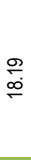 & 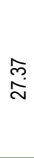 & 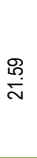 & is & $\begin{array}{l}\text { Pి } \\
\text { N }\end{array}$ & $\begin{array}{l}\text { ठ্. } \\
\text { ते }\end{array}$ & 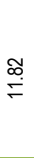 & $\begin{array}{c}\text { m } \\
\text { d }\end{array}$ & ָ̊. & 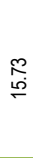 \\
\hline 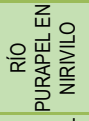 & 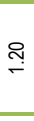 & $\stackrel{尺}{\stackrel{F}{r}}$ & छ़ & స̃. & $\stackrel{\text { }}{\text { S }}$ & 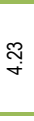 & 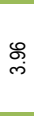 & $\underset{i}{\bar{N}}$ & ্ָণ & $\underset{\text { d }}{\text { i }}$ & 芯 & $\frac{s}{z}$ & $\underset{\infty}{\stackrel{\sim}{\infty}}$ & $\underset{\infty}{\infty}$ & $\stackrel{O}{\text { S }}$ & $\Sigma^{\Sigma}$ & 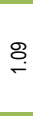 \\
\hline 을 & $\stackrel{?}{\stackrel{?}{\&}}$ & 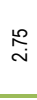 & $\underset{\infty}{\mp}$ & 菖 & S. & $\stackrel{\leftrightarrow}{\circ}$ & 怘 & ָุ & $\stackrel{\widehat{N}}{\mathrm{~N}}$ & 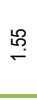 & 苦 & $\underset{6}{\bar{\sigma}}$ & $\stackrel{\frac{60}{m}}{m}$ & مֶّ & 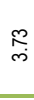 & क्. & గ్రి \\
\hline 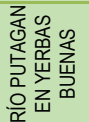 & $\underset{\stackrel{\circ}{6}}{\stackrel{0}{6}}$ & $\begin{array}{l}0 \\
\stackrel{0}{\infty} \\
\stackrel{\infty}{\leftarrow}\end{array}$ & $\begin{array}{l}\hat{N} \\
\text { d }\end{array}$ & $\begin{array}{l}\stackrel{2}{\stackrel{\alpha}{\sigma}} \\
\stackrel{\sigma}{2}\end{array}$ & $\begin{array}{l}\bar{i} \\
\text { }\end{array}$ & 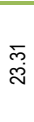 & 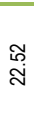 & 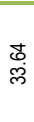 & $\stackrel{\leftrightarrow}{\stackrel{m}{0}}$ & $\stackrel{m}{\sigma}$ & $\underset{\substack{\infty \\
\infty}}{ }$ & 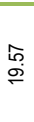 & $\begin{array}{l}\hat{\omega} \\
\stackrel{\alpha}{\leftarrow}\end{array}$ & 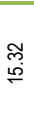 & $\stackrel{\circ}{\infty}$ & $\begin{array}{c}\infty \\
\infty \\
\infty \\
\infty\end{array}$ & 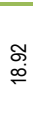 \\
\hline
\end{tabular}

\section{Precipitaciones brutas para las estaciones trabajadas según DGA}

\begin{tabular}{|c|c|c|c|c|c|c|c|c|c|c|c|c|c|c|c|c|c|c|c|}
\hline $\begin{array}{l}z \\
\frac{z}{0} \\
\frac{5}{5} \\
\text { w }\end{array}$ & 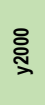 & ণ্ণু & స్త్ర & స్ָָ & 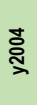 & 䒽 & 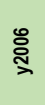 & స్త్ర & ণ্ণু & :్త్రి & 옳 & 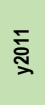 & స్ָે & స్ె & 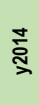 & 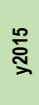 & ֻัญ & స્ત્ર & స్్ㄲ \\
\hline 党站 & $\begin{array}{l}\stackrel{\circ}{\circ} \\
\stackrel{\circ}{\circ}\end{array}$ & 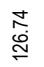 & 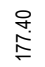 & 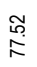 & \& & 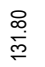 & 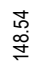 & 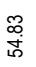 & 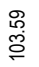 & $\underset{\infty}{\stackrel{\Xi}{\infty}}$ & $\begin{array}{l}\stackrel{8}{0} \\
\mathbb{0}\end{array}$ & $\underset{\stackrel{\leftrightarrow}{\circ}}{\stackrel{\leftrightarrow}{N}}$ & $\stackrel{\infty}{\stackrel{\infty}{0}}$ & ๙్య & $\begin{array}{l}\stackrel{9}{0} \\
\stackrel{8}{0}\end{array}$ & $\begin{array}{l}\text { 乃 } \\
\text { ळ్ }\end{array}$ & $\begin{array}{l}\mathscr{\infty} \\
\stackrel{\infty}{\infty} \\
\stackrel{0}{n}\end{array}$ & 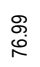 & 용 \\
\hline 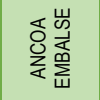 & 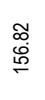 & $\begin{array}{l}\infty \\
\stackrel{\infty}{p} \\
\stackrel{p}{\rho}\end{array}$ & 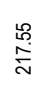 & 응 & 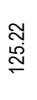 & 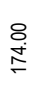 & $\begin{array}{l}\text { ్ָ } \\
\text { }\end{array}$ & $\underset{\infty}{\stackrel{\leftrightarrow}{\text { d }}}$ & $\begin{array}{l}\stackrel{\sim}{\alpha} \\
\stackrel{m}{\sim}\end{array}$ & 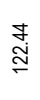 & $\begin{array}{l}\infty \\
\infty \\
\infty \\
\infty\end{array}$ & $\stackrel{\vec{D}}{\stackrel{\sim}{\sim}}$ & \& & 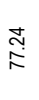 & 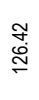 & 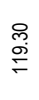 & $\underline{z}$ & $\begin{array}{l}\text { O্. } \\
\text { }\end{array}$ & $\frac{\pi}{z}$ \\
\hline 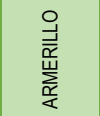 & : & 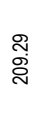 & $\stackrel{\circ}{\stackrel{\circ}{\circ}}$ & 冓 & 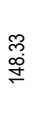 & 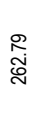 & $\begin{array}{l}\tilde{N} \\
\stackrel{\omega}{N}\end{array}$ & \begin{tabular}{l}
8 \\
\multirow{0}{*}{}
\end{tabular} & $\begin{array}{l}\underset{J}{d} \\
\text { }\end{array}$ & 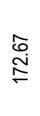 & 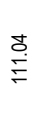 & 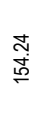 & స్ָ & 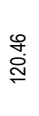 & $\begin{array}{l}\text { 芯 } \\
\text { o. } \\
\stackrel{\rho}{n}\end{array}$ & $\begin{array}{l}\infty \\
\infty \\
\stackrel{0}{0} \\
\stackrel{0}{0}\end{array}$ & $\begin{array}{l}\stackrel{\mathscr{N}}{ٍ ٍ ~} \\
\stackrel{\sim}{*}\end{array}$ & 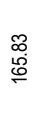 & 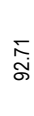 \\
\hline 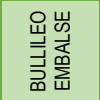 & $\begin{array}{l}\stackrel{\infty}{\sim} \\
\text { 心ิ }\end{array}$ & $\begin{array}{l}\hat{\imath} \\
\stackrel{\sim}{\infty}\end{array}$ & $\begin{array}{l}\widetilde{O} \\
\stackrel{\square}{d}\end{array}$ & 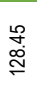 & $\begin{array}{l}\text { 吕 } \\
\text { هo }\end{array}$ & 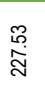 & $\begin{array}{l}\text { @ } \\
\text { ¿্ं }\end{array}$ & 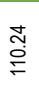 & $\begin{array}{l}\infty \\
\stackrel{\infty}{\circ} \\
\stackrel{\sim}{2}\end{array}$ & $\begin{array}{l}\stackrel{\infty}{0} \\
\stackrel{0}{0}\end{array}$ & $\stackrel{\stackrel{\sim}{N}}{\stackrel{N}{F}}$ & 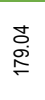 & 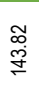 & 范 & $\begin{array}{l}\infty \\
\stackrel{0}{0} \\
\varrho\end{array}$ & 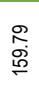 & ஃ̊․ & $\begin{array}{l}\stackrel{+}{\circ} \\
\stackrel{\rho}{\rightleftharpoons}\end{array}$ & 芯 \\
\hline 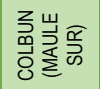 & $\begin{array}{l}\hat{\text { ț }} \\
\text { ¿े }\end{array}$ & $\stackrel{m}{\circ}$ & $\begin{array}{l}\text { ల్ల్ల } \\
\end{array}$ & 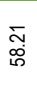 & 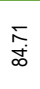 & $\begin{array}{l}\stackrel{0}{0} \\
\stackrel{0}{0}\end{array}$ & $\begin{array}{l}\& \\
\dot{\sigma} \\
\stackrel{5}{0}\end{array}$ & $\begin{array}{l}\stackrel{2}{2} \\
\stackrel{0}{\circ}\end{array}$ & $\begin{array}{l}\mathcal{O} \\
\tilde{\Phi} \\
\tilde{D}\end{array}$ & $\underset{\infty}{\stackrel{N}{N}}$ & $\begin{array}{l}\text { 它 } \\
\text { if }\end{array}$ & $\stackrel{\frac{9}{6}}{\dot{\theta}}$ & $\begin{array}{l}\text { त्र } \\
\text { bू }\end{array}$ & $\begin{array}{l}80 \\
\text { \& }\end{array}$ & 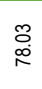 & $\begin{array}{l}\text { S. } \\
\text { è }\end{array}$ & $\begin{array}{l}\overline{1} \\
0 \\
0\end{array}$ & $\underset{\infty}{\stackrel{\leftrightarrow}{+\infty}}$ & 雚 \\
\hline $\begin{array}{l}\text { 우 } \\
\text { ơ } \\
\text { ơ } \\
\text { ठ․ }\end{array}$ & 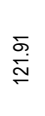 & 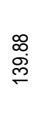 & 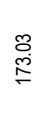 & 芯 & $\begin{array}{l}\stackrel{\infty}{\infty} \\
\stackrel{\infty}{\rightleftharpoons}\end{array}$ & 莕 & 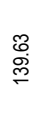 & 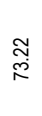 & 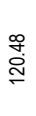 & 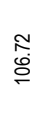 & 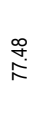 & 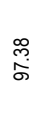 & $\underset{\infty}{\stackrel{\circ}{*}}$ & $\begin{array}{l}\infty \\
\infty \\
\stackrel{R}{R}\end{array}$ & $\begin{array}{l}\text { ?̦ } \\
\stackrel{8}{\circ}\end{array}$ & $\begin{array}{l}8 \\
0 \\
\stackrel{6}{*}\end{array}$ & 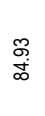 & 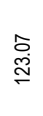 & $\underset{\sim}{\bar{c}}$ \\
\hline 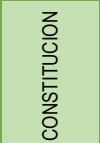 & 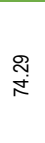 & $\begin{array}{l}\stackrel{R}{\sigma} \\
\stackrel{\sigma}{2}\end{array}$ & $\begin{array}{l}\infty \\
\stackrel{\infty}{\infty} \\
\stackrel{\infty}{0}\end{array}$ & 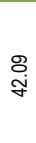 & 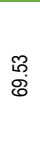 & $\begin{array}{c}\stackrel{\llcorner}{m} \\
\stackrel{\infty}{\infty}\end{array}$ & $\begin{array}{l}\text { 乃ু } \\
\stackrel{R}{R}\end{array}$ & 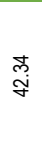 & $\begin{array}{l}\text { గ్ } \\
\mathbb{8}\end{array}$ & $\begin{array}{l}8 \\
\stackrel{8}{\circ}\end{array}$ & $\begin{array}{l}\stackrel{0}{c} \\
\stackrel{o}{q}\end{array}$ & $\begin{array}{l}\stackrel{0}{0} \\
\hat{0}\end{array}$ & $\begin{array}{l}\stackrel{9}{0} \\
\hat{0}\end{array}$ & $\underset{\substack{0 \\
\text { in }}}{ }$ & $\begin{array}{l}\infty \\
\stackrel{R}{R} \\
\stackrel{2}{n}\end{array}$ & $\begin{array}{l}\stackrel{\infty}{0} \\
\stackrel{0}{0}\end{array}$ & $\underset{⿱ 亠}{\dot{T}}$ & 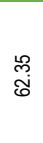 & $\begin{array}{l}\mathbb{I} \\
\underset{N}{J}\end{array}$ \\
\hline
\end{tabular}




\begin{tabular}{|c|c|c|c|c|c|c|c|c|c|c|c|c|c|c|c|c|c|c|c|}
\hline 通岂 & 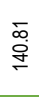 & 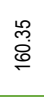 & 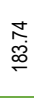 & $\begin{array}{c}\bar{\infty} \\
\infty \\
\infty\end{array}$ & $\begin{array}{l}\stackrel{+}{\circ} \\
\stackrel{\infty}{\leftarrow}\end{array}$ & 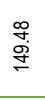 & 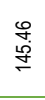 & 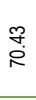 & 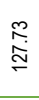 & $\begin{array}{l}\stackrel{\infty}{\infty} \\
\stackrel{0}{ }\end{array}$ & $\underset{\infty}{\stackrel{\infty}{\infty}}$ & 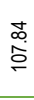 & $\stackrel{\text { }}{\sigma}$ & $\frac{R}{\infty}$ & 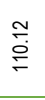 & $\begin{array}{l}\text { \% } \\
\text { ळ. } \\
\text {. }\end{array}$ & $\begin{array}{l}\text { مٌ } \\
\text { مٌ }\end{array}$ & 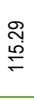 & $\stackrel{\circ}{\infty}$ \\
\hline 㟧变 & $\underset{\substack{\text { d } \\
\text { e }}}{ }$ & $\stackrel{\hat{\Phi}}{\stackrel{F}{d}}$ & $\begin{array}{l}\stackrel{\circ}{\circ} \\
\check{\sigma}\end{array}$ & $\stackrel{\infty}{\leftarrow \infty}$ & 苍 & $\underset{\infty}{\stackrel{\infty}{\infty}}$ & $\underset{\infty}{\stackrel{8}{0}}$ & 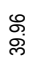 & $\underset{\infty}{\stackrel{\infty}{\infty}}$ & 品 & $\begin{array}{l}\text { g } \\
\dot{q}\end{array}$ & 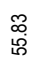 & : & 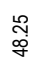 & $\stackrel{৫}{\circledR}$ & \&্ণ & 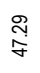 & 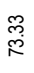 & Е. \\
\hline 辛 & 艿 & ম্ডু & $\begin{array}{l}\text { 足 } \\
\stackrel{d}{\sim}\end{array}$ & 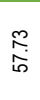 & $\begin{array}{l}\text { \% } \\
\ddot{0}\end{array}$ & 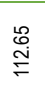 & 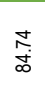 & $\stackrel{\llcorner}{\stackrel{\circ}{g}}$ & $\underset{\infty}{\stackrel{?}{i ~}}$ & 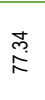 & $\begin{array}{l}\mathscr{\&} \\
\text { ஸे }\end{array}$ & $\begin{array}{l}\widetilde{0} \\
\stackrel{0}{0}\end{array}$ & 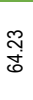 & $\begin{array}{l}\infty \\
\infty \\
\text { ه్ }\end{array}$ & $\begin{array}{l}\infty \\
\stackrel{\infty}{\mathbb{N}} \\
\stackrel{+}{n}\end{array}$ & 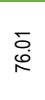 & 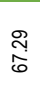 & 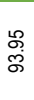 & $\begin{array}{l}\stackrel{2}{0} \\
\stackrel{f}{4}\end{array}$ \\
\hline 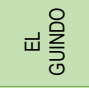 & $\begin{array}{l}\infty \\
\stackrel{\infty}{0} \\
\stackrel{0}{0}\end{array}$ & 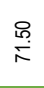 & $\begin{array}{l}\bar{N} \\
\ddot{8}\end{array}$ & $\begin{array}{l}\dot{d} \\
\dot{g}\end{array}$ & $\begin{array}{l}9 \\
\text { ơ } \\
0\end{array}$ & 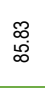 & $\begin{array}{l}\text { 芯 } \\
\text { d. }\end{array}$ & 䨌 & $\begin{array}{l}\stackrel{2}{0} \\
\stackrel{0}{0}\end{array}$ & 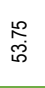 & $\begin{array}{l}\hat{5} \\
\stackrel{m}{m}\end{array}$ & $\begin{array}{l}\text { 品 } \\
\text { }\end{array}$ & $\begin{array}{l}\stackrel{\infty}{\sigma} \\
\stackrel{f}{q}\end{array}$ & $\begin{array}{l}\stackrel{\infty}{\infty} \\
\infty \\
\infty\end{array}$ & $\begin{array}{l}\ddot{\otimes} \\
\ddot{8}\end{array}$ & $\begin{array}{l}\bar{\delta} \\
.8 \\
0\end{array}$ & $\begin{array}{l}\stackrel{\infty}{\%} \\
\dddot{\gamma}\end{array}$ & $\frac{\widehat{\infty}}{\square}$ & 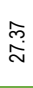 \\
\hline 岩山崖 & 章 & 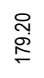 & $\begin{array}{l}\hat{0} \\
\stackrel{+}{+}\end{array}$ & $\stackrel{\infty}{\stackrel{\infty}{ }}$ & $\begin{array}{l}\stackrel{8}{0} \\
\stackrel{8}{+}\end{array}$ & 옹 & 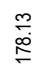 & 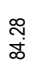 & 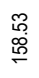 & 予 & 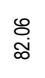 & : & 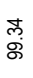 & 曽 & $\begin{array}{l}\bar{\infty} \\
\stackrel{0}{0} \\
\square\end{array}$ & 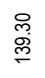 & 志 & $\begin{array}{l}\bar{\sigma} \\
\dot{\sigma} \\
\dot{y}\end{array}$ & 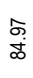 \\
\hline $\begin{array}{l}\text { 올 } \\
\text { 差 } \\
\text { 오 }\end{array}$ & $\begin{array}{l}\stackrel{9}{0} \\
\text { ì }\end{array}$ & $\begin{array}{l}\stackrel{8}{0} \\
\stackrel{\infty}{\sigma}\end{array}$ & 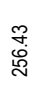 & $\begin{array}{l}\infty \\
\stackrel{\infty}{0} \\
\stackrel{p}{\rho}\end{array}$ & $\begin{array}{l}\text { 苞 } \\
\stackrel{\leftrightarrow}{\leftarrow}\end{array}$ & 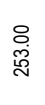 & $\begin{array}{l}\stackrel{R}{0} \\
\text { di }\end{array}$ & ণ & $\stackrel{m}{\stackrel{m}{i}}$ & 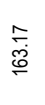 & $\begin{array}{l}\stackrel{\infty}{\infty} \\
\text { రు }\end{array}$ & 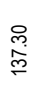 & 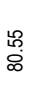 & $\begin{array}{l}\text { ¿. } \\
\stackrel{\leftrightarrow}{\sim}\end{array}$ & $\begin{array}{l}8 \\
\ddot{0} \\
\ddot{c}\end{array}$ & 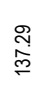 & $\begin{array}{l}\text { ơ } \\
\text { ô. } \\
\stackrel{0}{0}\end{array}$ & 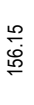 & 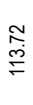 \\
\hline 武 & $\begin{array}{l}\text { 8̊. } \\
\text { ઠ̊ }\end{array}$ & $\begin{array}{l}\stackrel{2}{0} \\
\dot{\sigma}\end{array}$ & 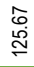 & $\begin{array}{l}\infty \\
\infty \\
\infty \\
\stackrel{\infty}{\infty}\end{array}$ & 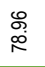 & 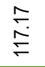 & $\begin{array}{l}\mathscr{乃} \\
\infty \\
\infty \\
\infty\end{array}$ & $\begin{array}{l}\text { న్ } \\
\text { \&̊ }\end{array}$ & $\begin{array}{l}\infty \\
\infty \\
\stackrel{\infty}{R}\end{array}$ & 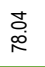 & 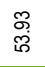 & $\underset{\substack{\mathbb{N} \\
0}}{\mathbb{N}}$ & $\underset{\tilde{\sigma}}{\tilde{\sigma}}$ & 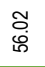 & $\stackrel{\stackrel{\rho}{R}}{\stackrel{2}{R}}$ & 芯 & $\begin{array}{l}\stackrel{2}{0} \\
\stackrel{0}{0}\end{array}$ & 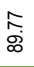 & $\stackrel{\substack{f \\
\&}}{\sigma}$ \\
\hline 点崫崖 & $\underset{i}{\stackrel{N}{i}}$ & $\stackrel{8}{\stackrel{8}{*}}$ & $\begin{array}{l}\text { 号 } \\
\text { ه్ }\end{array}$ & 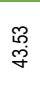 & $\underset{\stackrel{\infty}{\infty}}{\stackrel{\infty}{n}}$ & $\underset{\substack{\mathbb{N} \\
\stackrel{N}{N}}}{ }$ & 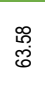 & $\begin{array}{l}\bar{\sigma} \\
\text { i্ల }\end{array}$ & 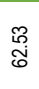 & 荅 & 㝦 & ?̊. & ঙ্ֶু & $\begin{array}{l}\text { 吕 } \\
\text { 邑 }\end{array}$ & $\begin{array}{l}\widetilde{N} \\
\stackrel{0}{0}\end{array}$ & $\stackrel{R}{i}$ & $\begin{array}{l}\mathbb{N} \\
\text { d }\end{array}$ & $\stackrel{5}{\stackrel{5}{R}}$ & 息 \\
\hline 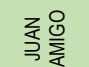 & 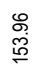 & $\stackrel{m}{\circ}$ & $\begin{array}{l}\infty \\
\infty \\
\infty \\
\stackrel{\infty}{\infty}\end{array}$ & ํ. & $\underset{\stackrel{8}{\sim}}{\stackrel{0}{\simeq}}$ & $\begin{array}{l}\mathscr{m} \\
\stackrel{\infty}{0} \\
\stackrel{0}{0}\end{array}$ & \begin{tabular}{l}
$\infty$ \\
$\infty$ \\
\multirow{5}{0}{} \\
$\stackrel{0}{0}$
\end{tabular} & $\begin{array}{l}\underset{0}{0} \\
\infty \\
\infty\end{array}$ & $\begin{array}{l}\mathscr{m} \\
\infty \\
\infty \\
\stackrel{\infty}{\infty}\end{array}$ & 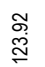 & $\begin{array}{l}\infty \\
\stackrel{0}{0} \\
\infty\end{array}$ & 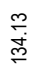 & $\begin{array}{l}\text { ஸे } \\
\text { षे }\end{array}$ & $\begin{array}{l}\stackrel{8}{\sigma} \\
\text {. }\end{array}$ & స̃. & 怘 & $\begin{array}{l}\text { ¿े } \\
\text { ه }\end{array}$ & 岕 & $\begin{array}{c}\stackrel{R}{a} \\
\stackrel{\infty}{\infty}\end{array}$ \\
\hline 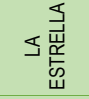 & $\stackrel{\circledast}{\stackrel{\infty}{K}}$ & $\begin{array}{l}\text { N్ } \\
\text { ְू }\end{array}$ & 离 & 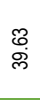 & $\stackrel{m}{\circ}$ & 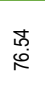 & స్త్ర & $\begin{array}{l}\text { 邑 } \\
\text { ల్ల }\end{array}$ & $\begin{array}{l}\text { న్ } \\
\text { B }\end{array}$ & 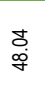 & $\underset{m}{\stackrel{J}{*}}$ & 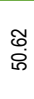 & \begin{tabular}{l}
$\infty$ \\
$\infty$ \\
\hdashline \\
\hdashline
\end{tabular} & $\stackrel{m}{\stackrel{m}{m}}$ & 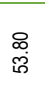 & $\underset{\substack{+\infty \\
q}}{+}$ & $\stackrel{\infty}{\stackrel{\infty}{\infty ~}}$ & $\begin{array}{l}\text { 足 } \\
\text { 㟔 }\end{array}$ & 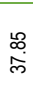 \\
\hline 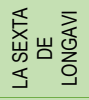 & 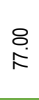 & 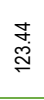 & 苞 & 怘 & $\underset{\substack{\infty \\
\infty}}{\stackrel{\infty}{\infty}}$ & $\begin{array}{l}\hat{\hat{O}} \\
\stackrel{\rho}{\risingdotseq}\end{array}$ & $\begin{array}{l}\bar{i} \\
\stackrel{\rho}{=}\end{array}$ & $\stackrel{\circ}{\circ}$ & $\begin{array}{l}\stackrel{0}{0} \\
\stackrel{8}{\circ}\end{array}$ & $\begin{array}{l}\stackrel{\infty}{\circ} \\
\stackrel{8}{\circ}\end{array}$ & $\begin{array}{l}9 \\
\stackrel{9}{0} \\
\text { d. }\end{array}$ & $\begin{array}{l}\stackrel{R}{0} \\
\stackrel{0}{\infty}\end{array}$ & 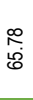 & $\underset{\substack{\infty \\
i \infty}}{+}$ & $\begin{array}{l}\mathbb{N} \\
\infty \\
\infty \\
\infty\end{array}$ & $\begin{array}{l}\stackrel{2}{\sim} \\
\stackrel{N}{\sim}\end{array}$ & $\begin{array}{l}\text { 员 } \\
\text { 多 }\end{array}$ & ๕. & $\begin{array}{l}\text { N్ } \\
\text { రิ }\end{array}$ \\
\hline 峷 & 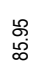 & $\frac{\infty}{\circ}$ & 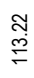 & $\stackrel{\mathscr{\infty}}{\leftarrow \infty}$ & 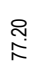 & $\begin{array}{l}\infty \\
\stackrel{\infty}{-}\end{array}$ & $\begin{array}{l}\frac{9}{9} \\
\text { d }\end{array}$ & 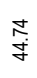 & $\begin{array}{l}\mathscr{\mathscr { B }} \\
\stackrel{\leftrightarrow}{0}\end{array}$ & $\begin{array}{c}\infty \\
\stackrel{\infty}{R}\end{array}$ & $\begin{array}{l}\underset{\mathscr{P}}{f} \\
\stackrel{f}{*}\end{array}$ & $\begin{array}{l}8 \\
\& \\
0\end{array}$ & 登 & 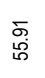 & $\begin{array}{l}\mathscr{\cong} \\
\underset{\infty}{\mathbb{S}}\end{array}$ & $\begin{array}{l}\text { R } \\
\text { Oे }\end{array}$ & $\begin{array}{l}\infty \\
\stackrel{\infty}{0} \\
0\end{array}$ & $\frac{8}{\dot{0}}$ & $\begin{array}{c}\stackrel{\mathscr{g}}{\sim} \\
\stackrel{+}{*}\end{array}$ \\
\hline 崩 & 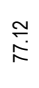 & $\underset{\infty}{\stackrel{f}{-}}$ & $\begin{array}{l}\underset{\pi}{0} \\
\stackrel{0}{\sim}\end{array}$ & $\begin{array}{l}\text { Oo } \\
o ̛ g\end{array}$ & $\stackrel{\stackrel{\leftrightarrow}{R ~}}{\stackrel{p}{N}}$ & $\begin{array}{l}\text { Fै } \\
\stackrel{5}{*}\end{array}$ & $\underset{\infty}{\stackrel{\varpi}{\infty}}$ & 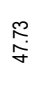 & $\begin{array}{l}\infty \\
\stackrel{\sim}{\Gamma}\end{array}$ & $\begin{array}{l}\hat{0} \\
\stackrel{0}{0} \\
0\end{array}$ & 吕 & ֻ & 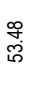 & $\begin{array}{l}\text { 号 } \\
\text { 呙 }\end{array}$ & $\stackrel{\mathscr{N}}{\stackrel{N}{N}}$ & $\begin{array}{c}\stackrel{\leftrightarrow}{0} \\
\hat{0}\end{array}$ & $\begin{array}{l}\text { D. } \\
\text { o. }\end{array}$ & $\begin{array}{l}\mathscr{L} \\
\stackrel{\infty}{\infty} \\
\infty\end{array}$ & $\underset{\text { io }}{\bar{\infty}}$ \\
\hline 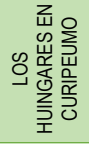 & 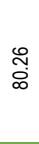 & $\begin{array}{l}\infty \\
\substack{\infty \\
\infty \\
\infty}\end{array}$ & $\begin{array}{l}\text { ஃ } \\
\infty \\
\infty\end{array}$ & 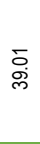 & 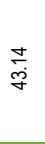 & \begin{tabular}{l}
$\mathbb{N}$ \\
\multirow{J}{0}{}
\end{tabular} & \begin{tabular}{l}
$\stackrel{0}{0}$ \\
\multirow{0}{0}{}
\end{tabular} & 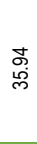 & ֻัণ & 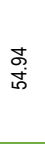 & $\stackrel{\circ}{\stackrel{G}{q}}$ & ్ֶలో & ્ָన్ & 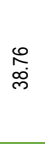 & ્ָ & 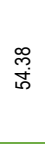 & 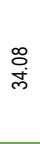 & ஜ. & $\begin{array}{l}\hat{i} \\
\text { o. } \\
\text { of }\end{array}$ \\
\hline $\begin{array}{l}\vec{N} \\
\text { O } \\
\text { 岀 }\end{array}$ & $\stackrel{\circ}{\circ}$ & $\begin{array}{l}\bar{\delta} \\
\stackrel{+}{N}\end{array}$ & $\begin{array}{l}\text { N } \\
\text { \& }\end{array}$ & 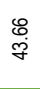 & $\begin{array}{l}\text { f } \\
\text { 岕 }\end{array}$ & $\stackrel{\stackrel{\leftrightarrow}{R}}{\stackrel{\leftrightarrow}{R}}$ & 芯 & $\begin{array}{l}\stackrel{8}{\circ} \\
\stackrel{m}{m}\end{array}$ & $\begin{array}{l}8 \\
0 \\
0\end{array}$ & 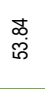 & $\begin{array}{l}\text { f } \\
\text { ه্ల. }\end{array}$ & 离 & $\begin{array}{l}\text { Oे } \\
\text { ơ }\end{array}$ & $\begin{array}{l}\infty \\
\stackrel{\leftrightarrow}{q}\end{array}$ & $\stackrel{m}{\frac{m}{6}}$ & $\begin{array}{l}\text { r } \\
\text { \& }\end{array}$ & $\begin{array}{l}\mathscr{\Omega} \\
\text { ర్ల }\end{array}$ & $\frac{\pi}{z}$ & 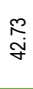 \\
\hline$\stackrel{\text { 일 }}{\stackrel{\underline{\underline{\alpha}}}{z}}$ & 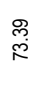 & $\begin{array}{l}\mathscr{8} \\
\stackrel{\infty}{\infty}\end{array}$ & 乫 & $\begin{array}{l}\mathbb{d} \\
\stackrel{\sigma}{G}\end{array}$ & $\stackrel{m}{\stackrel{m}{\circ}}$ & $\begin{array}{c}\text { ల్ } \\
\text { ه̊ }\end{array}$ & 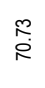 & $\underset{\sim \mathcal{J}}{\check{F}}$ & $\stackrel{\circ}{\circ}$ & $\begin{array}{l}\bar{m} \\
\bar{j}\end{array}$ & $\begin{array}{l}\stackrel{\leftrightarrow}{\sharp} \\
\stackrel{\gamma}{ }\end{array}$ & 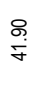 & $\begin{array}{l}\text { స్ } \\
\text { ల్ల }\end{array}$ & $\begin{array}{l}\stackrel{P}{P} \\
\stackrel{+}{*}\end{array}$ & $\begin{array}{l}\widetilde{N} \\
\stackrel{8}{8}\end{array}$ & 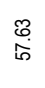 & 菅 & 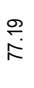 & $\underset{\mathscr{g}}{\stackrel{乛}{y}}$ \\
\hline 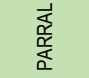 & $\begin{array}{l}\stackrel{2}{\circ} \\
\infty \\
\infty\end{array}$ & $\begin{array}{l}\bar{m} \\
\bar{s}\end{array}$ & 空 & $\begin{array}{l}\text { 心ొ } \\
\text { గn }\end{array}$ & $\stackrel{\infty}{\stackrel{\infty}{i ் ~}}$ & $\begin{array}{l}\infty \\
\substack{0 \\
\infty \\
\infty}\end{array}$ & $\begin{array}{l}\bar{c} \\
\text { og }\end{array}$ & $\begin{array}{l}\text { \% } \\
\stackrel{9}{\sigma}\end{array}$ & $\begin{array}{l}\text { 疋 } \\
\text { \& }\end{array}$ & $\underset{N}{\stackrel{N}{N}}$ & $\begin{array}{l}\text { 只 } \\
\text { 呙 }\end{array}$ & $\stackrel{\infty}{\stackrel{\infty}{i}}$ & 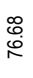 & $\stackrel{\circ}{\stackrel{\circ}{\circ}}$ & 点 & $\begin{array}{l}\hat{o} \\
\dot{d}\end{array}$ & 宗 & 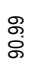 & 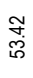 \\
\hline
\end{tabular}




\begin{tabular}{|c|c|c|c|c|c|c|c|c|c|c|c|c|c|c|c|c|c|c|c|}
\hline 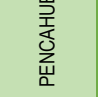 & $\stackrel{\infty}{\stackrel{\infty}{\sim}}$ & $\begin{array}{l}\text { 峘 } \\
\text { o. } \\
0\end{array}$ & $\begin{array}{l}\hat{0} \\
\infty \\
\infty\end{array}$ & 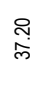 & $\frac{\pi}{6}$ & 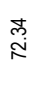 & ì & 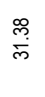 & $\begin{array}{l}\text { న్ } \\
\infty \\
0 \\
6\end{array}$ & 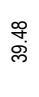 & 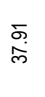 & Fì & $\begin{array}{l}\text { @ơ } \\
\text { co }\end{array}$ & 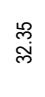 & $\begin{array}{l}8 \\
\text { d } \\
\text { L }\end{array}$ & $\stackrel{\frac{9}{6}}{\dot{g}}$ & 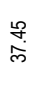 & 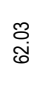 & $\Sigma$ \\
\hline 氶 & 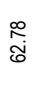 & $\begin{array}{l}\stackrel{\bullet}{\oplus} \\
\stackrel{\tilde{C}}{0}\end{array}$ & $\underset{\infty}{\stackrel{\infty}{\infty}}$ & $\begin{array}{l}\hat{\omega} \\
\stackrel{p}{p}\end{array}$ & 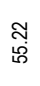 & $\frac{\infty}{8}$ & $\begin{array}{l}\hat{A} \\
\text { 峁 }\end{array}$ & 卢 & 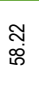 & $\underset{i n}{\stackrel{m}{5}}$ & $\begin{array}{l}\infty \\
\stackrel{m}{0} \\
\bar{m}\end{array}$ & $\stackrel{\widetilde{\sigma}}{\sigma}$ & 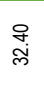 & $\underset{\substack{\tilde{m} \\
\text { 足 }}}{ }$ & $\begin{array}{l}\text { ळ్ } \\
\text { ర్d }\end{array}$ & 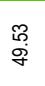 & $\begin{array}{l}\stackrel{\leftrightarrow}{\mathrm{f}} \\
\text { : }\end{array}$ & 文 & $\begin{array}{l}\stackrel{\circ}{\leftrightarrow} \\
\text { ̛ु }\end{array}$ \\
\hline 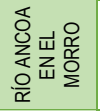 & 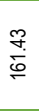 & $\begin{array}{l}\overline{0} \\
\stackrel{0}{0} \\
\stackrel{0}{2}\end{array}$ & $\begin{array}{l}\text { 芯 } \\
\text { స్ }\end{array}$ & $\begin{array}{l}\hat{0} \\
\dot{0}\end{array}$ & $\stackrel{\stackrel{\leftrightarrow}{\sim}}{\stackrel{\sim}{\sim}}$ & 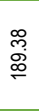 & 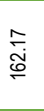 & $\begin{array}{l}\infty \\
\infty \\
\infty \\
\infty \\
\infty\end{array}$ & 莡 & $\begin{array}{l}\underset{\Im}{\circ} \\
\stackrel{\circ}{\digamma}\end{array}$ & $\stackrel{\infty}{\stackrel{\infty}{N}}$ & $\begin{array}{l}\stackrel{8}{0} \\
\stackrel{\infty}{\sim}\end{array}$ & $\begin{array}{l}\text { Фे } \\
\stackrel{\sigma}{\sigma}\end{array}$ & $\underset{\substack{\infty \\
\stackrel{\infty}{0}}}{ }$ & 吕 & 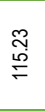 & 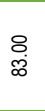 & $\begin{array}{l}\stackrel{\infty}{\sim} \\
\underset{\sim}{\sim}\end{array}$ & 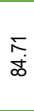 \\
\hline 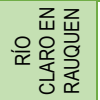 & 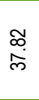 & $\underset{\stackrel{\leftrightarrow}{\leftrightarrow ٌ}}{\stackrel{\leftrightarrow}{0}}$ & $\underset{\infty}{\underset{\infty}{\tau}}$ & $\begin{array}{l}\text { R. } \\
\text { o. } \\
\text { d. }\end{array}$ & $\stackrel{N}{i}$ & $\stackrel{\infty}{\stackrel{\infty}{i}}$ & $\underset{\tilde{\sigma}}{\tilde{\sigma}}$ & $\underset{\sim}{=}$ & $\underset{\mathrm{D}}{\mathrm{E}}$ & 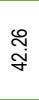 & 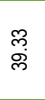 & $\underset{\widetilde{N}}{\widetilde{0}}$ & 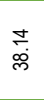 & ০্লি, & 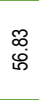 & 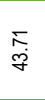 & $\begin{array}{l}\text { 芯 } \\
\text { d. }\end{array}$ & $\frac{\circ}{\dot{0}}$ & $\stackrel{R}{i}$ \\
\hline 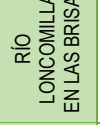 & $\underline{z}$ & 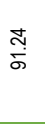 & זٓ & $\begin{array}{l}\infty \\
\stackrel{\infty}{0} \\
\dot{q}\end{array}$ & $\begin{array}{l}\infty \\
\stackrel{\infty}{n} \\
i n\end{array}$ & $\begin{array}{l}\text { ్ָ } \\
\text { Dֶ }\end{array}$ & $\begin{array}{l}\mathscr{8} \\
\ddot{8}\end{array}$ & $\begin{array}{l}\text { ్ָల } \\
\text { }\end{array}$ & $\begin{array}{l}\ddot{\leftrightarrow} \\
\stackrel{\sim}{0}\end{array}$ & $\begin{array}{l}\mathbb{N} \\
\stackrel{0}{0}\end{array}$ & $\stackrel{f}{\stackrel{f}{f}}$ & $\begin{array}{l}8 \\
\dot{0} \\
\text {. }\end{array}$ & 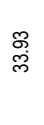 & 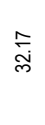 & స్ట & $\stackrel{\circ}{\stackrel{g}{g}}$ & 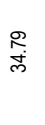 & $\begin{array}{l}\stackrel{0}{0} \\
\stackrel{0}{\circ}\end{array}$ & 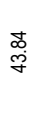 \\
\hline 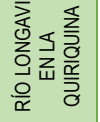 & 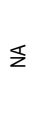 & 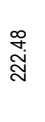 & 离 & \begin{tabular}{c} 
\} $\\
{\infty} \\
{\infty}$ & $\begin{array}{l}\underset{N}{\mathbb{N}} \\
\text { }\end{array}$ & $\begin{array}{l}\stackrel{0}{\circ} \\
\stackrel{0}{\circ}\end{array}$ & 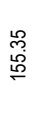 & $\stackrel{\sim}{\stackrel{g}{y}}$ & $\begin{array}{l}\hat{\tilde{O}} \\
\ddot{c}\end{array}$ & $\begin{array}{l}\stackrel{\mathfrak{L}}{\infty} \\
\stackrel{\infty}{\circ}\end{array}$ & $\begin{array}{l}\stackrel{\infty}{\infty} \\
\stackrel{\infty}{\infty}\end{array}$ & 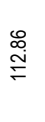 & 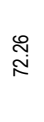 & $\begin{array}{l}\bar{\sigma} \\
\bar{\sigma}\end{array}$ & $\begin{array}{l}\stackrel{+}{0} \\
\stackrel{\infty}{=}\end{array}$ & $\begin{array}{l}\stackrel{ \pm}{0} \\
\stackrel{0}{0}\end{array}$ & $\underset{\widetilde{్}}{\widetilde{0}}$ & 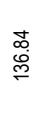 & $\begin{array}{l}\text { ठే } \\
\text { ळ. }\end{array}$ \\
\hline 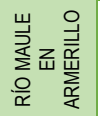 & $\underline{z}$ & $\begin{array}{l}\overline{6} \\
\ddot{\theta}\end{array}$ & $\begin{array}{l}\stackrel{0}{0} \\
\stackrel{\infty}{\infty}\end{array}$ & $\begin{array}{l}\stackrel{R}{\dot{D}} \\
\stackrel{0}{c}\end{array}$ & 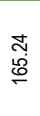 & $\begin{array}{l}\text { న్ } \\
\stackrel{8}{0}\end{array}$ & 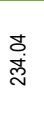 & 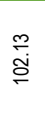 & 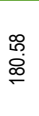 & 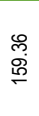 & $\begin{array}{l}\overline{\tilde{N}} \\
\stackrel{\rho}{\rightleftharpoons}\end{array}$ & 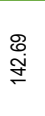 & $\begin{array}{l}\stackrel{F}{d} \\
\stackrel{d}{d}\end{array}$ & 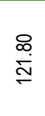 & 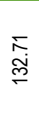 & 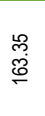 & $\begin{array}{l}\ddot{8} \\
8\end{array}$ & 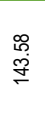 & 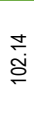 \\
\hline 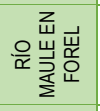 & $\underline{z}$ & 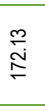 & $\begin{array}{l}\otimes \\
\infty \\
0\end{array}$ & $\underset{\sim}{\stackrel{\infty}{N}}$ & ণু & $\begin{array}{l}\stackrel{\infty}{\circ} \\
\stackrel{\infty}{\rightleftharpoons}\end{array}$ & $\frac{\infty}{\check{\delta}}$ & $\begin{array}{l}\infty \\
\stackrel{\infty}{q} \\
\stackrel{y}{y}\end{array}$ & $\begin{array}{l}\text { ָే } \\
\tilde{\sigma}\end{array}$ & 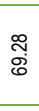 & $\begin{array}{l}\stackrel{R}{\infty} \\
\stackrel{i}{n}\end{array}$ & $\underset{i}{\stackrel{8}{i n}}$ & $\begin{array}{l}\bar{\delta} \\
\dot{0}\end{array}$ & $\begin{array}{l}\stackrel{2}{2} \\
\text { is }\end{array}$ & $\begin{array}{l}\infty \\
\stackrel{\infty}{0} \\
\text {. }\end{array}$ & 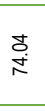 & 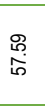 & $\begin{array}{l}\stackrel{0}{0} \\
\stackrel{0}{\rightleftharpoons}\end{array}$ & $\begin{array}{l}\text { 㭆 } \\
\text { 迥 }\end{array}$ \\
\hline 否点 & 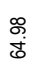 & $\underset{⿱}{\stackrel{5}{R}}$ & $\begin{array}{l}\stackrel{8}{8} \\
\stackrel{8}{\circ}\end{array}$ & $\stackrel{\infty}{\stackrel{\infty}{\dot{g}}}$ & $\begin{array}{l}8 \\
i n \\
\end{array}$ & 尔 & 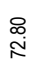 & 壱 & 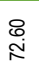 & $\begin{array}{l}\stackrel{0}{0} \\
\text { o. }\end{array}$ & $\begin{array}{l}\text { 岕 } \\
\text { g }\end{array}$ & 㢈 & $\begin{array}{l}\hat{f} \\
\text { go }\end{array}$ & $\begin{array}{l}\stackrel{œ}{\infty} \\
\stackrel{+}{+}\end{array}$ & $\begin{array}{l}8 \\
\text { ஸे }\end{array}$ & 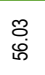 & $\begin{array}{l}8 \\
\dot{q} \\
\end{array}$ & 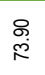 & 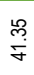 \\
\hline 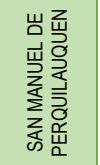 & 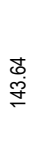 & $\begin{array}{l}\stackrel{8}{8} \\
\text { ه. } \\
\stackrel{\rho}{2}\end{array}$ & $\begin{array}{l}\stackrel{\leftrightarrow}{\sigma} \\
\stackrel{\sigma}{\sigma}\end{array}$ & $\begin{array}{l}\infty \\
\infty \\
\infty \\
\infty\end{array}$ & 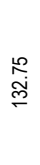 & 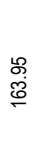 & \begin{tabular}{l}
$\bar{\top}$ \\
\multirow{J}{0}{}
\end{tabular} & $\underset{\infty}{\stackrel{\infty}{\infty}}$ & 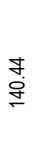 & 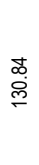 & 帝 & $\begin{array}{l}\stackrel{\mathscr{B}}{\rho} \\
\stackrel{\rho}{=}\end{array}$ & $\begin{array}{l}\infty \\
\stackrel{\infty}{\infty} \\
\stackrel{\rho}{\rightleftharpoons}\end{array}$ & $\underset{\infty}{R}$ & $\stackrel{\sim}{\stackrel{\sim}{\sim}}$ & 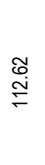 & 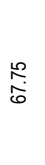 & 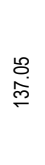 & $\begin{array}{l}\text { के } \\
\infty \\
\stackrel{0}{0}\end{array}$ \\
\hline 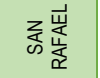 & 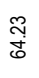 & 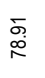 & 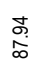 & 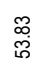 & $\begin{array}{l}\tilde{N} \\
\stackrel{0}{\circ}\end{array}$ & 怘 & ס్ֶల & $\underset{\infty}{\infty}$ & $\underset{\infty}{\tilde{c}}$ & $\stackrel{m}{\stackrel{\circ}{\circ}}$ & $\begin{array}{l}\infty \\
\stackrel{+}{q} \\
\stackrel{+}{*}\end{array}$ & $\begin{array}{l}\bar{\delta} \\
\text { bo }\end{array}$ & 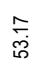 & $\begin{array}{l}\infty \\
\infty \\
\stackrel{q}{q}\end{array}$ & 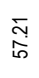 & 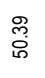 & $\begin{array}{l}\underset{\infty}{\infty} \\
\underset{f}{f}\end{array}$ & $\underset{\infty}{\stackrel{N}{\infty}}$ & $\underset{\sim}{\infty}$ \\
\hline 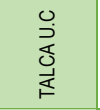 & $\begin{array}{l}\overline{0} \\
\text { iें }\end{array}$ & $\underset{\ddot{B}}{\overline{8}}$ & $\underset{\infty}{\stackrel{2}{\infty}}$ & $\begin{array}{l}0 \\
0 \\
00 \\
0\end{array}$ & $\begin{array}{l}\text { ?) } \\
\text { of }\end{array}$ & 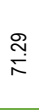 & $\begin{array}{l}\bar{\delta} \\
\tilde{\delta}\end{array}$ & 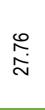 & $\begin{array}{l}\text { \% } \\
\text { 囱 }\end{array}$ & $\underset{\sigma}{\stackrel{q}{g}}$ & 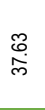 & $\begin{array}{l}\stackrel{8}{\Omega} \\
o g \\
o g\end{array}$ & 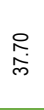 & $\begin{array}{l}\text { 芯 } \\
\text { D. }\end{array}$ & $\begin{array}{l}\text { : } \\
\text { ํํ }\end{array}$ & 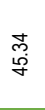 & $\begin{array}{l}\stackrel{\sim}{n} \\
\underset{m}{\infty}\end{array}$ & $\begin{array}{l}\text { ஜ } \\
\text { ô }\end{array}$ & 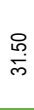 \\
\hline 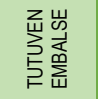 & $\underset{\substack{\infty \\
\sim}}{\stackrel{\infty}{n}}$ & 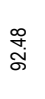 & $\begin{array}{l}\stackrel{0}{2} \\
\stackrel{\phi}{0}\end{array}$ & $\begin{array}{l}\tilde{0} \\
\text { 吕 }\end{array}$ & $\stackrel{\infty}{\stackrel{\infty}{\circ}}$ & $\begin{array}{l}\infty \\
\stackrel{\infty}{\infty} \\
\stackrel{0}{0}\end{array}$ & $\begin{array}{l}\widetilde{\tilde{s}} \\
\stackrel{8}{8}\end{array}$ & 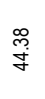 & 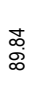 & ֻ̊. & $\begin{array}{l}\text { 品 } \\
\stackrel{g}{G}\end{array}$ & $\begin{array}{l}\mathscr{8} \\
0 \\
0 \\
0\end{array}$ & స్ స్ర & $\begin{array}{l}\hat{\mathfrak{n}} \\
\stackrel{f}{f}\end{array}$ & 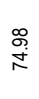 & $\begin{array}{l}\text { ల్ } \\
\stackrel{d}{0}\end{array}$ & $\begin{array}{l}\text { 芯 } \\
\text { d्ల }\end{array}$ & 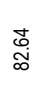 & 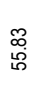 \\
\hline
\end{tabular}
\end{tabular}




\section{Impacto de la evolución de la superficie urbana edificada en el escurrimiento superficial de la ciudad de Tandil, Buenos Aires, Argentina: un escenario de simulación con HEC-RAS}

Impact of the evolution of the urban built-up area on surface runoff in the city of Tandil, Buenos Aires, Argentina: a simulation scenario with HEC-RAS

María Lorena La Macchia

Centro de Investigaciones Geográficas

Facultad de Ciencias Humanas Universidad Nacional del Centro Provincia de Buenos Aires (UNICEM) Instituto de Geografía, Historia y Ciencias Sociales Consejo Nacional de Investigaciones Científica y Técnicas (CONICET)

Argentina

llamacchia@fch.unicen.edu.ar

Santiago Linares

Centro de Investigaciones Geográficas

Facultad de Ciencias Humanas Universidad Nacional del Centro Provincia de Buenos Aires (UNICEM) Instituto de Geografía, Historia y Ciencias Sociales Consejo Nacional de Investigaciones Científica y Técnicas (CONICET)

Argentina slinares@fch.unicen.edu.ar

\section{RESUMEN}

El siguiente artículo forma parte de una investigación en curso que estudia y profundiza los procesos que intervienen en la modelización hidrodinámica de una cuenca urbana. Este concepto parte de considerar la construcción de un modelo hidrológico que tiene en cuenta principalmente la superficie de drenaje y un modelo hidráulico definido por las características y parámetros de la infraestructura que presenta la cuenca. 
En los últimos diez años, los modelos hidrológicos han sido cada vez más utilizados para evaluar, comprender y analizar la dinámica de escurrimiento en los sistemas de cuencas posibilitando la predicción de escenarios a corto y mediano plazo a partir de la simulación de eventos de diferentes intensidades e implicancias socioespaciales.

El objetivo de este trabajo es construir un modelo matemático de modelización de crecidas para la cuenca urbana de la ciudad de Tandil mediante la herramienta HECRAS. Los parámetros que definen la construcción del modelo numérico dependen de la topografía o Modelo Digital del Terreno, la red de drenaje, los modelos de expansión urbana que fijaron la configuración territorial actual del espacio urbano, los coeficientes de rugosidad diferenciando las zonificaciones dentro de la ciudad y el caudal de lluvia determinado por su intensidad y velocidad. En este caso, la única variable "input" que no se utilizó fue la red geométrica de drenaje. A partir de la herramienta implementada fue posible realizar simulaciones para los años 1996 y 2011. Su análisis permitió conocer el efecto de los cambios de coberturas del suelo en el escurrimiento superficial, indispensable para evaluar y recomendar políticas de gestión y planificación de algunos factores como por ejemplo, el tratamiento, mantenimiento y extensión de la red de desagües pluviales, restricciones a la densificación en la edificación, generación de nuevos espacios verdes que actúen como amortiguadores de infiltración, entre otras medidas semiestructurales a la planificación urbana vigente.

PALABRAS CLAVE: Modelización hidrodinámica - Cuenca urbana - Tandil - HEC-RAS

\section{ABSTRACT}

The following article is part of an ongoing investigation that studies and deepens the processes involved in the hydrodynamic modeling of an urban basin. This concept starts from considering the construction of a hydrological model that mainly takes into account the drainage surface and a hydraulic model defined by the characteristics and parameters of the infrastructure that the basin presents.

In the last ten years, hydrological models have been used to assess, understand and analyze runoff dynamics in basin systems, making it possible to predict short and medium-term scenarios from the simulation of events of different intensities and socio-spatial implications.

The objective of this work is to build a mathematical model of flood modeling for the urban basin of the city of Tandil using the HEC-RAS tool. The parameters that define the construction of the numerical model depend on the topography or Digital Land Model, the drainage network, the urban expansion models that established the current territorial configuration of the urban space, the roughness coefficients differentiating the zoning within the city and the rainfall flow determined by its intensity and speed. In this case, the only "input" variable that wasn't used was the 
geometric drainage network. From the implemented tool, it was possible to carry out simulations for the years 1996 and 2011. Their analysis allowed us to know the effect of the changes in land cover on the surface runoff, essential to evaluate and recommend management policies and planning of some factors. For example, the treatment, maintenance and extension of the storm drainage network, restrictions on densification in the building, generation of new green spaces that act as infiltration buffers, among other semi-structural measures to current urban planning.

KEYWORDS: Hydrodynamic modeling - Urban basin - Tandil - HEC-RAS

\section{INTRODUCCIÓN}

Los abordajes y dimensiones de análisis desde la gestión integral del riesgo requieren pensar los impactos que los problemas espaciales urbanos acontecen en el territorio y redefinen la dialéctica sociedad-naturaleza. Las políticas de intervención derivadas del monitoreo, gestión y control para la construcción de ciudades sostenibles necesitan potenciar una mirada integral e interdisciplinar para trabajar y analizar las interrelaciones de estos procesos desde una óptica compleja.

Un sistema complejo, en términos de Rolando García (2006), se define como la representación de un recorte de la realidad, la cual es entendida como una totalidad organizada, integrada por unidades complejas, llamadas subsistemas, que no pueden estudiarse aisladamente. De esta manera, es fundamental su estudio teniendo en cuenta cada uno de los elementos que entran en contradicción en los estudios de riesgo: el subsistema social y el natural. Ambos conforman un par dialéctico en permanente proceso de definición y redefinición.

La gestión del riesgo constituye una ecuación de los conceptos de amenaza, vulnerabilidad y riesgo que implica el análisis de distintas dimensiones de los fenómenos (Herzer, 2002; Carballo y Goldberg, 2014; Natenzon 1998). El proceso de urbanización y expansión urbana de las ciudades, la planificación y modificación de usos del suelo, el desarrollo de infraestructura, trae aparejadas las respuestas del ambiente y el ecosistema urbano a esas acciones generando riesgos y problemas ambientales.

El análisis de inundaciones y anegamientos (Ferrando y Francisco, 2006) representa un tema de investigación siempre vigente en la Geografía (Johnston, Gegory y Smith, 
1981; López Trigal, 2015) y constituye una problemática socioeconómica y ambiental intrínsecamente ambivalente, dado que es la misma acción que la sociedad ejerce sobre el territorio, la que incrementa los efectos negativos de dicha eventualidad, la cual dinamizada por las actividades económicas, antropización del medio natural y pauta de localización de la población en áreas urbanas, termina por modificar las características de escorrentía de las cuencas mediante cambios de usos del suelo y el reemplazo de las coberturas naturales por coberturas impermeables, intensificando con ello el riesgo a inundaciones (Melesse y Wang, 2007).

En la llanura pampeana Fuschini Mejia (1998) considera que las inundaciones pueden clasificarse en inundaciones por desborde, por anegamiento y mixtas. En muchas zonas, las características geomorfológicas del territorio provocan que las planicies sean el escenario del desborde de los cursos de agua que, en épocas de excedentes, producen inundaciones hacia áreas laterales, fenómenos conocidos como almacenamiento lateral, que puede cubrir campos y tener lento movimiento. Las inundaciones por anegamiento se desarrollan en áreas sin pendiente en las cuales el agua queda estancada por periodos de tiempo, según la magnitud del evento y, por último, las mixtas ocurren por la combinación de ambas, por desborde y anegamiento. Profundizando estas características, Adriana Pereyra (2014) destaca que las inundaciones y los anegamientos pueden ser upstream floods, definidas como inundaciones aguas arriba, producto de intensas precipitaciones en cortos periodos de tiempo en zonas de pendiente alta o zonas montañosas y downstream floods consecuencia de tormentas de larga duración en grandes extensiones, propias de ambientes de baja pendiente o zonas llanas. En estas aparecen las flashfloods, propias de la rapidez con la que acontecen. Según la autora en muchas ocasiones se contemplan la dinámica natural del área y de la cuenca, obviando los procesos de valoración y uso del territorio, altamente vulnerable. Además, no se reflexiona sobre las transformaciones en la cuenca mediante la construcción de canales y otras obras que modifican el comportamiento y dinámica del sistema.

En palabras de Rolando García (2006) hablamos de una problemática compleja donde el estudio de los problemas espaciales urbanos permite pensar en los procesos transversales (políticos, económicos, institucionales, sociales y ambientales) que parten de un modelo de desarrollo cuyo principal objetivo es la construcción de un espacio productivista y dinámico que no mide los impactos que 
generan en el territorio y en la relación sociedad-naturaleza. Por ello, es necesario un diagnóstico integrado para proponer acciones concretas y políticas de intervención orientadas a las propiedades del sistema y los subsistemas involucrados, analizando su vulnerabilidad y resiliencia y considerando su dinámica y evolución temporal a diferentes escalas.

Cuando analizamos los subsistemas que intervienen en un proceso de inundación, además del social, el económico y el político institucional, encontramos el natural: el territorio. En esta línea, González, Torchia y Viand (2015:33) mencionan las precipitaciones intensas o prolongadas, la crecida de un río, la marea de tormenta, el oleaje, la falla de alguna estructura hidráulica, la capacidad de absorción de los suelos, la insuficiente capacidad de descarga de los cursos de agua y la pendiente del terreno, como las más destacadas. Pero en todos los casos conviven las interrelaciones entre todos los subsistemas.

Específicamente sobre las ciudades, las autoras señalan que las inundaciones más características tienen que ver con la ocurrencia de precipitaciones intensas, las cuales saturan la capacidad del sistema de desagüe pluvial, como consecuencia de un aumento del escurrimiento superficial producto de una disminución de la infiltración por superficies pavimentadas y edificaciones (González, Torchia y Viand, 2015:34).

Los procesos de ocupación y transformación del espacio nos permiten entender el modelo de desarrollo existente en las áreas urbanas y la falta de una lógica coherente con las premisas del desarrollo sustentable sobre todo para explicar el problema de las inundaciones. Conceptos clave como el de justicia espacial, equidad, capacidad de carga y valoración ecosistémica del paisaje urbano se encuentran sujetos a intereses y actores que definen políticas públicas en pos de costos ambientales como la densificación urbana no planificada, urbanización en áreas de protección natural o paisajística y reducción de áreas verdes que impactan decisivamente en la alteración del sistema hidrológico e hidráulico modificando el drenaje superficial y subsuperficial y derivando en la construcción de obras de infraestructura, rellenos, canalizaciones y entubados no proyectados.

Tucci (2005:90-91) va a describir detalladamente las alteraciones que la urbanización produce al ciclo hidrológico. En términos resumidos constaría de la siguiente 
secuencia: comenzando por la reducción de la infiltración del suelo, la cual provoca que el volumen de agua que no infiltra permanezca en la superficie, aumentando con ello la escorrentía superficial; por la reducción de la infiltración, el acuífero tiende a disminuir el nivel del nivel freático (especialmente cuando el área urbana es muy extensa) reduciendo el flujo subterráneo; y finalmente, dada la sustitución de la cobertura natural por zonas impermeables, hay una reducción de la evapotranspiración, ya que la superficie urbana no retiene agua como la cubierta vegetal y no permite evapotranspiración como ocurre por el follaje y el suelo. Él mismo autor enfatiza que este proceso de alteración del ciclo hidrológico, y posterior anegamiento, es sensible también a la falta de control del espacio urbano e infraestructura hídrica, compuesta esencialmente por sistemas de abastecimiento de agua, alcantarillado sanitario, red de desagüe pluvial y tratamiento de residuos sólidos (Tucci, 2005:9).

Desde un punto metodológico, existe una vasta y creciente experiencia en implementar herramientas geotecnológicas que permitan analizar, evaluar, modelar y brindar soluciones ante el riesgo a inundaciones y anegamientos urbanos. Algunos antecedentes los podemos mencionar en los trabajos de DeVantier, y Feldman, 1993; Vanneuville et al. 2003; Henríquez Ruiz, 2009; Ellis et al. 2012; Sanchez y Lastra, 2011; Fernández et al. 2018 y Collazos et al. 2018. En estos casos se trabaja sobre la elaboración de modelos hidrológicos e hidráulicos unidimensionales o bidimensionales para analizar el comportamiento del escurrimiento superficial en los ejes del cauce o arroyo principal para cada recorte espacial y bajo un hidrograma o caudal de un evento.

Scioli (2009) en su trabajo estudia y evalúa el aporte desde los distintos modelos hidrológicos implementando y calibrando el que más se ajusta en áreas de llanura. Su objetivo consiste en analizar el movimiento multidireccional del agua sobre el terreno y evaluar la variabilidad de la superficie con el aporte de los modelos digitales de elevación (MDE) SRTM.

La diversidad de trabajos se reduce, por un lado, a la propuesta de diferentes modelos de simulaciones hidrológicas, hidráulicas o ambas para distintos tipos de relieve y al aporte de los modelos digitales de elevación (MDE) y a la extracción de parámetros morfométricos de la cuenca para incorporarlos a las modelizaciones. 
Teniendo en cuenta el recorrido bibliográfico de la problemática, la mayoría de los aportes provienen desde las ciencias exactas, como las ciencias de la ingeniería, física, agrimensura e hidráulica y es, en este sentido, donde es necesario considerar una visión entre disciplinas considerando la gestión, planificación y monitoreo del territorio desde el campo de la geografía aplicada. Es decir, analizar la relación sociedad-naturaleza y su complejidad para la construcción de ciudades sostenibles. Los trabajos más afines a nuestra disciplina están vinculados a estudios de riesgo. Estas investigaciones refieren al diagnóstico del sistema natural actual de las ciudades medias, a su vulnerabilidad y a la elaboración de cartas de riesgo hídrico para generar estrategias de intervención respecto a su posterior mitigación, gestión y evaluación.

La aplicación de geotecnologías para el desarrollo de modelos predictivos, monitoreo y mitigación de inundaciones permite dar respuesta y tomar decisiones en el desarrollo de políticas públicas que eviten los problemas de anegamiento en ciudades bonaerenses, pero en muchos casos es difícil contar con fuentes de información debido a la falta de datos disponibles a diferentes escalas, a la forma de compatibilizar la información espacial y temporal, a la ausencia de una secuencia procedimental fácilmente replicable y a una norma de interpretación de los resultados estandarizada. Este artículo persigue ese propósito de transferencia, desde un punto de vista metodológico, describir fuentes accesibles de información en base a los recursos disponibles, indicar etapas generales del procedimiento y norma de interpretación estandarizada de resultados como una primera aproximación al problema. Como objetivo final se pretende poder clasificar zonas de peligro o amenaza en base a la determinación de escalas que plantea la guía AEMI 2013 utilizando mapas de velocidad y profundidad del escurrimiento sobre el terreno. Si bien la guía conjuga ambos mapas en curvas de mayor o menor vulnerabilidad y determina grados de peligro y afectación en lo urbano, en este trabajo, solamente se analizan los resultados del producto de los mapas de $\mathrm{D} \times \mathrm{V}$ (depth por velocity).

En la ciudad de Tandil, según investigaciones precedentes (La Macchia, 2015), existen zonas de mayor peligro que se localizan, en primer lugar, hacia el norte, noroeste y noreste caracterizados por zonas de baja pendiente, con escasa infiltración del suelo y una velocidad y sentido de escurrimiento hacia la misma 
dirección. Esta zona, ha evidenciado un gran crecimiento urbano y se ha expandido considerablemente entre los años 1991 y 2011, lo cual, provoca impactos en el proceso de escorrentía superficial.

En segundo lugar, el sur, suroeste y sureste de la ciudad constituye otra de las zonas de amenaza ante la intensidad y duración de un evento. Si bien estas áreas se ven favorecidas por el emplazamiento del piedemonte serrano, que actúan como superficies de infiltración y drenaje del agua, el problema radica en la velocidad y multidireccionalidad con que se desarrolla el escurrimiento superficial. Esta área también se ha expandido en los últimos años y la dinámica del mercado inmobiliario junto a su especulación han significado el aumento de las actividades vinculadas a la recreación y oferta de complejos hoteleros destinado al consumo de las clases de altos ingresos.

En tercer lugar, otra zona de impacto es el área central de la ciudad enmarcada por la presencia de los entubamientos del A을 Blanco y A을 Del Fuerte. Las precipitaciones desde aguas arriba y el aumento de su velocidad en superficie impactan tanto en las zonas aledañas de ambos conductos como sobre los ramales y ejes de circulación. El aumento del tiempo de retención se produce debido a la saturación del sistema de drenaje y la insuficiencia de los sumideros para captar y drenar el agua de lluvia. Asimismo, se debe tener en cuenta la gran densificación que se manifiesta en el área central y la baja o nula infiltración del suelo que impacta aguas abajo.

Este artículo describe un método para elaborar un modelo bidimensional de escurrimiento superficial en la ciudad de Tandil, como base para detectar amenazas de inundación en un área urbana, esto es, identificación del origen, área de afectación potencial, intensidad, duración, temporalidad y probabilidad de ocurrencia en zonas y áreas cercanas. Los principales inputs estarán determinados por el modelo digital del terreno, el parcelamiento del área urbana, la evolución de la superficie edificada para los años 1996 y 2011 y algunos parámetros hidrológicos e hidráulicos determinados para toda la cuenca. Como resultados se obtienen escenarios de profundidad y velocidad del agua superficial para los dos momentos analizados (1996 y 2011), ajustados según sus respectivos coeficientes de rugosidad y parámetros hidrológicos. 
La guía AEMI 2013 permite cuantificar el peligro y establecer escalas de zonas de mayor a menor vulnerabilidad según la multiplicación de los escenarios de profundidad y velocidad. La determinación de estas áreas contribuirá a monitorear y mitigar los impactos de eventos impredecibles, reducir la incertidumbre y servirán como base para la formulación de planes, programas y proyectos en el marco de la gestión integral del riesgo a inundaciones.

\section{MATERIALES Y MÉTODOS}

El presente trabajo fue desarrollado empleando la extensión HEC-GeoRAS en su versión 10.2 para ArcGIS 10.2. Es una herramienta desarrollada conjuntamente por el Hydrologic Engineering Center (HEC) del United States Army Corps of Engineers y el Environmental System Research Institute (ESRI). Básicamente es un conjunto de procedimientos, herramientas y utilidades especialmente diseñadas para procesar datos georreferenciados que permiten bajo el entorno de los Sistemas de Información Geográfica (SIG), facilitar y complementar el trabajo con HEC-RAS 5.0.3.

La aplicación se desarrolla sobre la ciudad de Tandil, localizada al sudeste de la provincia de Buenos Aires, Figura 1. Se encuentra emplazada en un relieve de piedemonte y valle distal, rodeada por sierras bajas que forman parte del Sistema de Tandilia, lo que le otorga gran belleza paisajística y destacada importancia geológica (Linares, 2012). Desde su origen la ciudad se ubicó en el interfluvio de los Arroyos Del Fuerte y Blanco, y desde ese punto, la ciudad se ha extendido en forma radial hacia el noroeste, norte, noreste y este donde predomina la llanura, y por ende la disponibilidad de suelo edificable y a bajo costo. En las últimas décadas, los cambios sociales y nuevas pautas residenciales generaron una fuerte demanda de construcciones residenciales y alojamiento orientado al turismo hacia el piedemonte serrano, alterando el tradicional marco natural del cordón serrano localizado al suroeste y sur de la ciudad.

Para ejecutar dicha modelización fue necesario contar con los siguientes insumos: 
1) Modelo Digital del Terreno (MDT) de la ciudad de Tandil sobre la base del Modelo Digital de Elevación de la misión SRTM de 12,5 metros de resolución espacial ${ }^{1}$. Para ello se procedió a superponer la capa de parcelas vectoriales del catastro del área urbana y complementaria de la ciudad por encima del MDE, exagerando su escala vertical 5 metros, Figura 2. Este proceso permitió forzar durante la simulación del evento, que el agua escurra sobre la red de drenaje urbano y las principales vías de comunicación, como regularmente ocurre en la realidad.

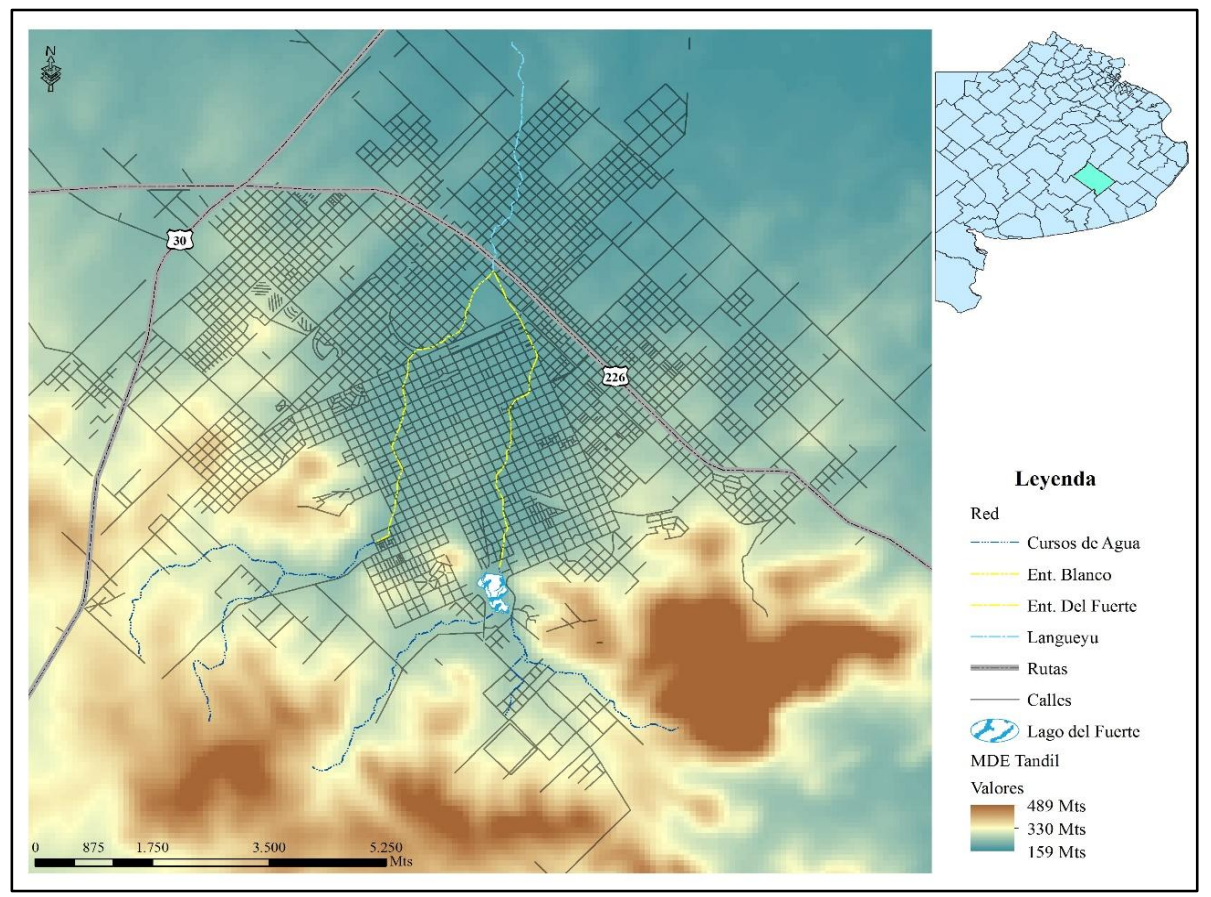

Figura 1. Situación geográfica ciudad de Tandil, Buenos Aires, Argentina Fuente: La Macchia, 2015.

\footnotetext{
${ }^{1}$ Disponible en: https://vertex.daac.asf.alaska.edu/\#
} 


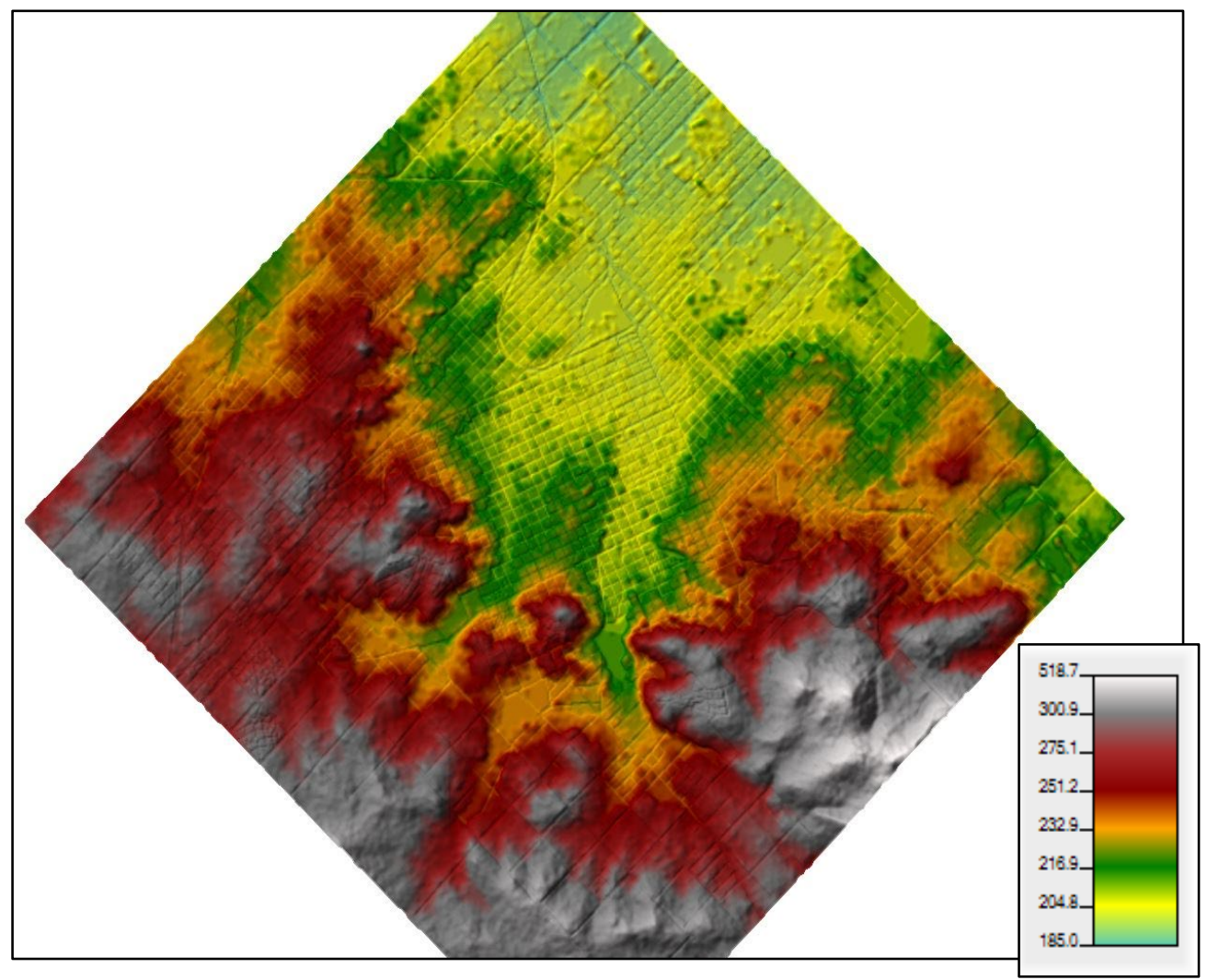

Figura 2. Modelo Digital del Terreno de la Ciudad de Tandil Fuente: Elaboración personal mediante procesamiento en RAS Mapper. HEC-RAS 5.0 .3

2) Mapas ráster con diferentes porcentajes de superficie edificada en la cuenca del Arroyo Langueyú de la ciudad de Tandil obtenido mediante el procesamiento de mezclas espectrales en base a imágenes satelitales Landsat de $30 \mathrm{~m}$ de resolución espacial, Figuras 3 y 4 . Se escogieron dos imágenes Landsat 5 TM con fechas: 30 de octubre de 1996 y 24 de octubre de 2011, correspondientes a la escena Path 225 y Row $86^{2}$. Se seleccionaron las bandas $1,2,3,4,5$ y 7 , que corresponden al espectro visible, infrarrojo cercano y medio. El método para generar los clasificadores de

\footnotetext{
${ }^{2}$ Obtenidas de la página web del U. S. Geological Survey (http://glovis.usgs.gov/)
} 
superficie edificada implicó cuatro etapas, las cuales se describen en Linares y Picone (2018). Como resultado se obtienen cuatro tipos de categorías de coberturas según densidad de superficie edificada, (1) sin edificaciones, (2) baja densidad de edificaciones. (3) media densidad de edificaciones y (4) alta densidad de edificaciones.

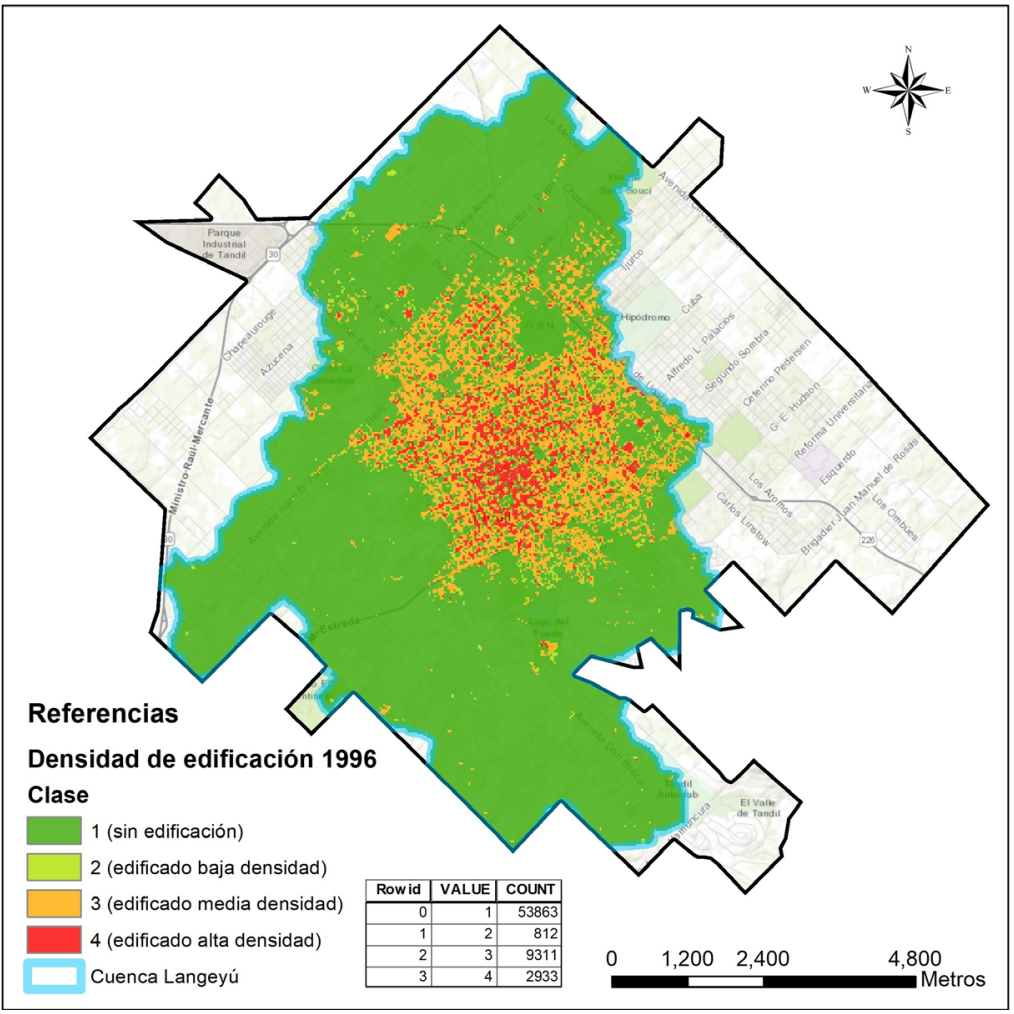

Figura 3. Densidad de edificación en la Ciudad de Tandil. Cuenca urbana Langeyú (año 1996) Fuente: Elaboración personal mediante ArcGIS 10.2. 


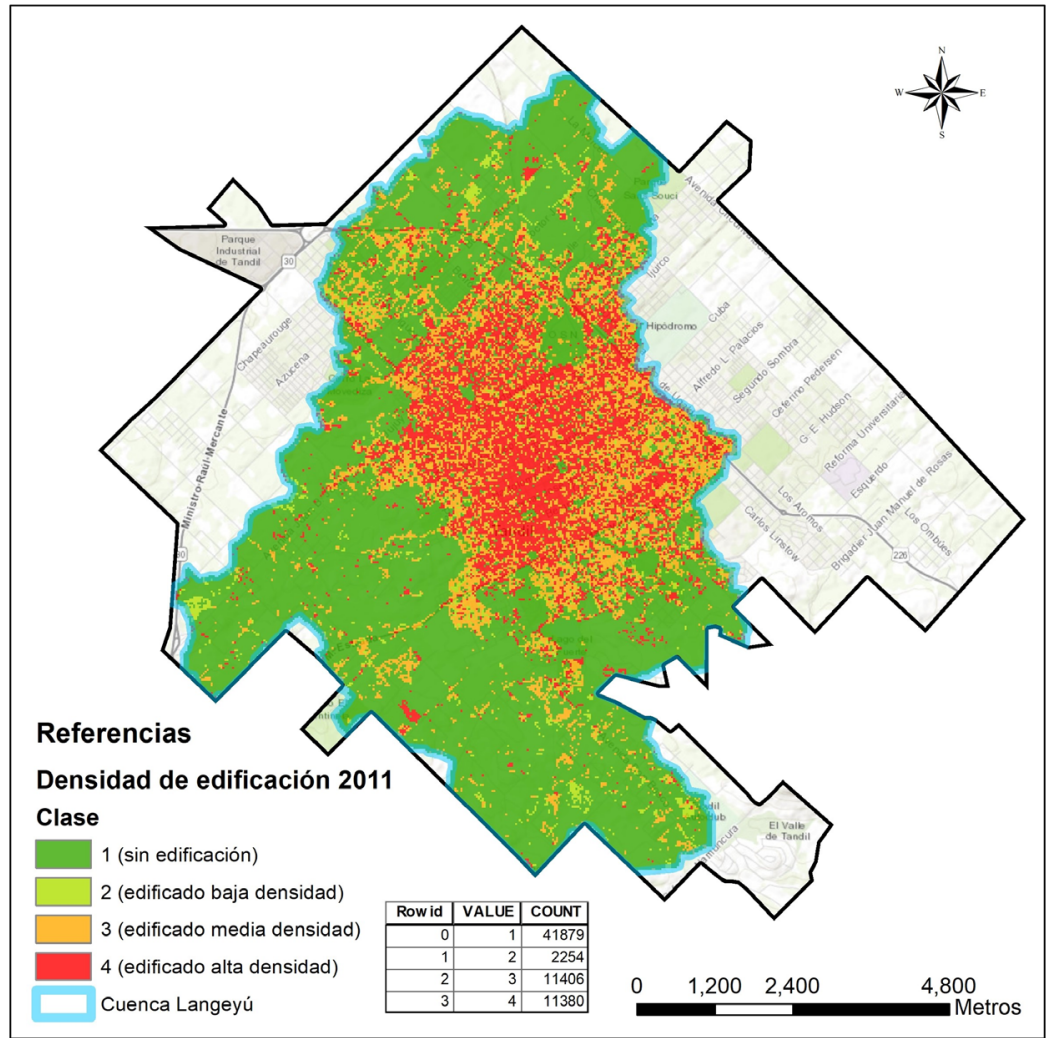

Figura 4. Densidad de edificación en la Ciudad de Tandil. Cuenca urbana Langeyú (año 2011) Fuente: Elaboración personal mediante ArcGIS 10.2.

Las conclusiones arribadas a partir del trabajo publicado en Linares y Picone (2018) permiten explicar que la superficie de infiltración (categoría 1 en la clasificación) era en 1996 de 53863 pixeles y para 2011 de 41879 pixeles. Es decir, se observa una significativa disminución de 53863 - $41879=11984$ pixeles. Si cada pixel posee una resolución espacial de 30 metros, entonces su superficie equivale a $900 \mathrm{~m}^{2}$, deduciendo que la cantidad de hectáreas de infiltración pérdida es igual a $11984 \mathrm{x}$ $900=10785600 \mathrm{~m}^{2}=1078,56$ ha. Este insumo es central para ingresarlo como superficie urbana edificada en los escenarios planteados para este trabajo y poder 
asignarle diferentes coeficientes de rugosidad para que influya en la modelización del escurrimiento superficial.

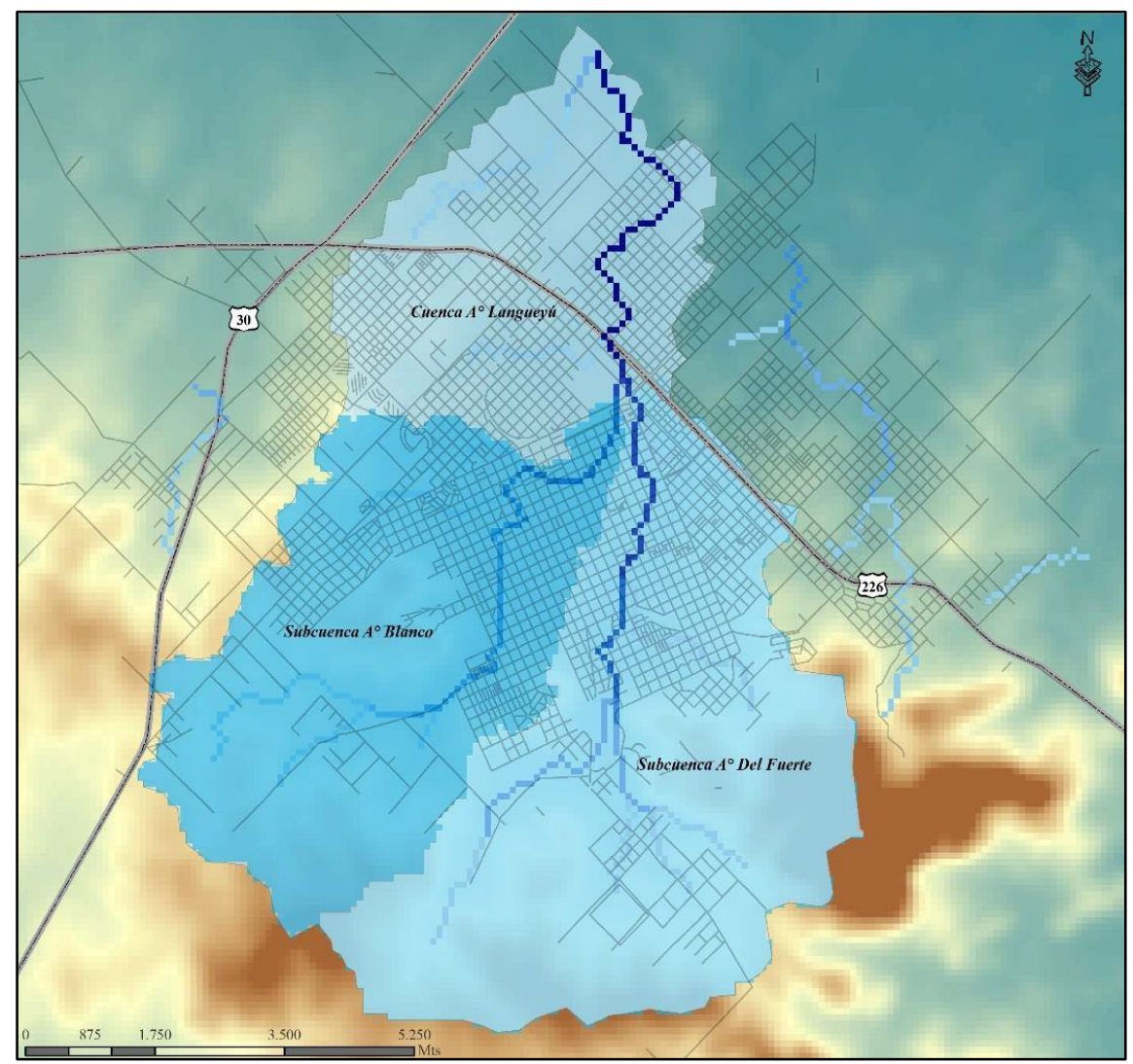

Figura 5. Cuenca urbana Langeyú. Ciudad de Tandil Fuente: La Macchia, 2015.

3) Cuenca urbana de la ciudad de Tandil y su red de infraestructura pluvial, Figura 5 y Figura 6. En primer lugar, se llevó a cabo la extracción de algunos parámetros morfométricos derivados del estudio del MDE y, en segundo lugar, se realizó la digitalización y edición de la red de infraestructura pluvial del área urbana (La Macchia, 2015). Para ello, para el primer caso, se utilizó el módulo de hidrología de ArcGIS y, para el segundo caso, las fuentes partieron de la planimetría disponible en 
formato analógico de la Dirección de Hidráulica de la provincia de Buenos Aires. Se discriminaron los conductos principales y ramales de los arroyos Blanco y Del Fuerte. Cada arco o segmento de la red, entubamiento y ramales, tiene definido un conjunto de atributos y variables referidos a sus características estructurales, espaciales y topológicas. Se constató y avanzó en la carga de información proveniente de los perfiles longitudinales de cada tramo o sección completando atributos que podrán utilizarse en futuros trabajos como pesos y restricciones al escurrimiento en zonas testigo obtenidas del mapa de peligro de anegamiento en La Macchia, 2015. Los nodos definidos por las alcantarillas y/o cámaras de inspección, suponen la conexión entre arcos y contienen información respecto al sentido y tipo de dirección que siguen los recursos gestionados por la red.

Finalmente, una vez generados los insumos básicos, el proceso siguiente consistió en la ejecución de la simulación, que en sí mismo implicó tres etapas:

1) PREPROCESO, trabajo previo de integración de inputs mediante ArcGIS y HEC-GeoRAS, para generar un archivo de importación para HEC-RAS que va a contener la información geométrica de las secciones transversales.

2) MODELIZACIÓN, consiste en la modelización del flujo del escurrimiento en HEC-RAS y generación de los archivos de exportación para procesarlos en ArcGIS.

3) POSPROCESO, nuevamente en ArCGIS y HEC-RAS, en donde se analizan los resultados de la modelización, detectando áreas con peligro a inundación con base en mapas de profundidad y velocidad, metodología extraída de la guía AEMI 2013 que establece una escala de peligro cuantificando el riesgo vinculando los resultados obtenidos del producto de las variables depth y velocity.

Siguiendo la metodología propuesta anteriormente, la primera etapa consistió en integrar los inputs que conformarán el modelo hidrológico e hidráulico, esto incluye, ingresar el MDT mediante la herramienta RAS Mapper; la geometría con los elementos que componen la red, mediante la herramienta Hec-GeoRAS para ArcGIS y la asignación de los coeficientes de rugosidades (mannings) a la red a partir de los valores de la evolución de la superficie edificada para los años 1996 y 2011. 

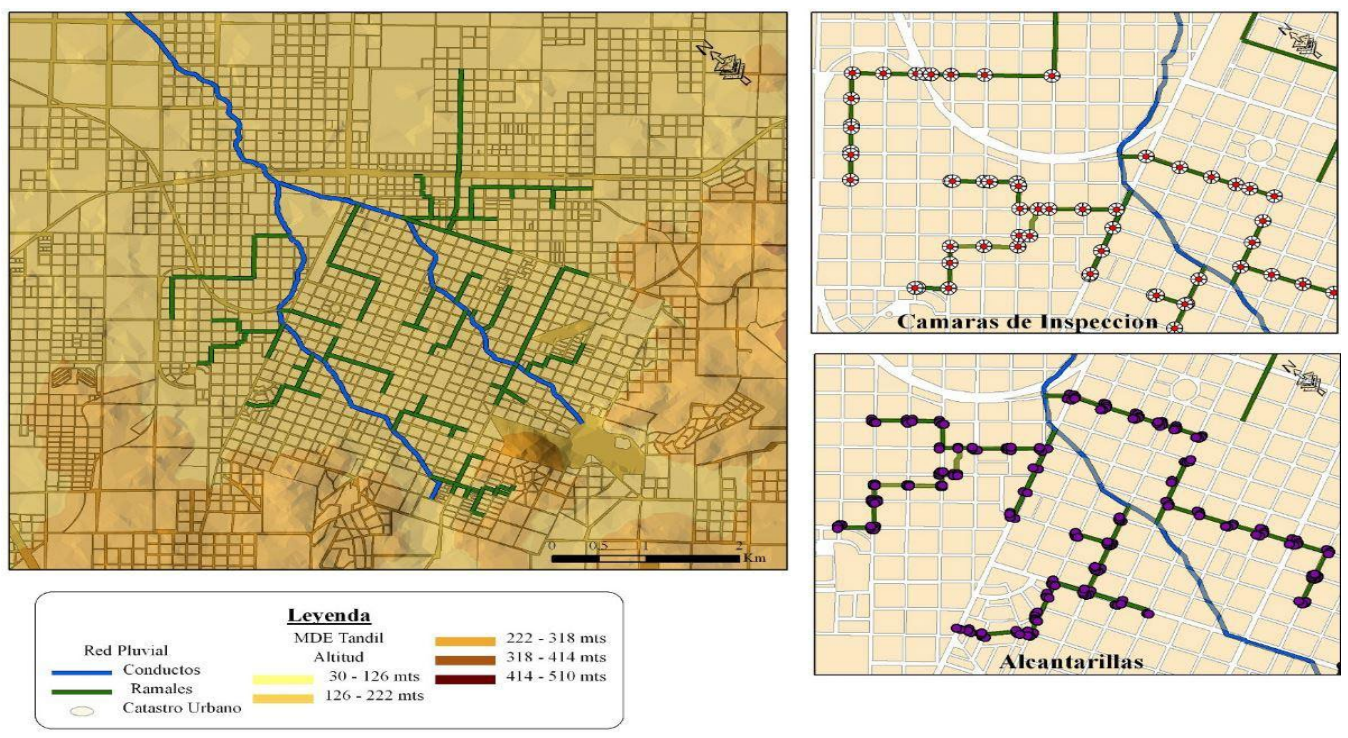

Figura 6. Red de infraestructura pluvial de la cuenca urbana de la ciudad de Tandil Fuente: La Macchia, 2015.

Posteriormente, se integró la red y la cuenca, Figura 7 a, b y c. A tales fines se emplea la herramienta RAS Mapper para el ingreso de los usos de suelo (a) y la asignación de coeficientes de rugosidad (mannings) según las clases establecidas de menor a mayor costo de escurrimiento, dependiendo del material de cubierta del terreno, de menos edificado a más edificado en este caso (b), en nuestro ejemplo se asignaron diferentes mannings para seleccionar los más indicados que reflejen la realidad. En ese caso se recurrió a revisar los parámetros estándares de coeficientes que se manejan según cada tipología de uso (HEC-RAS, 2016a y HEC-RAS, 2016b). En este sentido, según la topografía del terreno, su geomorfología y pendiente se determinaron para el Uso 1: 0.03, Uso 2: 0.05 , Uso 3: 0.084 y Uso 4: 0.152. Finalmente, se asoció la geometría a los usos (c). 
Fig 7 (a)

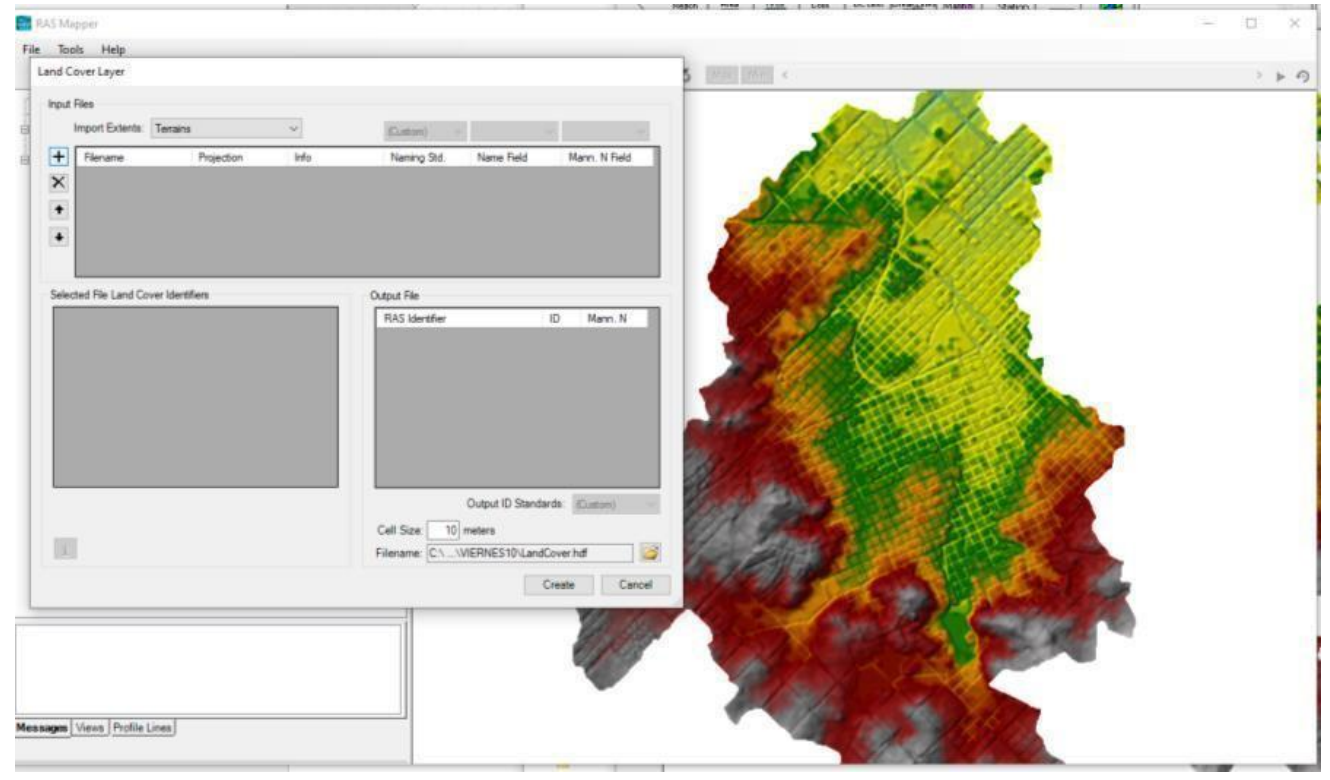

Fig 7 (b)

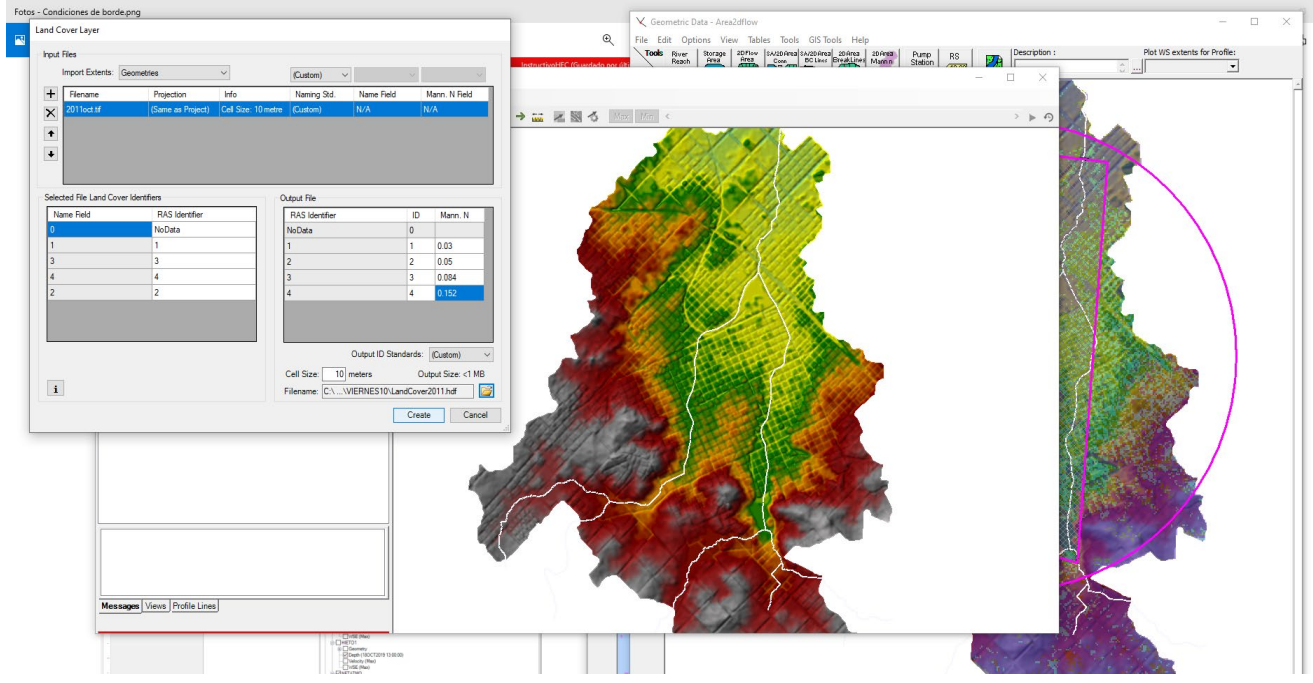

CC BY-NC 4.0 | BOLETín DE ESTUDIOS GEOGRÁFICOS 115 | ISSN 0374-6186 | ISSN: 2525-1813 (DIGITAL) | 81 
Fig 7 (c)

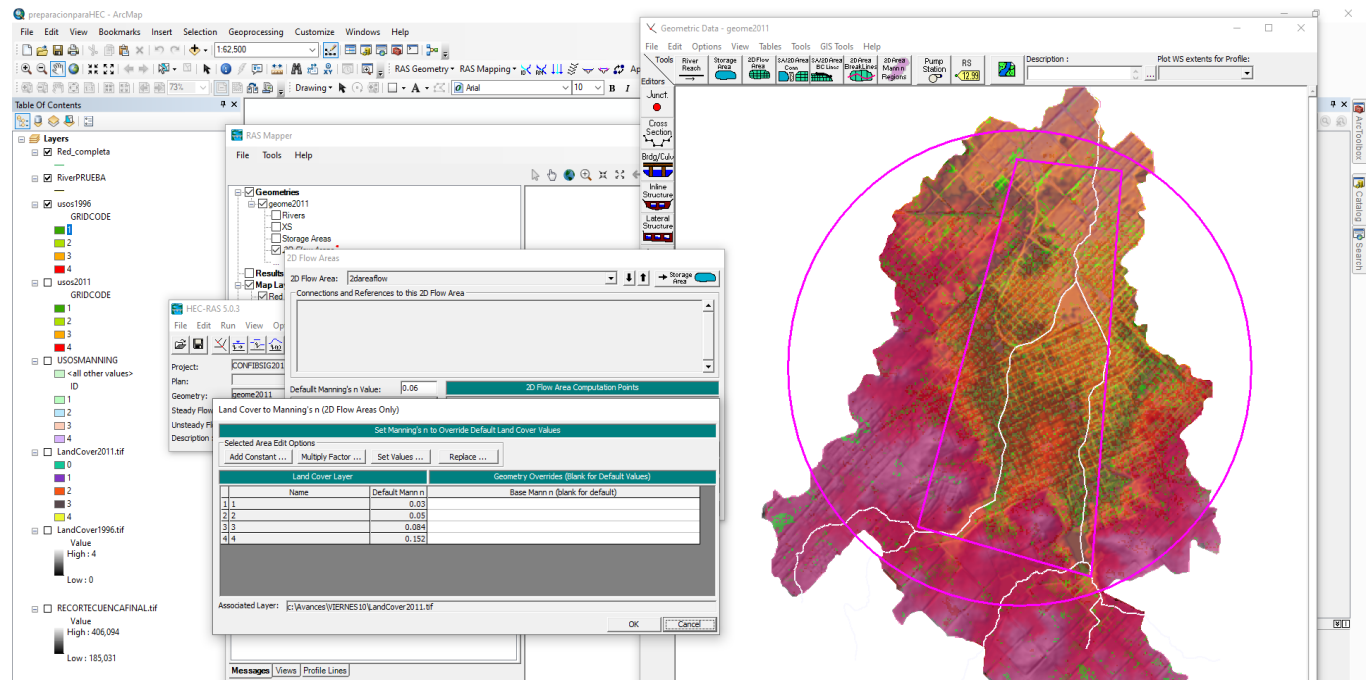

Figura 7. Integración de red y cuenca en HEC-RAS

Fuente: Elaboración personal en base a procesamiento con HEC-RAS 5.0.3.

Fig 8 a)

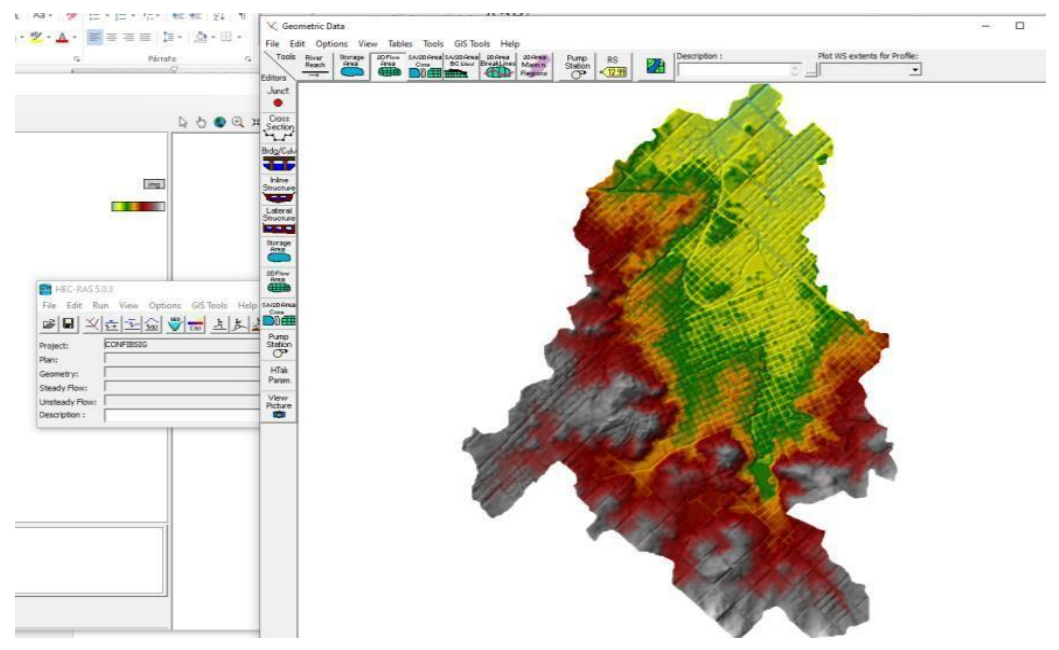

82 | CC BY-NC 4.0 | BOLETín DE ESTUDIOS GEOGRÁFICOS 115 | ISSN 0374-6186 | ISSN: 2525-1813 (DIGITAL) 


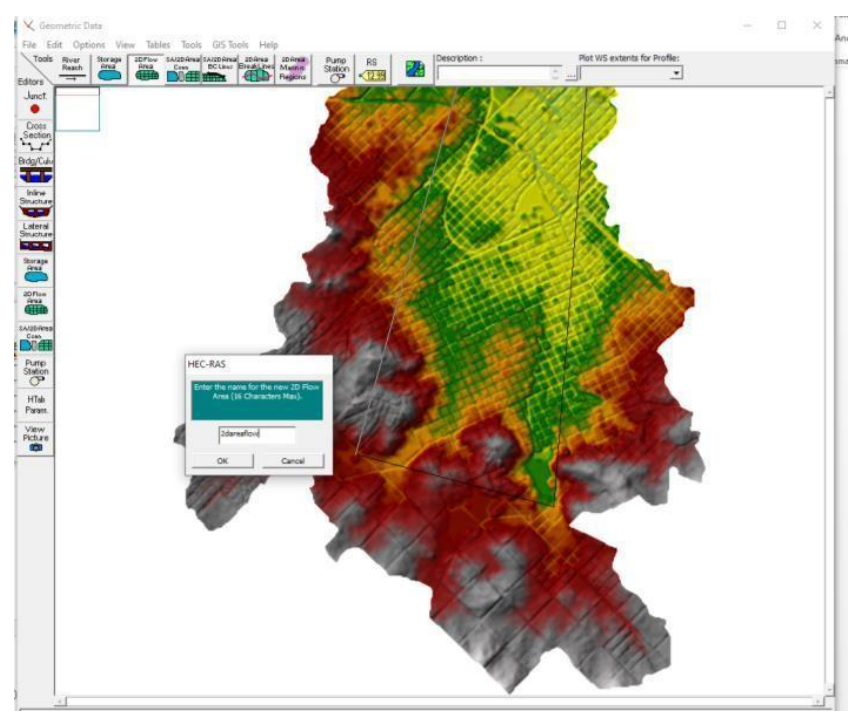

Fig 8 b)

La opción default manning values permite identificar el mapa de coberturas (landcover) con sus respectivos coeficientes de rugosidad (mannings) asignados.

Definida la malla es requisito establecer las condiciones de contorno (2DFLOWConditionboundary), en donde se asignan las fuentes (sources/entradas) y los sumideros (sinks/salidas). Para la simulación se definieron los IN y OUT, figura 9, indicando dos fuentes, en el arroyo Blanco y el arroyo Del Fuerte y un sumidero, en el Arroyo Langueyú. 


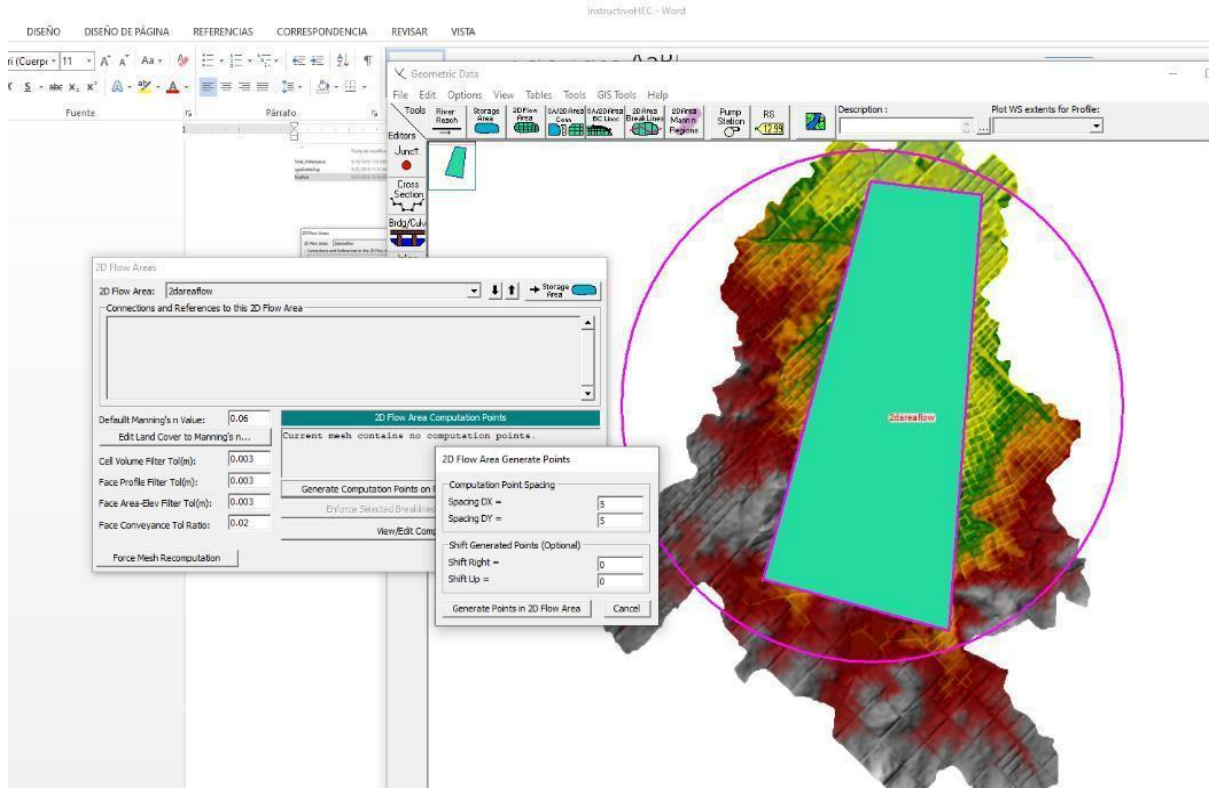

Figura 8. Construcción del dominio de la cuenca

Fuente: Elaboración personal en base a procesamiento con HEC-RAS 5.0.3.

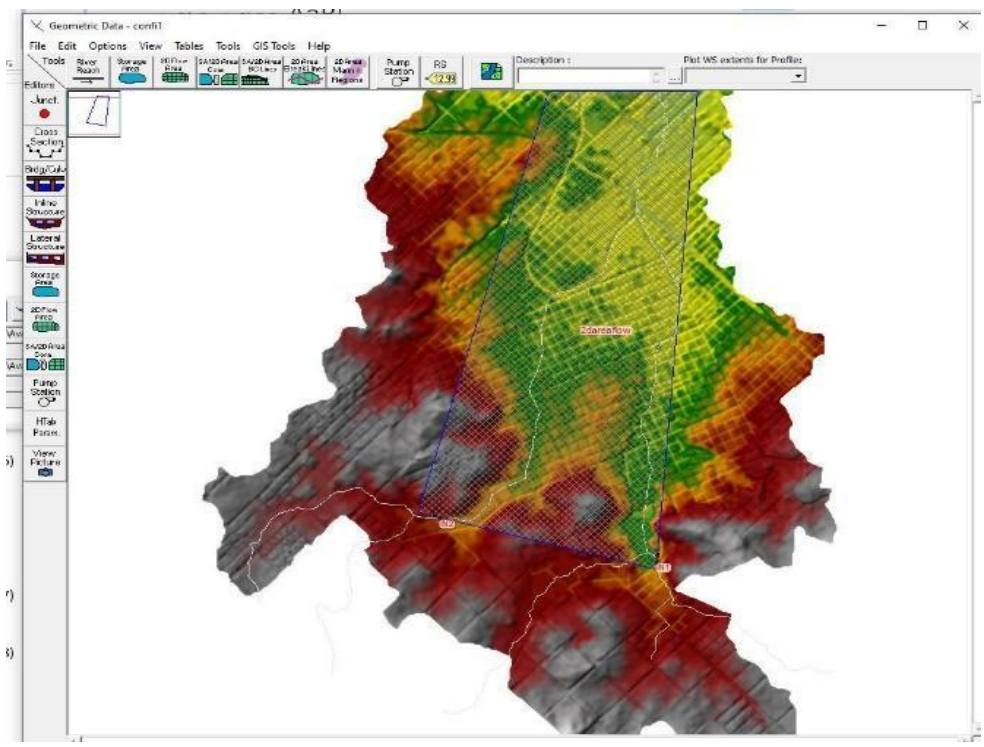

84 | CC BY-NC 4.0 | BOLETín DE ESTUdIOS GEOGRÁFICOS 115 | ISSN 0374-6186 | ISSN: 2525-1813 (DIGITAL) 


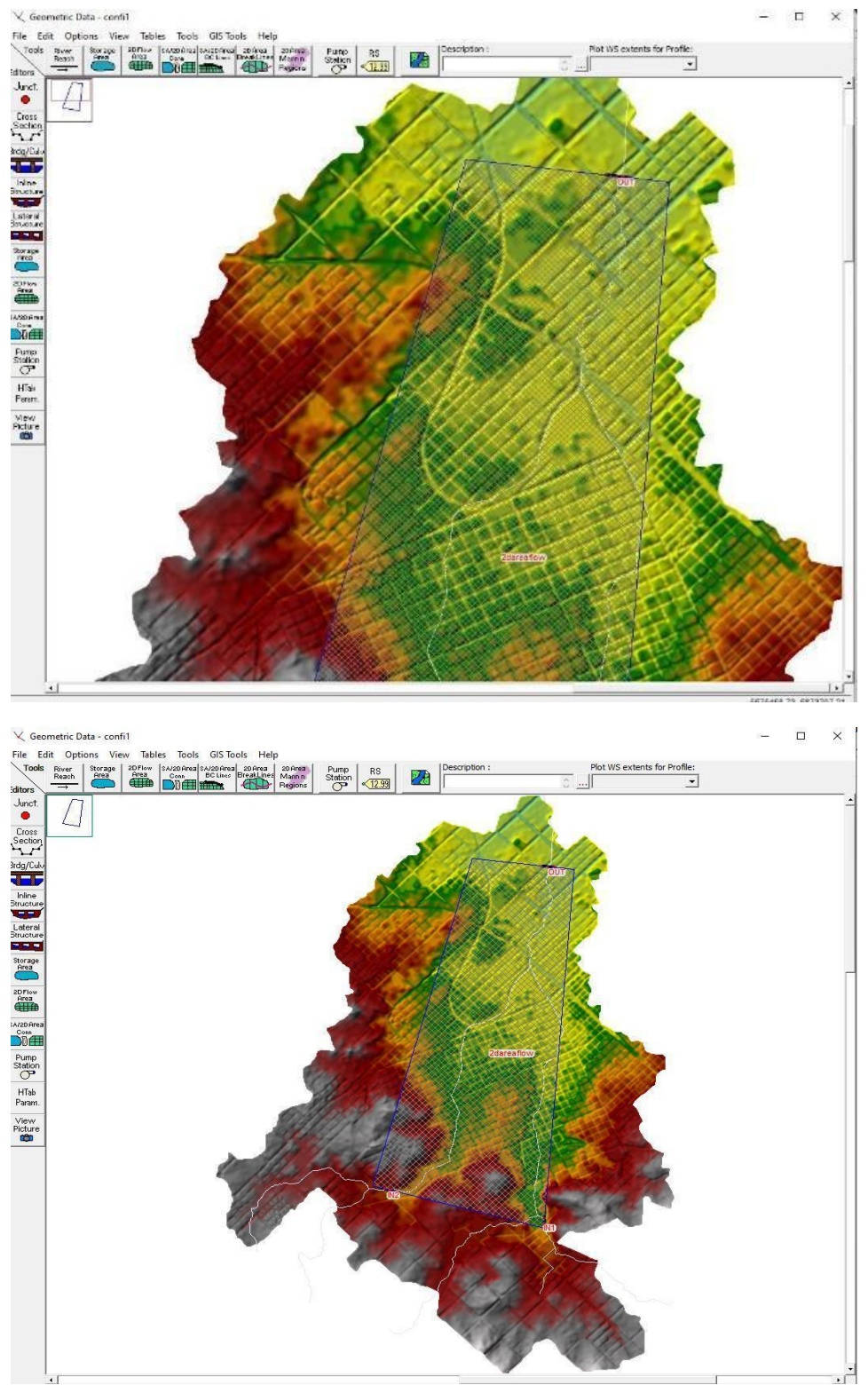

Figura 9. Definición de las condiciones de contorno del mallado Fuente: Elaboración personal en base a procesamiento con HEC-RAS 5.0.3. 
Delimitados los ingresos y egresos, mediante HEC-RAS se introdujeron los caudales estables o inestables. La opción Steadyflowdata aplica para un caudal permanente o constante, mientras que Unsteadyflowdata refiere a un caudal variable según la intensidad de la lluvia en fracciones de tiempo (duración). Para la simulación ingresamos los datos en Unsteadyflowdata, Figura 10.

Esta instancia requirió de la confección de un hietograma o un hidrograma para simular las precipitaciones según los parámetros establecidos previamente. La opción adoptada fue la del hidrograma a partir del cual es posible observar la evolución de la lámina de agua en el tiempo, Figura 11 y Figura 12. A nivel de sección, esta definición permitió conocer cómo sube la lámina de agua llegando a su punto máximo y como va bajando conforme pasa el tiempo. En el presente trabajo se ensayaron distintos escenarios con base en hidrogramas de lluvias en $\mathrm{mm}$ obtenidos mediante la toma de datos por la estación meteorológica NET ATMO (datos $\mathrm{x}$ horas del 17/10 al 18/10 del año 2019)3. Pero para obtener resultados más evidentes se decidió trabajar un escenario con hidrogramas de caudales en $\mathrm{m} 3 / \mathrm{seg}$.

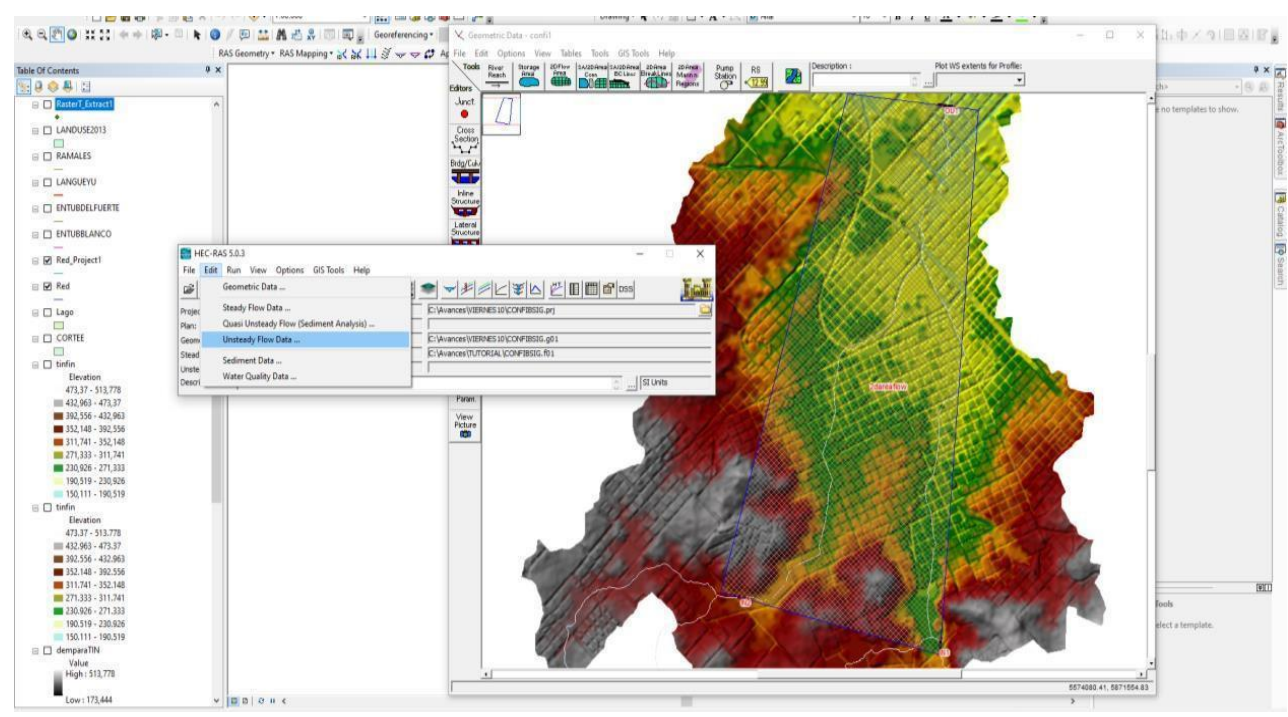

Figura 10. Introducción de caudales mediante HEC-RAS

Fuente: Elaboración personal en base a procesamiento con HEC-RAS 5.0.3.

\footnotetext{
${ }^{3}$ Disponible en: https://www.netatmo.com/es-es/weather/weatherstation
} 
Flow Hydrograph

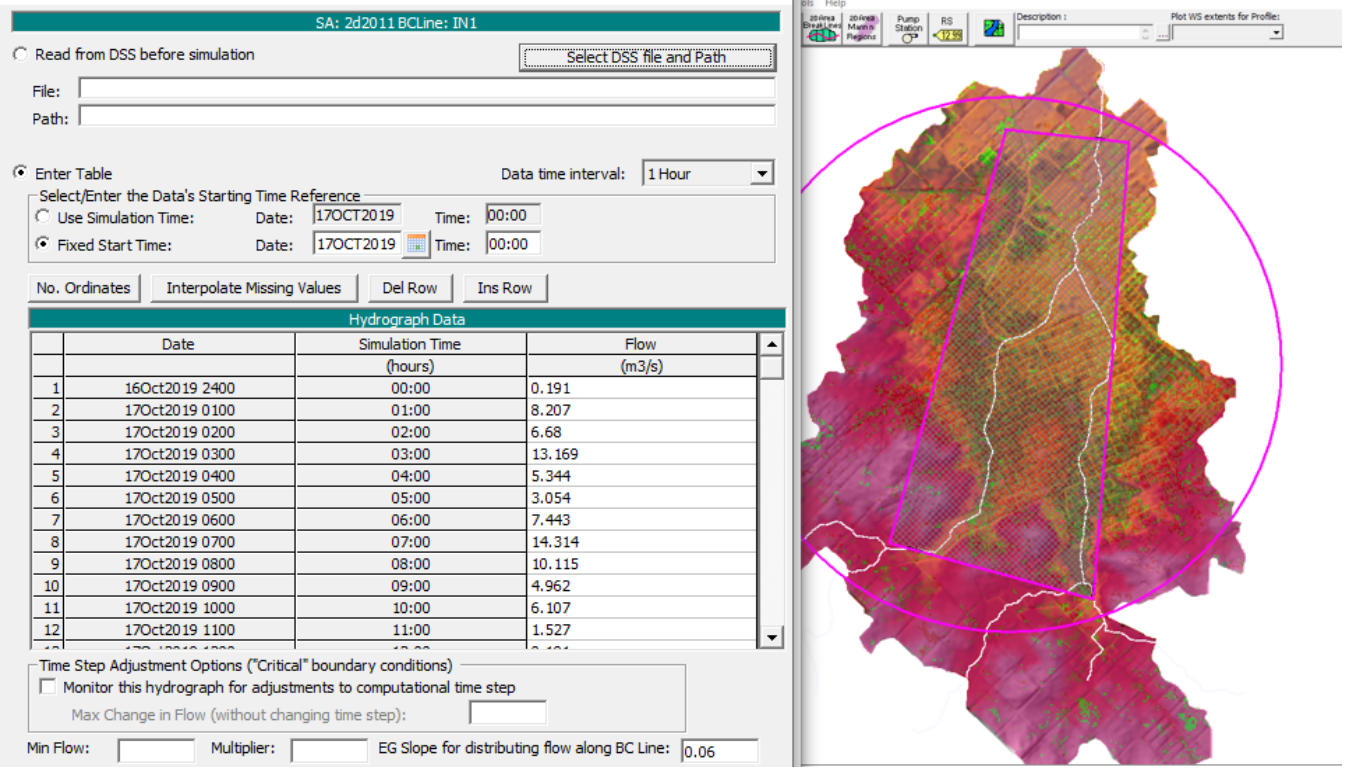

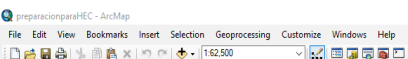

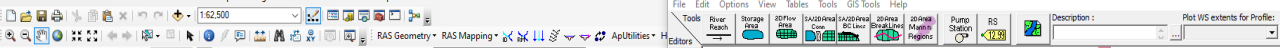

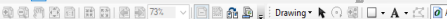

Toble 아 Contents

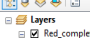

G $\mathrm{T}$ Riveprueba

日) usos 1996

จ1 USOS1996
GRIDCODE

Gil

$\square_{2}^{2}$
$\square^{3}$
$\square_{4}^{4}$
45052011

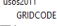

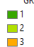

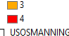

$\square$ <all ther values

10

$\square 1$

$\square^{3}$

LandCover2011.tif

믄 1

물

$\square$ Landcover 1998

Value
High:
tom:

$\square$ RECORTECUENCAFNQLLIf

Value
High: 406,004

File Edit Run View Options Gistools Hép

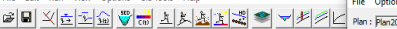

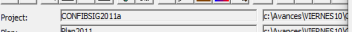

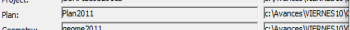

Geomedy: beame 011

Unsteady Flow: Freborat 2011
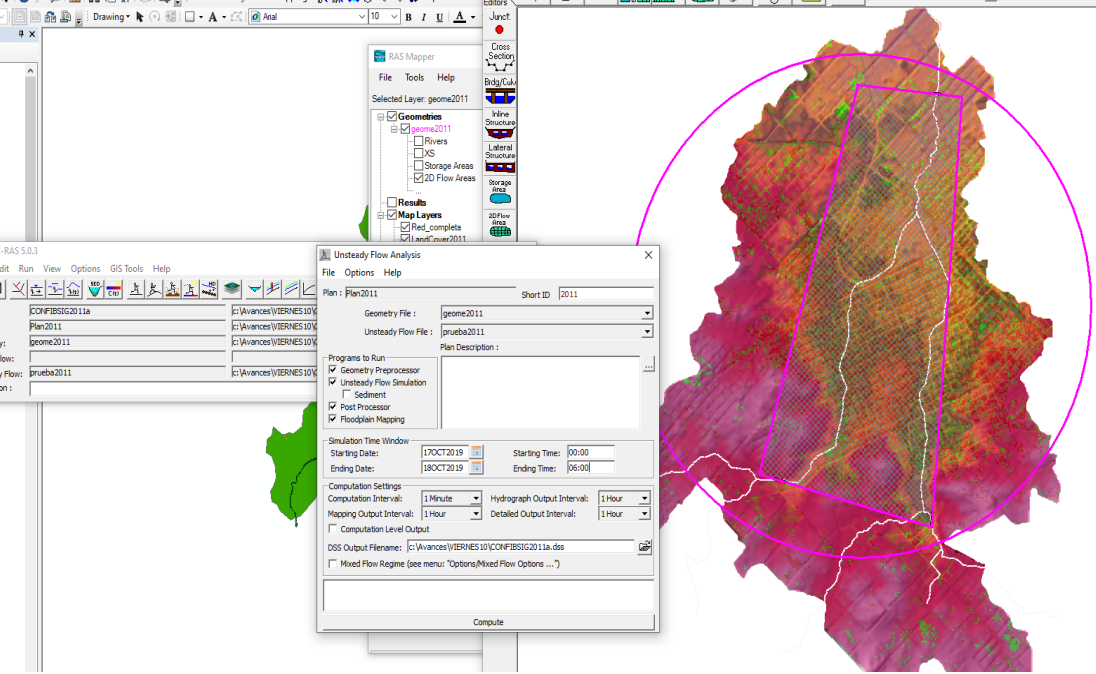

Figura 11. Introducción de hidrograma mediante HEC-RAS

Fuente: Elaboración personal en base a procesamiento con HEC-RAS 5.0.3.

CC BY-NC 4.0 | BOLETín DE ESTUDIOS GEOGRÁFICOS 115 | ISSN 0374-6186 | ISSN: 2525-1813 (DIGITAL) | 87 


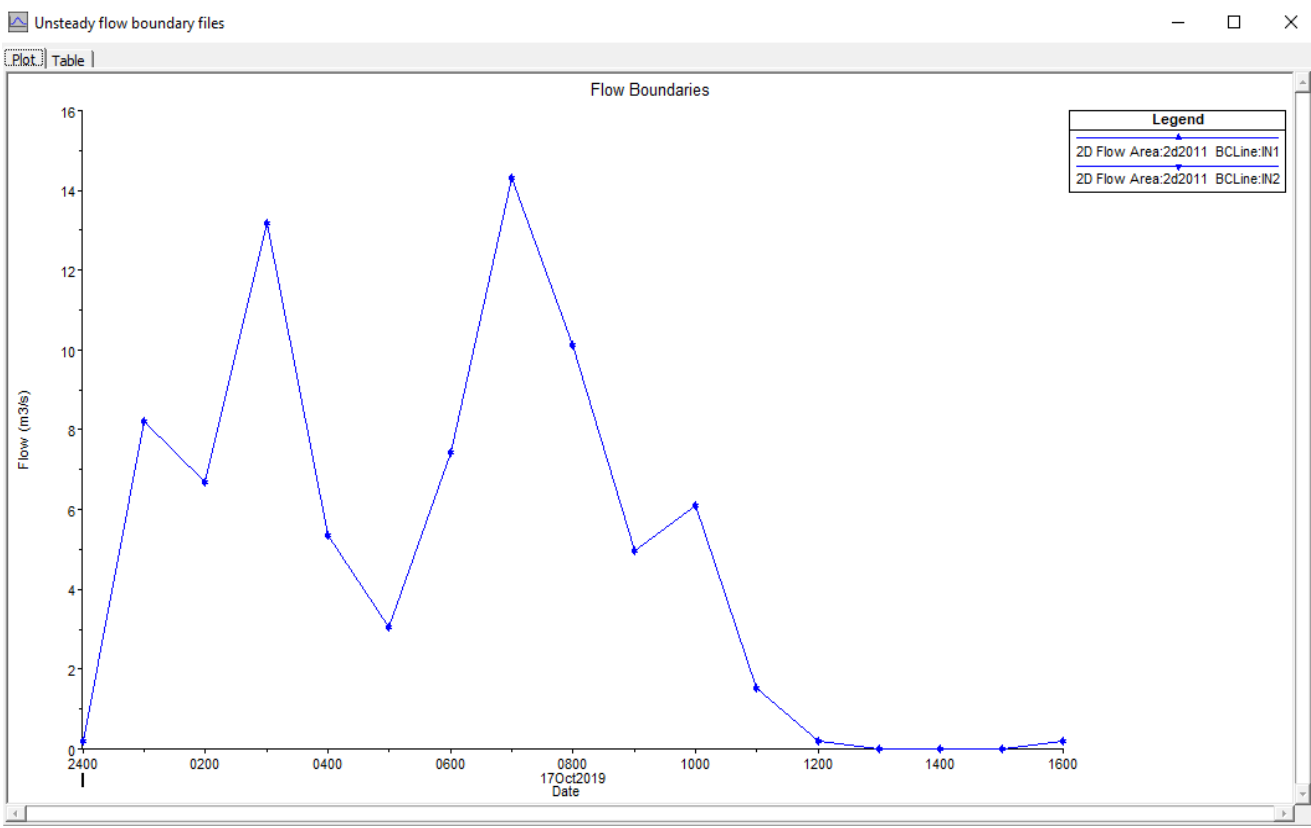

Figura 12. Vista en plot del hidrograma del evento en HEC-RAS Fuente: Elaboración personal en base a procesamiento con HEC-RAS 5.0.3

\section{RESULTADOS}

La etapa de pos procesamiento mediante la simulación de los escenarios se presenta en RAS Mapper. En esta ventana se visualizan los resultados tanto por: perfiles, hora, tiempo determinado, profundidad y velocidad máxima, entre las representaciones más destacadas. El rango global de valores con respecto a la profundidad del agua, Figuras 13 y 14 no varía durante el período, alcanzando un umbral de 5.02 metros en 1996 y 2011 . Sin embargo, se observa un incremento de celdas en el rango de 1.9 metros en detrimento del rango de 1.2 metros. El hallazgo más importante se encuentra al realizar un análisis de distribución espacial de las diferencias entre ambos momentos, Figura 15 donde se presentan cuáles han sido las celdas que han arrojado variación positiva y negativa con respecto a la profundidad del agua acumulada entre las simulaciones 1996-2011, en el mapa se observa que un $70 \%$ de las celdas en el área simulada incrementa la profundidad del agua retenida, 
exhibiendo aumentos hasta de 1.2 metros en algunos puntos, corroborando la clara asociación entre aumento de la densidad de superficie edificada y retención del agua ante eventos extremos, lo cual genera ineludiblemente un mayor peligro a inundaciones. Esta primera parte del análisis se complementa a su vez con los resultados siguientes, Figuras 16, 17 y 18, en los cuales, se detecta un leve incremento de las celdas en el rango $0.1 \mathrm{~m} / \mathrm{s}$ en detrimento de una disminución del rango $0.05 \mathrm{~m} / \mathrm{s}$. Asimismo, un $58 \%$ de las celdas incrementan la velocidad de escurrimiento $(\mathrm{m} / \mathrm{s})$ producto de la impermeabilización de la superficie que genera el aumento de las construcciones.
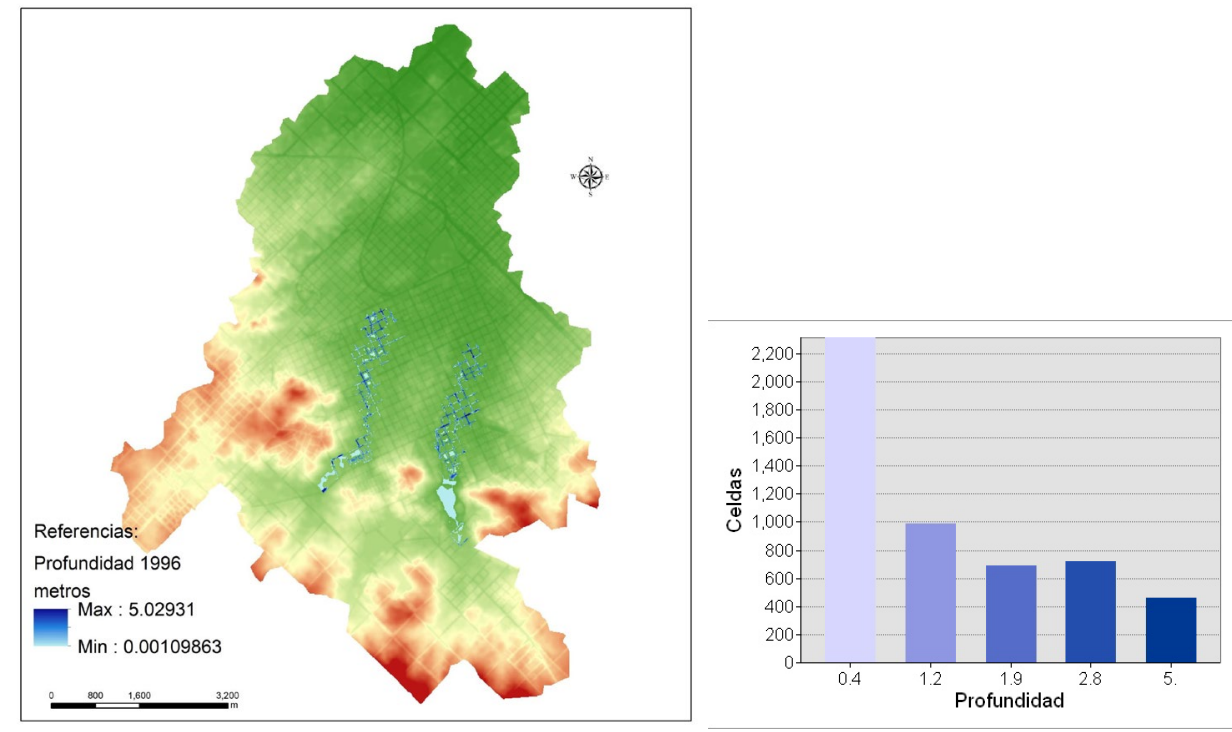

Figura 13. Escenario profundidad simulada 1996 Fuente: Elaboración personal. ArcGIS 10.2. 

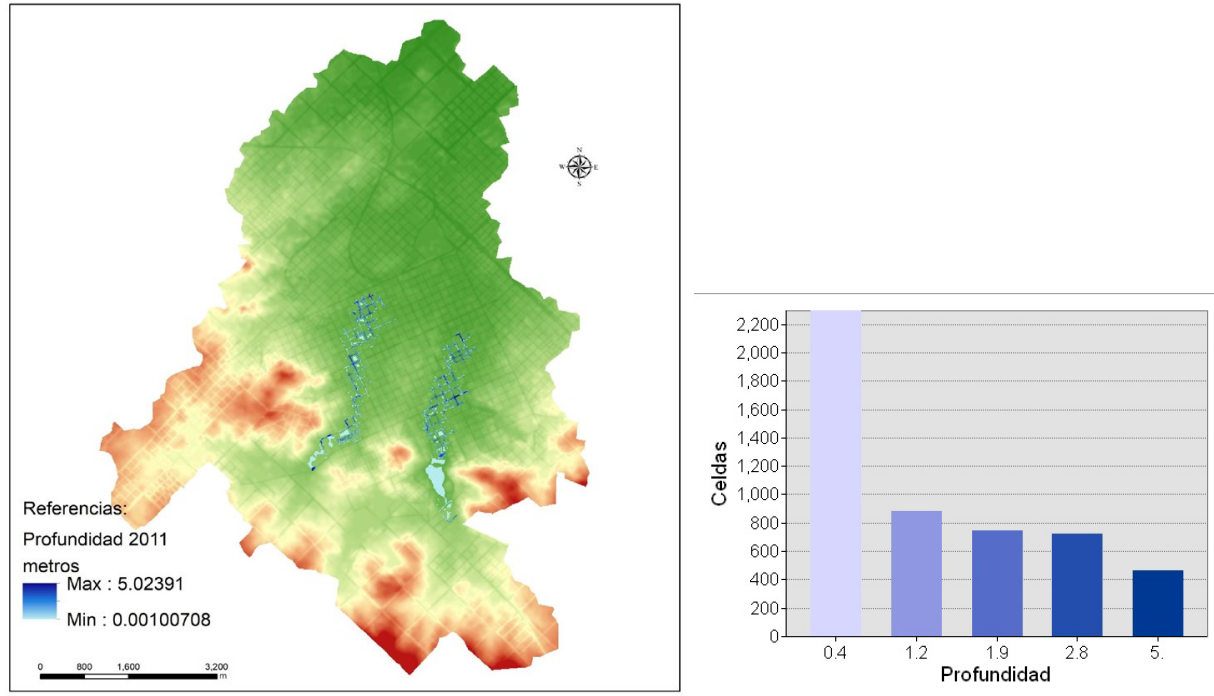

Figura 14. Escenario profundidad simulada 2011 Fuente: Elaboración personal. ArcGIS 10.2. 


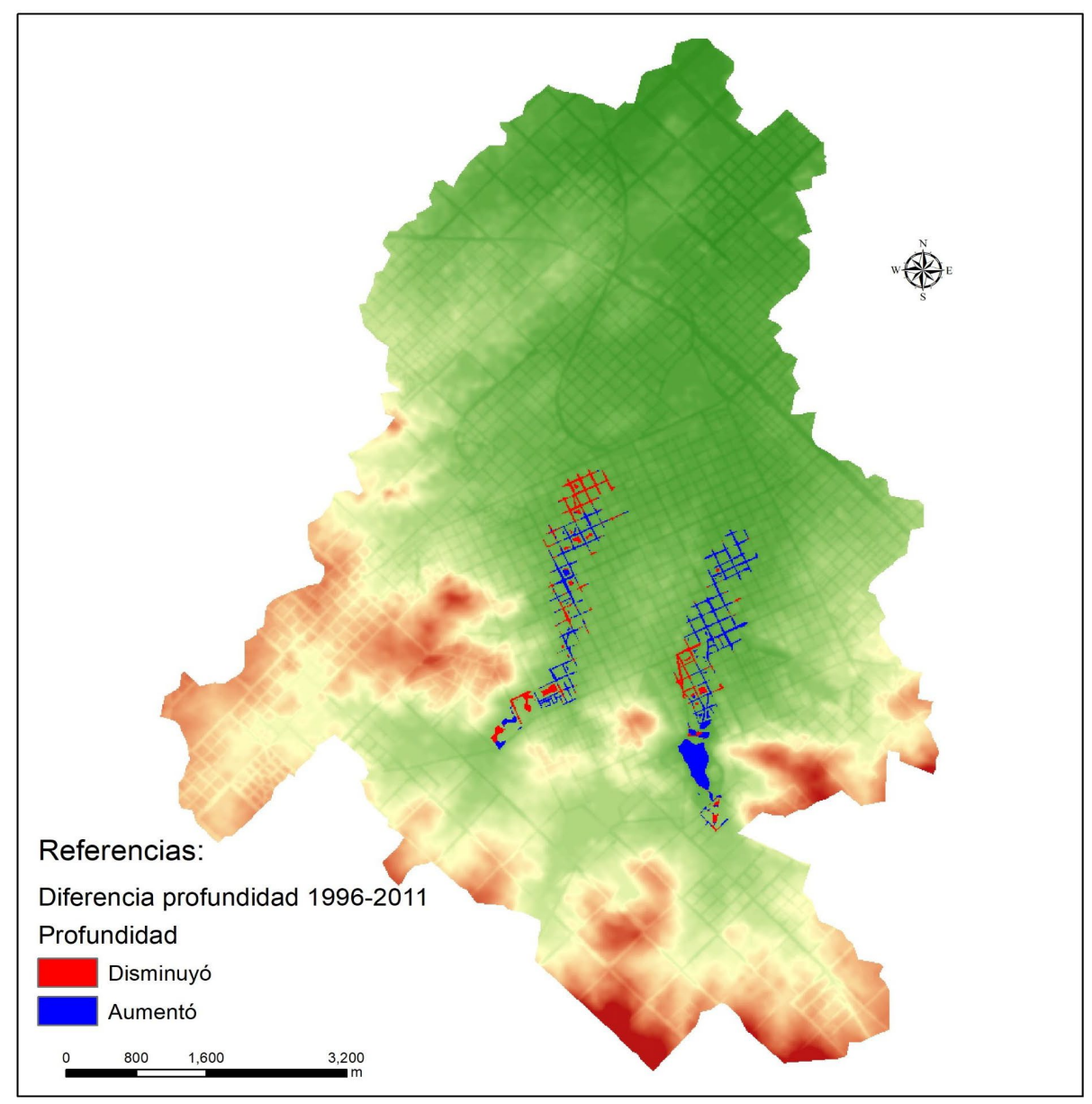

Figura 15. Diferencias profundidad simulada 1996-2011 Fuente: Elaboración personal. ArcGIS 10.2 

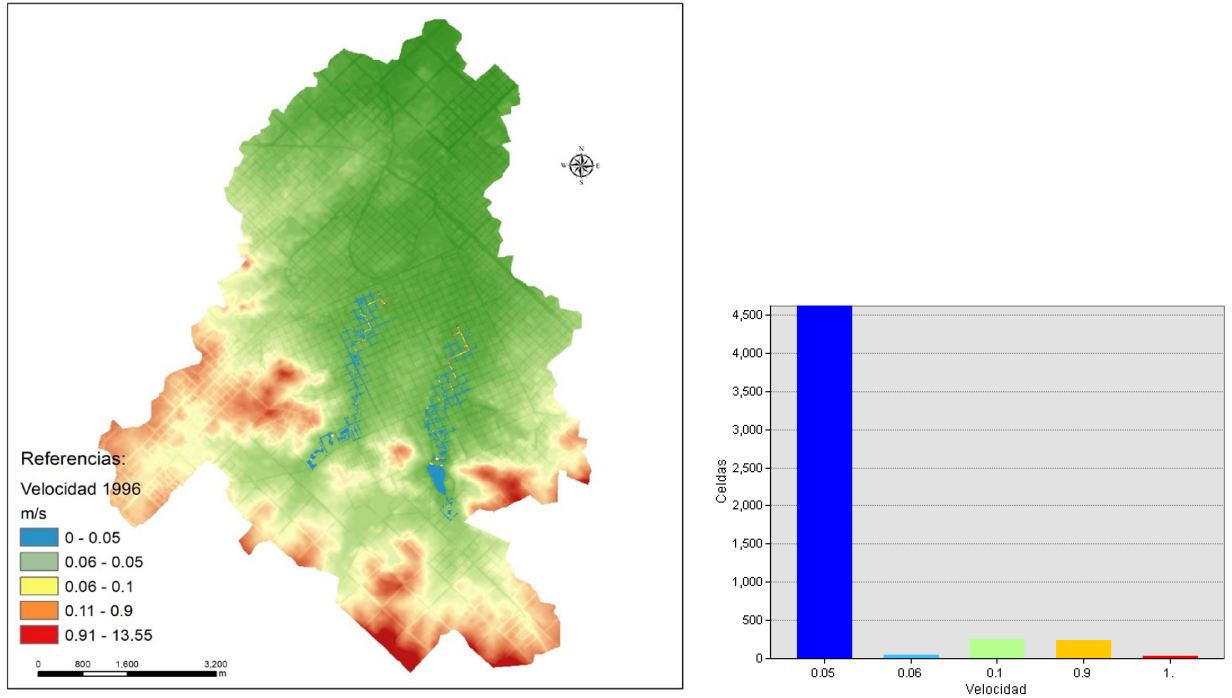

Figura 16. Escenario velocidad simulada 1996 Fuente: Elaboración personal. ArcGIS 10.2.
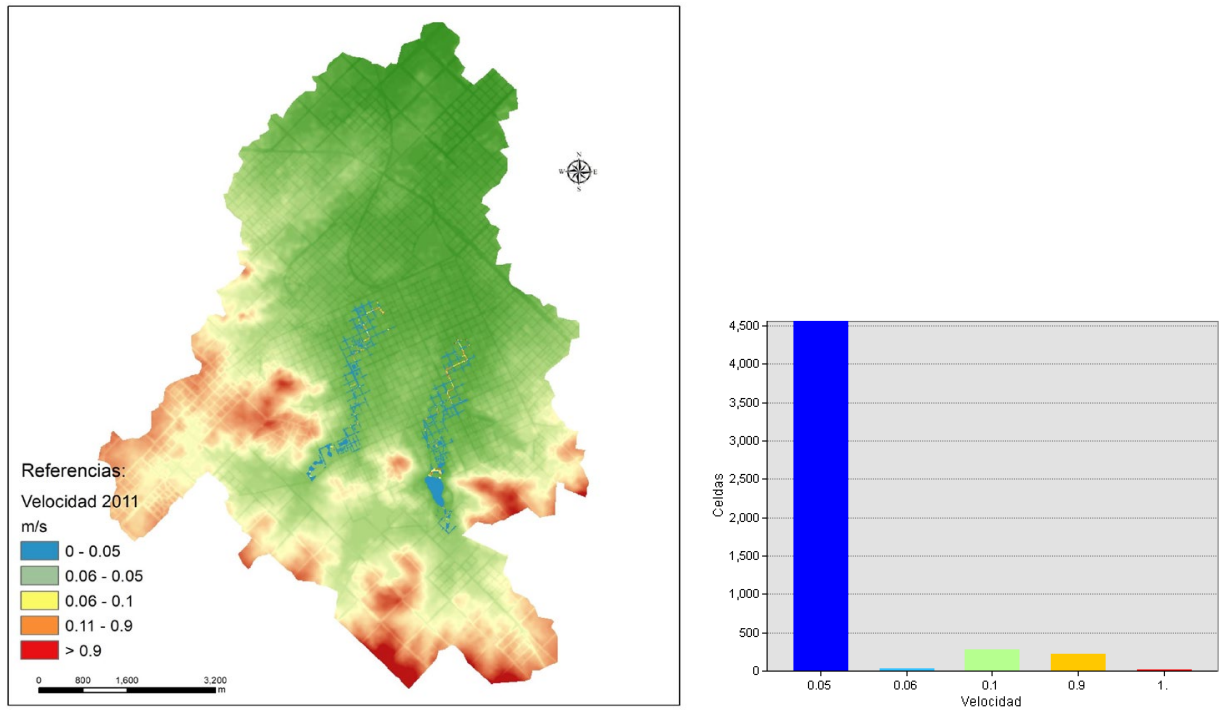

Figura 17. Escenario velocidad simulada 2011 Fuente: Elaboración personal. ArcGIS 10.2. 


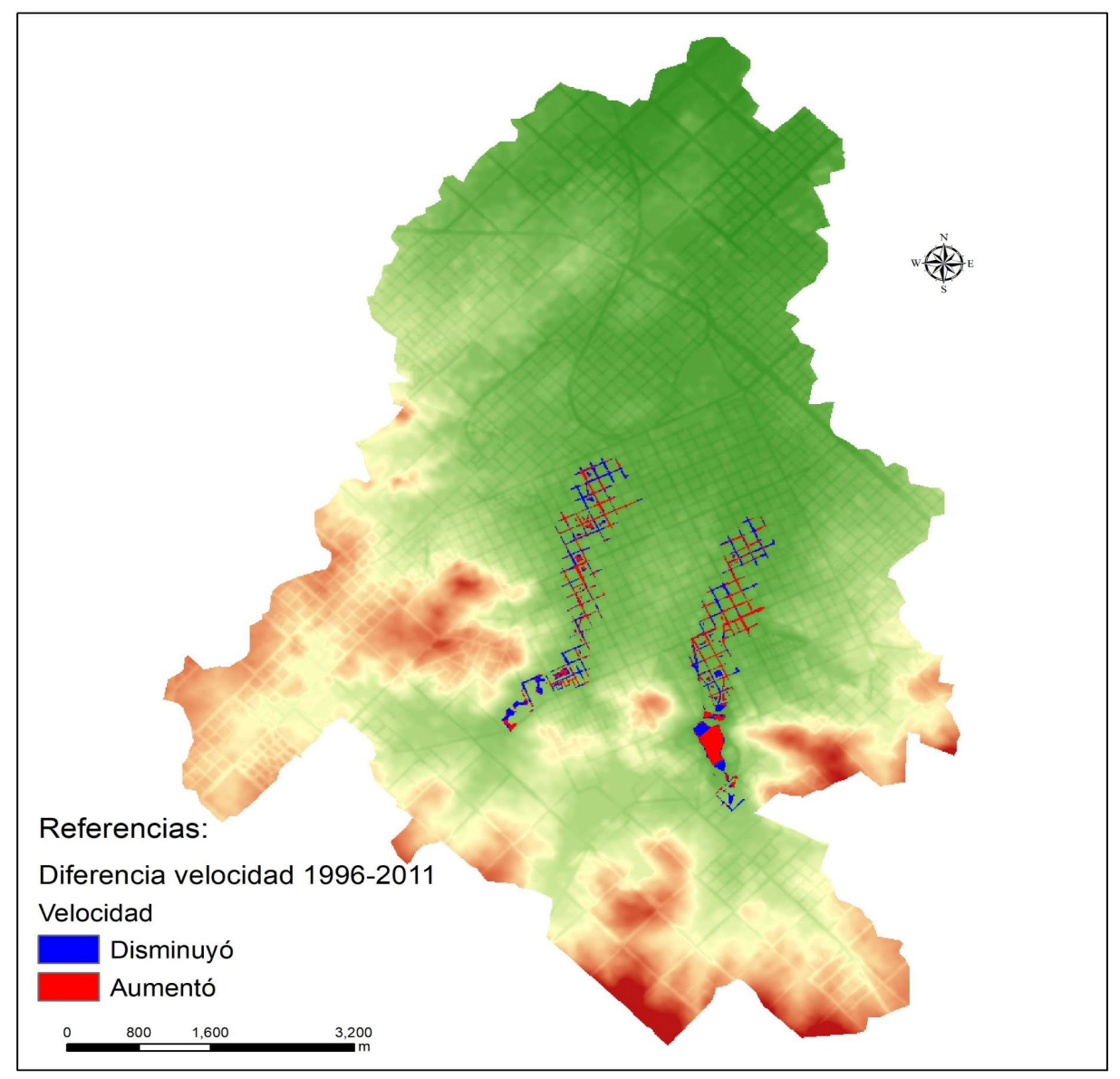

Figura 18. Diferencias velocidad simulada 1996-2011 Fuente: Elaboración personal. ArcGIS 10.2.

A partir de los productos cartográficos obtenidos fue posible definir un mapa de áreas de peligro a inundaciones, las cuales resultan de suma utilidad práctica para la toma de decisiones territoriales y se construyen a partir de una combinación de la profundidad por la velocidad (AIDR, 2014 y AEMI, 2013). En este sentido, el peligro es mayor a medida que aumenta la profundidad y la velocidad, profundizándose la 
situación por la combinación entre ambas variables. En este trabajo se realizó una adaptación local del método elaborado por el Instituto Australiano de Resiliencia ante Desastres, partiendo de una operación de multiplicación entre las capas ráster de profundidad y velocidad, cuyo ráster resultante permitió definir cuatro rangos con niveles de peligrosidad creciente que se establecieron de la siguiente manera: nulo, bajo, medio-bajo y medio, Figura 19:

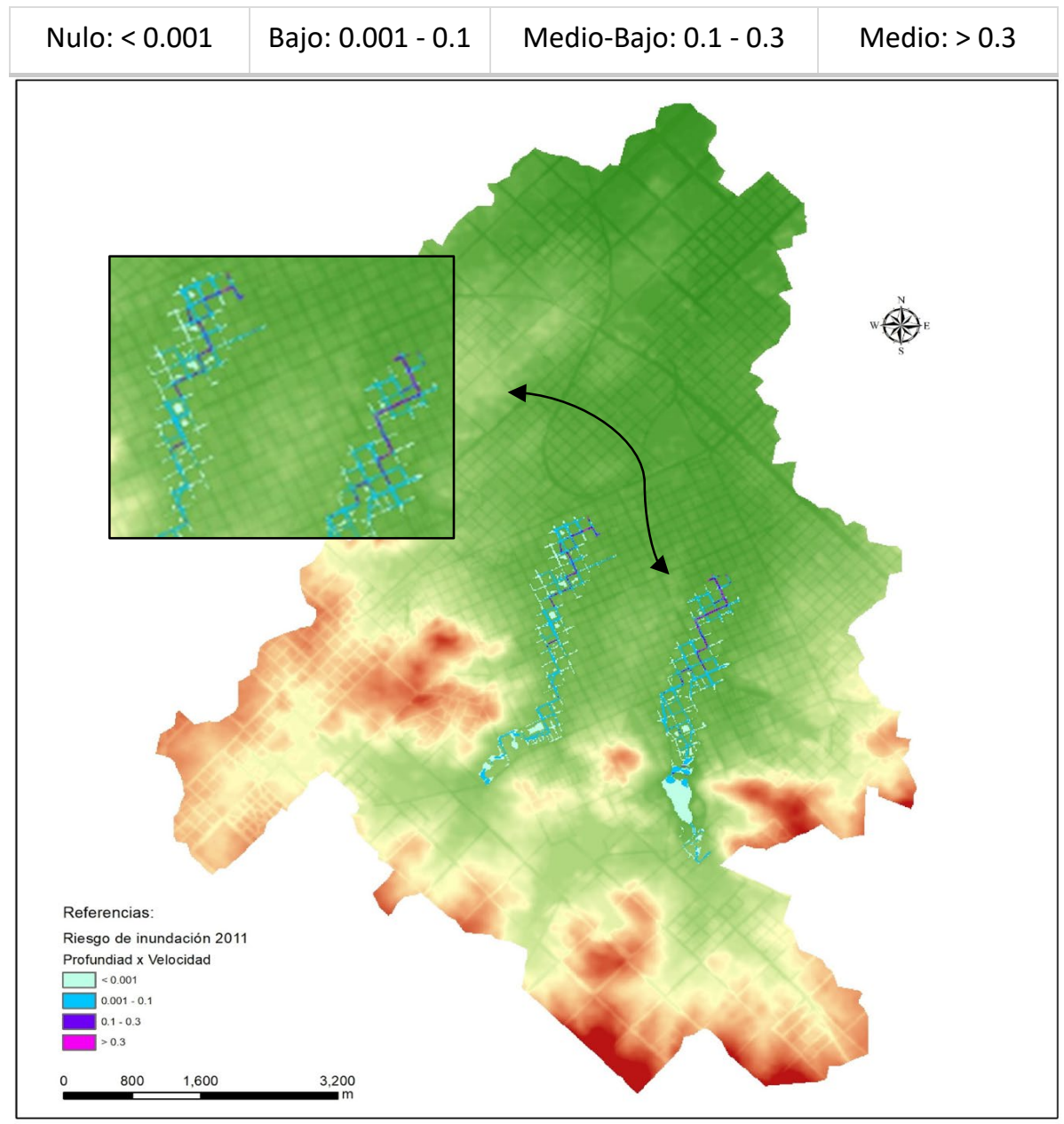

Figura 19. Riesgo de inundación 2011

Fuente: Elaboración personal. ArcGIS 10.2. 
La figura 18 permite identificar cuatro áreas según niveles de riesgo mediante un indicador sintético, como sustento para generar medidas de gestión urbanísticas estructurales o semiestructurales ante eventos extremos. La interpretación de los niveles de peligro indicados, expresan potenciales niveles de vulnerabilidad de las personas que caminan o conducen a través del área de estudio durante un evento extremo. El presente resultado se expone como un recorte preliminar a modo de corroboración metodológica y utilidad práctica, a partir del cual se pretende profundizar en un estudio sobre el manejo integral en toda el área urbana y complementaria de la ciudad de Tandil que se encuentra en desarrollo.

\section{DISCUSIÓN Y CONCLUSIÓN}

Se destaca la posibilidad de integrar satisfactoriamente diversas fuentes y modelos de geodatos para la simulación de escurrimiento superficial, imágenes de sensores ópticos y radar, capas vectoriales de fuentes primarias y secundarias como elementos básicos que configuran el espacio urbano y componentes geométricos propio del análisis de redes integrados dentro del modelo hidrológico. También la capacidad de asignar atributos que relacionen, conecten e integren cada uno de estos elementos de la trama urbana con el modelado final del escurrimiento.

La capacidad de vincular una variedad de herramientas geotecnológicas garantizó la correcta interoperabilidad entre los insumos básicos y resultados durante cada fase del procedimiento metodológico sugerido. Todo ello hizo posible corroborar la hipótesis de trabajo, a partir de la cual pronosticamos el impacto que tiene el aumento de densidad de edificaciones sobre el riesgo de áreas urbanas a inundarse. La determinación de zonas de peligro en base a la clasificación que propone AEMI 2013 es un antecedente importante desde la Geografía Aplicada intentando detectar zonas de mayor y menor vulnerabilidad conjugando el producto de los escenarios de los mapas de profundidad (depth) y velocidad (velocity). El análisis para cuantificar de manera precisa el riesgo requiere tener más variables en consideración y mayor precisión en los resultados, ya que las curvas de vulnerabilidad se establecen en base a los umbrales establecidos (número de píxeles) para cada categoría utilizada en los mapas obtenidos. 
Este aporte constituye una nueva evidencia que contrarresta el poder de la naturaleza como el único agente de los desastres, si bien los factores físicos pueden ser poderosos detonadores de acontecimientos, los procesos conductuales reales son los sociales, es la naturaleza de esos procesos sociales los que determinan qué ocurrirá, dónde y con qué intensidad se materializará en el territorio.

No obstante, varios aspectos de nuestro procedimiento metodológico son optimizables, comenzando por la reducción de la exageración de la escala vertical en el Modelo Digital de Terreno, cuya elección de elevar cinco metros por encima del MDE a aquellos polígonos que componen el catastro urbano, resulta un artificio distorsionando las interpretaciones de los valores físicos de profundidad y velocidad en los escenarios. Si bien se reconoce la debilidad en la fiabilidad de la precisión de los modelos digitales del terreno $(12,5 \mathrm{~m})$, se continúa trabajando en la mejora de su obtención y posterior procesamiento mediante el trabajo de campo, la vinculación con otras fuentes de información y la reconstrucción de los modelos a partir de vuelos de drones para las áreas más críticas o de mayor peligro en el área urbana. Sin duda estos aportes disminuirán la incertidumbre de los escenarios simulados y servirán para validar los resultados obtenidos.

Asimismo, en los escenarios obtenidos no se tuvo en cuenta el recorrido del agua dentro de los canales de la red pluvial, sólo el escurrimiento superficial, creemos que, al vincular la red mediante su drenaje a través de sus conductos y secciones transversales, el resultado variará significativamente al obtenido en este trabajo. Esta decisión metodológica también afectará a los coeficientes de rugosidad adoptados, los cuales deberán ser calibrados nuevamente.

Como conclusión general de esta aplicación, reforzamos que la implementación de Sistemas de Información Geográfica es una herramienta de gran utilidad en la definición de los escenarios, principalmente como base para la toma de decisiones. Dependiendo del aspecto que se desee analizar, pueden realizarse diversos tipos de mapas y escenarios, por ejemplo: mapas de amenaza, vulnerabilidad y/o mapas de riesgo, vinculando por un lado, la recurrencia de los eventos, los períodos de retorno, los daños potenciales en pérdidas materiales y el impacto en la calidad de vida de la población, como también, la evaluación de inversiones en términos de costos y 
beneficios económicos para la ejecución de obras derivadas de medidas de gestión y planificación territorial en pos de lograr ciudades más sostenibles.

\section{BIBLIOGRAFÍA}

Australian Emergency Management Institute (AEMI) (2013). Managing the floodplain: A guide to best practice in flood risk management in Australia, Australian Emergency Handbook (7), Canberra.

Australian Institute for Disaster Resilience (AIDR) (2014). Australian Disaster Resilience Guideline 7-3: Technical flood risk management guideline: Flood hazard, 2014, CC BY-NC.

Carballo, T.; Goldberg, S. (2014). Comunidad e información ambiental del riesgo. Las inundaciones y el Río Luján. Buenos Aires: Editorial Dunken.

Collazos, G.; Villanueva, I.; Briceño, N.; Cazenave, G.; Guevara, C.; y Blanco, M. (2018). Modelo bidimensional de inundación urbana de la ciudad de Azul (Argentina) con herramientas de uso libre. XXVIII Congreso Latinoamericano de Hidráulica. Buenos Aires, Argentina, septiembre de 2018.,2064-2075.

DeVantier, B. A. y Feldman, A. D. (1993). Review of GIS Applications in Hydrologic Modeling. Journal of Water Resources Planning and Management, 119, (2), Paper 3607, 246-259

Ellis, E. A.; Romero, J. A.; Hernández, I.U.; Gallo, C. A. y Alanís, J. L. (2012). Evaluación geográfica de áreas susceptibles a inundación en la cuenca del río Tuxpan, Veracruz. Avances en Investigación Agropecuaria. 2012. 16(1): 7-28.

Fernández Pato, J. y García Navarro, P. (2018). Development of a New Simulation Tool Coupling a 2D Finite Volume Overland Flow Model and a Drainage Network Model. Geosciences. 8-288.

Ferrando A. y Francisco J. (2006). Sobre inundaciones y anegamientos. Revista de Urbanismo, (15), Facultad de Arquitectura, Universidad de Chile. Disponible en: https://web.uchile.cl/vignette/revista urbanismo/CDA/urb_complex/0,1311,SCID\%253D19141\%2526ISID\%253D668\%2526IDG\%253D2\%2526A CT\%253D0\%2526PRT\%253D19132,00.html

Fuschini Mejia, M. (1998) El agua en las llanuras. En Durán, D. (compiladora). La Argentina Ambiental. Naturaleza y Sociedad. Buenos Aires: Lugar.

García, R. (2006). Sistemas complejos: conceptos, método y fundamentación epistemológica de la investigación interdisciplinaria. Barcelona: Editorial Gedisa.

González, S., Torchia, N. y Viand, J. (2015). Inundaciones urbanas, En: Secretaría de Ambiente y Desarrollo Sustentable. Inundaciones urbanas y cambio climático: Recomendaciones para la gestión, Ciudad Autónoma de Buenos Aires, 33-47.

HEC-RAS (2016a). River Analysis System. User's Manual. Version 5.0. US Army Corps of Engineers Institute for Water Resources. Hydrologic Engineering Center. Davis. Disponible en: www.hec.usace.army.mil. 
HEC-RAS. (2016b). River Analysis System. 2D Modeling. User's Manual. US Army Corps of Engineers. Institute for Water Resources. Hydrologic Engineering Center. Davis. Disponible en: www.hec.usace.army.mil.

Henríquez Ruiz, C. (2009). El proceso de urbanización en la cuenca del río Chillán y su capacidad adaptativa ante precipitaciones extremas. Estudios Geográficos, LXX, (266), 155-179.

Herzer, H.; Rodríguez, Carla.; Celis, A.; Bartolomé, M. y Caputo, G. (2002). Convivir con el riesgo o la gestión del riesgo. LA RED. Disponible en: https://www.researchgate.net/profile/Alejandra_Celis/publication/ 237638971_CONVIVIR_CON_EL_RIESGO_O_LA_GESTION_DEL_RIESGO1/links/5591847c08ae1e1f9baff7 84.pdf

Johnston, R. J.; Gregory, D.; Smith, D. (1987). Diccionario de Geografía Humana, Madrid: Alianza.

La Macchia, M.L. (2015). Modelización y análisis espacial del drenaje urbano de la ciudad de Tandil mediante Tecnologías de la información Geográfica. Tesis de Licenciatura en Geografía. Universidad Nacional del Centro de la Provincia de Buenos Aires.

Linares, S. (2012). Análisis y modelización de la segregación socioespacial en ciudades medias bonaerenses mediante Sistemas de Información Geográfica: Pergamino, Olavarría y Tandil (1991-2001). Revista Geográfica de Valparaíso, Instituto de Geografía, Pontificia Universidad Católica de Valparaíso. Valparaíso (Chile), (45), 3-22.

Linares, S.; Picone, N. (2018). Application of Remote Sensing and Cellular Automata Model to Analyze and Simulate Urban Density Changes. En Qihao Weng. Edited by Qihao Weng, Dale Quattrochi, and Paolo E. Gamba. Chapter 10. Urban Remote Sensing. Second Edition. Remote Sensing Applications. Series Editor, 213-228. Indiana, USA: Indiana State University. Terre Haute.

López Trigal, Lorenzo (Dir.) (2015). Diccionario de Geografía aplicada y profesional. Terminología de análisis, planificación y gestión del territorio. Ed. Universidad de León.

Melesse, A.; Wang, X. (2007). Impervious Surface Area Dynamics and Storm Runoff Response. Remote Sensing of Impervious Surfaces, 369-384.

Natenzon, C. (1998). Riesgo, vulnerabilidad e incertidumbre. Desastres por inundaciones en Argentina. PIRNA. Facultad de Filosofía y Letras. UBA.

Pereyra A. (2014). El riesgo a las inundaciones en la trama de los eventos extremos. En Carballo, T.; Goldberg, S. Comunidad e información ambiental del riesgo. Las inundaciones y el Río Luján. Buenos Aires: Editorial Dunken. 13-26.

Sánchez, F. J. y Lastra, J., coords (2011). Guía metodológica para el desarrollo del Sistema Nacional de Cartografía de Zonas Inundables. Madrid: Ministerio de Medio Ambiente y Medio Rural y Marino.

Scioli, C. (2009). Modelación del escurrimiento superficial en áreas de llanura: Implementación y calibración de un modelo distribuido de grilla. Maestría en Recursos Hídricos en zonas de llanura. Facultad de Ciencias Exactas, Ingeniería y Agrimensura. Universidad Nacional del Rosario. 
Tucci, C. (2005). Gestão de inundações urbanas. Porto Alegre: UNESCO-PHI.

Vanneuville W., De Maeyer Ph., Maeghe K. \& Mostaert F. (2003). Model the effects of a flood in the Dender catchment, based on a risk methodology. Society of Cartography Bulletin, 37 (2), 59-64.

\section{LOS AUTORES}

María Lorena La Macchia Es Técnica en SIG, Profesora y Licenciada en Geografía, títulos otorgados por la Facultad de Ciencias Humanas de la Universidad Nacional del Centro de la provincia de Buenos Aires (FCHUNCPBA). Desde el año 2009 forma parte del Centro de Investigaciones Geográficas (CIG-FCH- UNCPBA) aportando y publicando diversos trabajos sobre distintas áreas que vinculan a la Geografía aplicada y las potencialidades de las TIG a problemas urbanos, como así también, participando en proyectos de Extensión y Transferencia del CIG-FCH- UNCPBA.

En el año 2015 ingresó a la carrera de Personal de Apoyo en Investigación (CPA-CONICET) en el Instituto de Geografía, Historia y Ciencias Sociales (IGEHCS).

Actualmente es Maestranda de la Maestría en Teledetección y SIG de la Facultad de Agronomía de la ciudad de Azul, Buenos Aires (FAA-UNCPBA) y se encuentra trabajando sobre la modelización de escenarios de riesgo de inundaciones mediante el aporte de las TIG y la ingeniería hidráulica e hidrodinámica a la cuenca urbana de la ciudad de Tandil.

llamacchia@fch.unicen.edu.ar

Santiago Linares Es profesor de Geografía, magister en Teledetección y Sistemas de Información Geográfica por la Universidad Nacional del Centro de la Provincia de Buenos Aires (UNCPBA) y Doctor en Geografía por la Universidad Nacional del Sur (UNS). Sus temas de investigación son referidos a la modelización y análisis del espacio urbano y aplicaciones de Sistemas de Información Geográfica a la investigación en Geografía y a diversas esferas de la planificación territorial. Es Investigador Adjunto del Consejo Nacional de Investigaciones Científicas y Técnicas (CONICET) de Argentina. Integrante del Instituto de Geografía, Historia y Ciencias Sociales (IGEHCS) dependiente de CONICET-UNCPBA. Docente del Departamento de Geografía de la Facultad de Ciencias Humanas (UNCPBA), a cargo de las cátedras relacionadas a la aplicación de Tecnologías de la Información Geográfica y análisis espacial cuantitativo. Director de la Revista Estudios Socioterritoriales. Participa en diversos proyectos de investigación acreditados institucionalmente, ha dictado numerosos cursos de capacitación y postgrado sobre investigación y análisis espacial con SIG, participa como miembro de redes nacionales e internacionales sobre Sistemas de Información Geografía, como así también, es responsable de proyectos de extensión y transferencia donde se aplican las geotecnologías a la solución de problemas socioeconómicos y ambientales en diversos municipios de la Argentina.

slinares@fch.unicen.edu.ar 